\title{
NONCOGNITIVE VARIABLES FOR PLACEMENT: A RANDOMIZED CONTROL TRIAL
}

\author{
A Dissertation submitted to the faculty of \\ US San Francisco State University \\ 35 In partial fulfillment of \\ $27: 8$ The Requirements for \\ FDD \\ The Degree \\ .$k 43$ \\ Doctor of Education
}

In

Educational Leadership

by

Katrina Ann Keating

San Francisco, California

May 2018 


\section{CERTIFICATION OF APPROVAL}

I certify that I have read Noncognitive Variables For Placement: A Randomized Control Trial by Katrina Ann Keating, and that in my opinion this work meets the criteria for approving a dissertation submitted in partial fulfillment of the requirements for the degree: Doctor of Education in Educational Leadership at San Francisco State University.

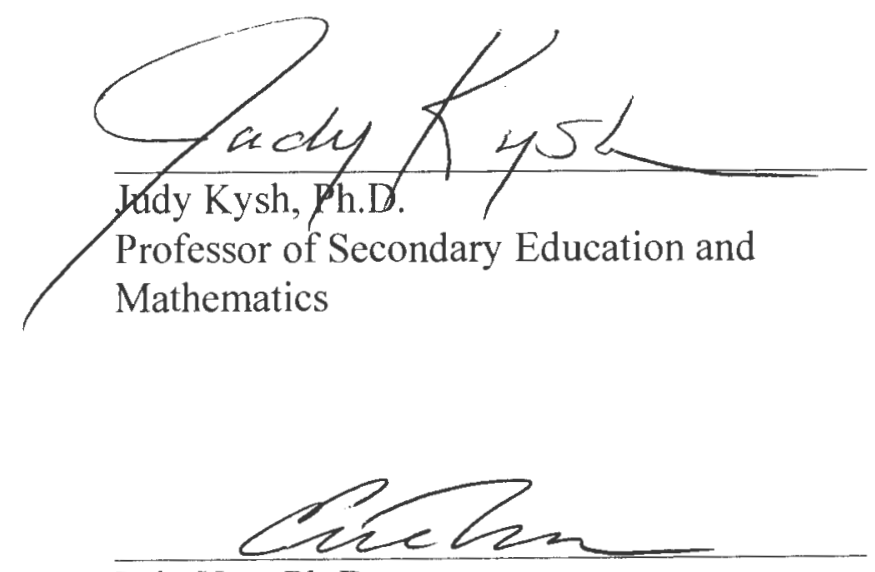

Eric Hsu, Ph.D.

Professor of Mathematics

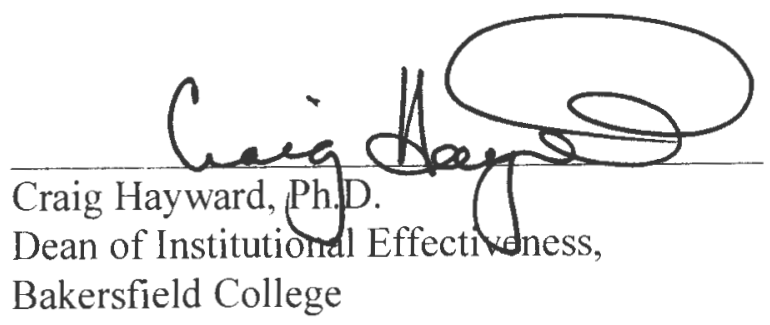




\title{
NONCOGNITIVE VARIABLES FOR PLACEMEN'T: \\ A RANDOMIZED CON'TROL TRIAL
}

\author{
Katrina Ann Keating \\ San Francisco State University
}

2018

This study was born out of a concern that U.S. community colleges were currently using or considering using noncognitive variables for academic placement without an understanding of how students would react to these scales in a high-stakes setting. While the use of noncognitive variables for placement often stems from a desire to overcome the myriad of limitations of content-based placement tests, the researcher was concerned that noncognitive variables had the potential to become an extension of the problems caused by the test.

This study was guided by two research questions: How does the high-stakes nature of academic placement impact student responses on noncognitive scales? How does the context, demand, characteristics, and framing of the noncognitive variables impact stereotype threat, if at all? The researcher performed a random control trial of incoming community college students to determine how they might react to questions about noncognitive variables. One group was told their responses would be used for placement, and the other was told that their responses would be used to improve instruction.

The major findings suggest that initial framing played a role in participant responses and lowered responses on some noncognitive variables, but that the act of having taken a placement test was also a moderator of student behavior and whether or not students believed the initial framing. Stereotype threat susceptibility appeared to have a statistically significant relationship with some participants' responses on some noncognitive scales, and there was evidence that initial framing was not related. Finally, while participants were generally honest, those who did change their answers did so in a manner that was inconsistent, more so when given high stakes framing.

I certify that the Abstract is a correct representation of the content of this dissertation.

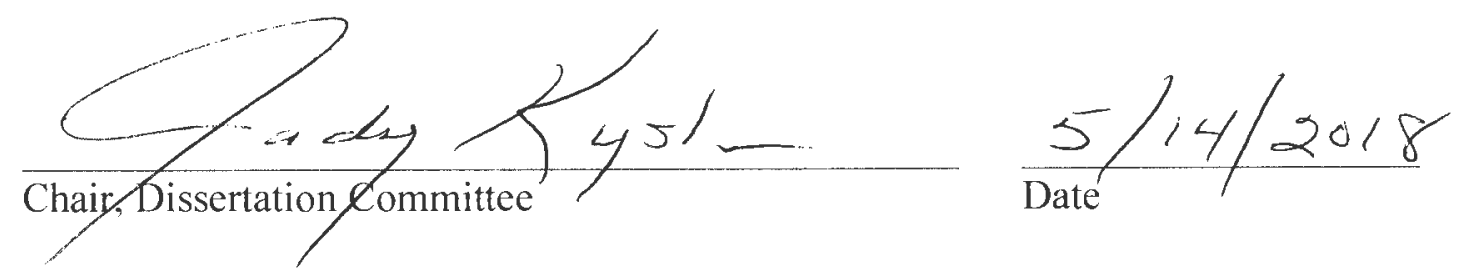




\section{ACKNOWLEDGEMENTS}

This dissertation could not have been completed with the participation, support, and encouragement of many people — far too many to name individually.

I am appreciative to the 296 community college students who participated, and am grateful to all the people who provided statistical support.

I am indebted to everyone who read this thing in its many forms, and am honored by the thoughtful guidance, input, and critiques of my advisors and committee members, past and present.

After four years of declining invitations to events and outings, I am touched by the continued encouragement and understanding of my friends and family. I am appreciative of the patience of my colleagues who have supported me and taken up my slack.

I am indebted to my mother for her support and encouragement, and for being the task-master by continually asking, "I thought you were dissertating?"

Above all else, I could not have done this without the love and patience of my husband and our furry, four-legged family. Thank you for keeping me well fed and hydrated. After eighteen years, this was just one of our many adventures. We've survived worse, but this was probably the most challenging - so far. There's still time to give it a run for the money... Where to next? 
TABLE OF CONTENTS

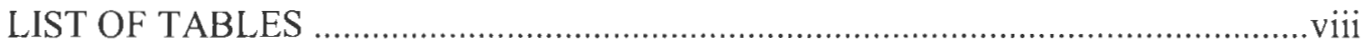

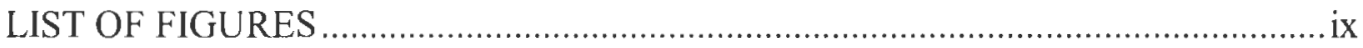

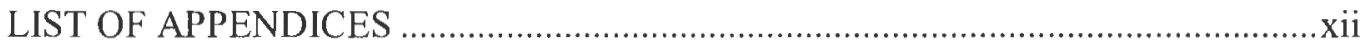

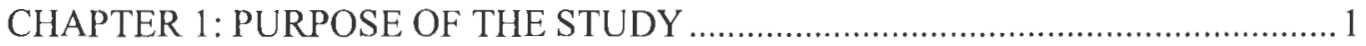

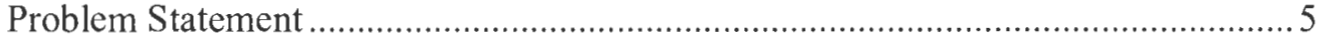

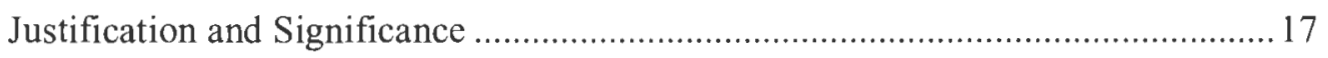

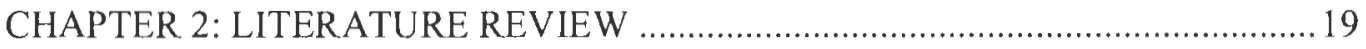

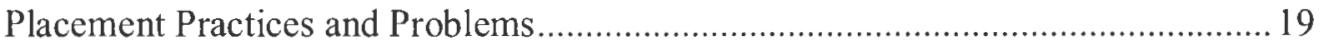

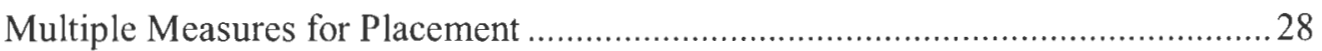

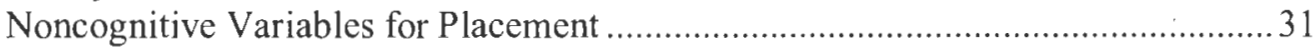

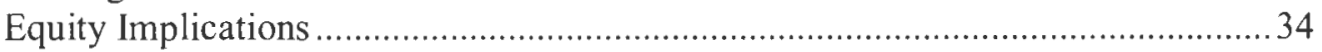

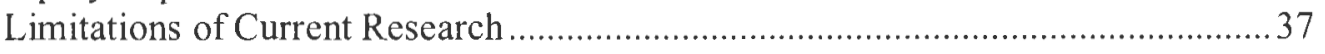

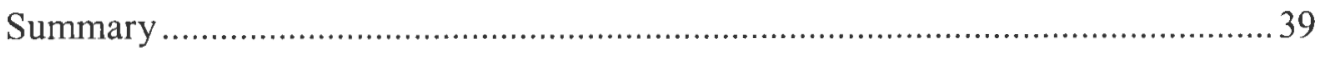

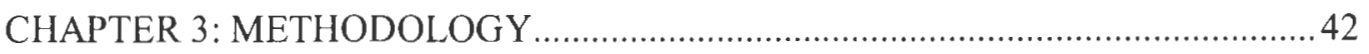

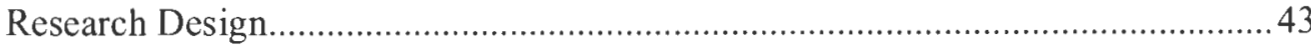

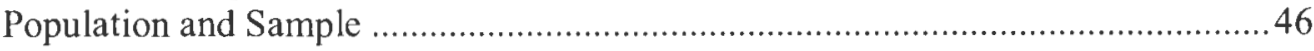

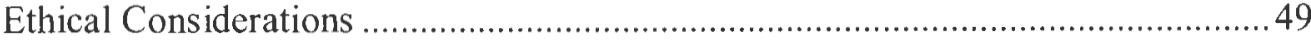

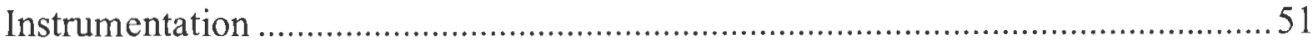

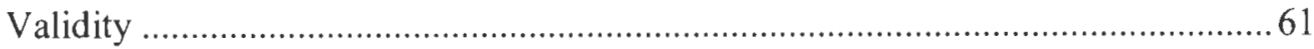

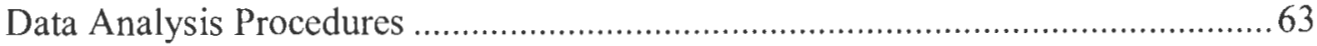

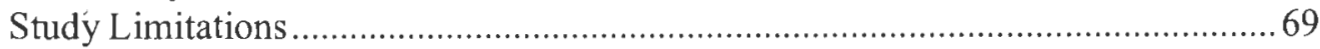

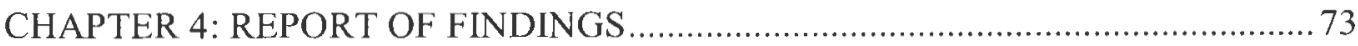

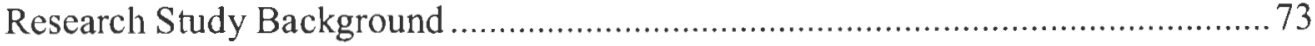

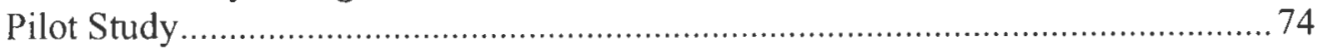

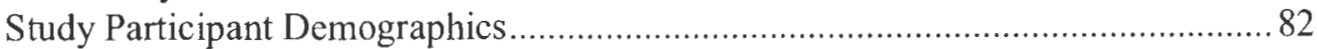

Noncognitive Variables and High Stakes Academic Placement ............................ 84

Stereotype Threat as a Moderator ...................................................................... 103 


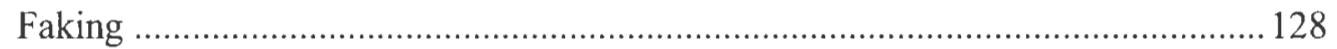

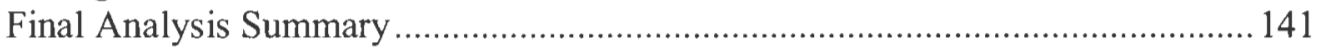

CHAPTER 5: DISCUSSION AND RECOMMENDATIONS ............................... 144

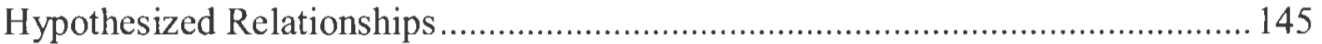

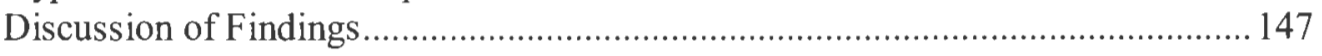

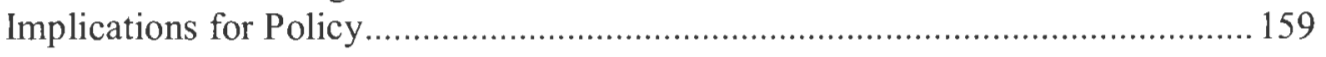

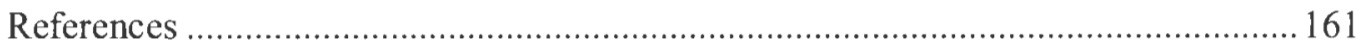

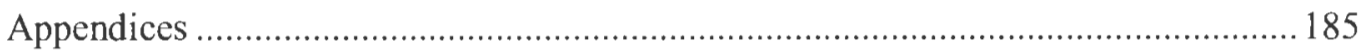




\section{LIST OF TABLES}

Table Page

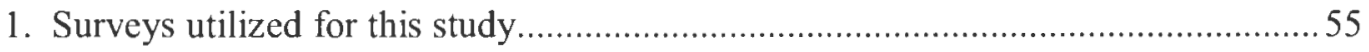

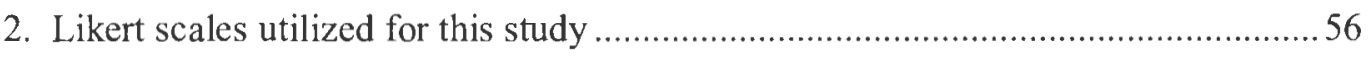

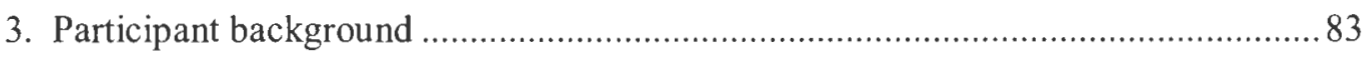

4. Independent Samples T-Test of Noncognitive Variables ..................................... 88

5. ANOVA of noncognitive variables by study group and assessment test .................89

6. Participants' susceptibility to stereotype threat ..................................................... 104

7. ANOVA of stereotype threat identities across noncognitive variables .................. 105

8. ANCOVA of noncognitive variables by study group with covariate SST

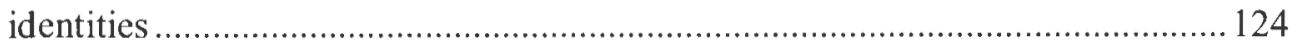

9. Relationships of noncognitive variables and stereotype threat identities ............... 126

10. (Control Group) ANOVA of faking by stereotype threat identities ..................... 138 


\section{LIST OF FIGURES}

Figure

Page

1. (Pilot) Distribution of belief in high stakes framing by study group ........................76

2. (Pilot) Distribution of belief in high stakes framing by taken assessment test ..........77

3. (Pilot) Boxplots of belief in high stakes framing by study group and assessment test

4. (Pilot) Boxplots of increased answers by decreased answers ....................................79

5. (Pilot, control) Boxplots of increased answers by decreased answers .......................8 80

6. (Pilot, treatment) Boxplots of increased answers by decreased answers. ...................8 80

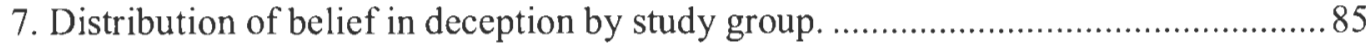

8. Boxplots of belief that responses would be used for placement by taken assessment test.

9. Boxplots of belief that responses would be used for course placement by study group

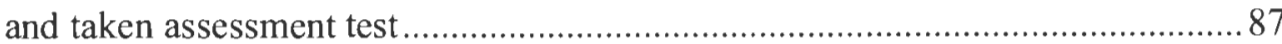

10. Boxplots of academic self efficacy (ASE) by study group....................................90

11. Mean academic self efficacy (ASE) score by high school gpa, disaggregated by

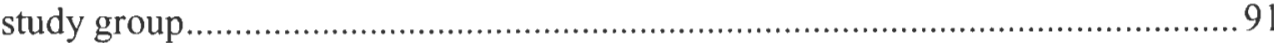

12. (Treatment) boxplots of academic self efficacy (ASE) by family income ..............92

13. Boxplots of college identity by taken assessment test ...........................................93

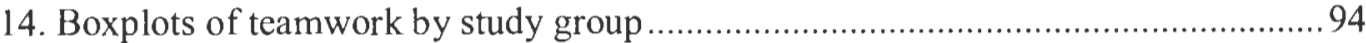

15. Mean teamwork by high school GPA, disaggregated by study group .....................95

16. Mean teamwork by institution, disaggregated by study group ................................96

17. Boxplots of teamwork by study group and taken assessment test ...........................97 


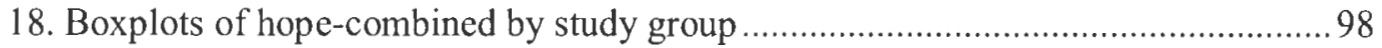

19. Mean hope-combined by institution, disaggregated by study group ...................... 98

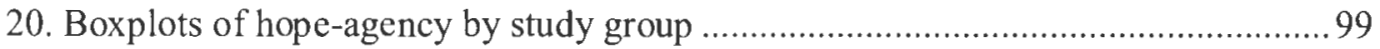

21. Mean hope-agency by ethnicity, disaggregated by study group ........................... 101

22. Mean hope-agency by institution, disaggregated by study group ......................... 101

23. Mean hope-agency by high school gpa, disaggregated by study group ................ 100

24. Boxplots of college identity by SST math identity ............................................. 107

25. Boxplots of college identity by SST ethnic identity ......................................... 108

26. Mean college identity by ethnic group, disaggregated by SST ethnic identity ...... 109

27. Mean college identity by institution, disaggregated by SST ethnic identity ......... 110

28. Boxplots of college identity by SST gender identity ........................................111

29. Mean college identity by ethnic group, disaggregated by SST gender identity .... 112

30. Mean college identity by institution, disaggregated by SST gender identity ......... 112

31. Boxplots of mindfulness-observing by SST ethnic identity ................................. 113

32. Mean mindfulness-observing by ethnic group, disaggregated by SST ethnic identity

33. Mean mindfulness-observing by institution, disaggregated by SST ethnic identity

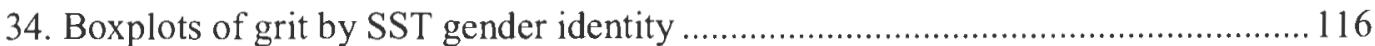

35. Mean grit by ethnicity, disaggregated by SST gender identity .............................117

36. Mean grit by institution, disaggregated by SST gender identity ........................... 117

37. Boxplots of hope-agency by SST math identity ............................................ 118

38. Mean hope-agency by ethnicity, disaggregated by SST math identity .................. 119

39. Boxplots of hope-agency by SST ethnic identity ............................................ 120

40. Boxplots of mindset by SST math identity profiles .......................................... 120 
41. Mean mindset by ethnicity, disaggregated by SST math identity ......................... 121

42. Mean mindset by institution, disaggregated by SST math identity ..................... 122

43. Distribution of sst gender identity by study group ............................................ 123

44. Boxplots of increased answers by decreased answers. ........................................ 130

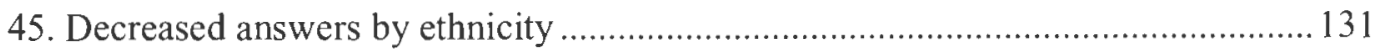

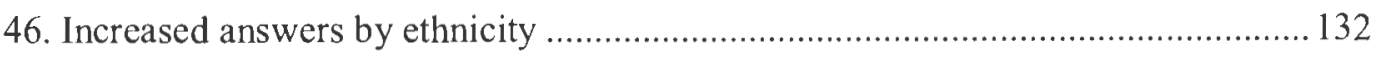

47. (Control) Boxplots of increased answers by decreased answers .......................... 133

48. (Treatment) Boxplots of increased answers by decreased answers. ...................... 134

49. (Treatment) Decreased answers by ethnicity ....................................................... 135

50. (Treatment) Increased answers by ethnicity ........................................................ 136

51. (Control) Boxplots of decreased answers by SST ethnic identity .......................... 139

52. (Control) Boxplots of decreased answers by SST gender identity ........................ 140

53. Hypothesized relationships between the variables ............................................ 145 


\section{LIST OF APPENDICES}

Appendix

Page

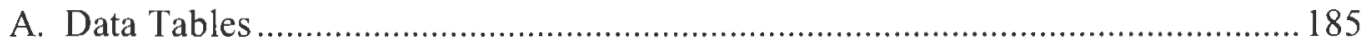

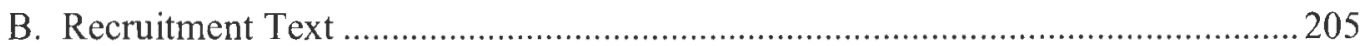

C. Implied Consent \& Kick-Out Question .............................................................207

D. Instrumentation Part One - Introductory Wording...........................................209

E. Instrumentation Part Two - Noncognitive Scales.............................................. 210

F. Instrumentation Part Three - Social Identities Attitudes Scale ............................213

G. Instrumentation Part Four - Demographic Questionnaire ..................................215

H. Instrumentation Part Five - Debriefing \& Verification......................................218

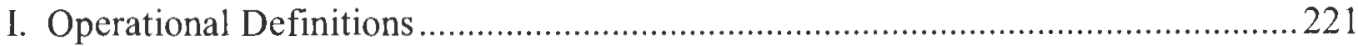




\section{CHAPTER 1: PURPOSE OF THE STUDY}

"[W]e're taking someone who may have had a bad day and making them take three semesters of remediation." (Grubb \& Gabriner, 2013, p. 154)

Nearly forty percent of all U.S. college undergraduates attend a community college (National Center for Education Statistics, 2016) and almost a quarter of these students attend one of California's 114 community colleges (California Community College Chancellor's Office [CCCCO], 2015). California community colleges are openaccess institutions that admit students regardless of their level of preparation, but students must fulfill a mathematics requirement to earn an associate's degree or to transfer to a four-year institution. Yet there is no single, shared definition of what it means to be ready for transfer-level mathematics. ${ }^{1}$ For the majority of California Community Colleges, readiness is determined by how well a student performs on an assessment/placement test (Ngo \& Kwon, 2014; Perry et al., 2010; Regional Educational Lab (REL) West at WestEd, 2011). Thus, a student's time at the community college--and their likelihood of finishing by earning a degree or

1 The literature often refers to college-level, transfer-level, and gatekeeper mathematics courses interchangeably, but California community colleges see a distinction between the first two. College-level courses are those which are associates-degree applicable-the lowest of which is intermediate algebra - whereas transfer-level mathematics courses tend to have intermediate algebra as a prerequisite. California community college students must pass at least one transferlevel mathematics course in order to be transfer-ready. Here, gatekeeper and transfer-level will be used interchangeably. 
transferring - is greatly influenced by a test that only provides a single snapshot in time, rather than giving credit for existing knowledge and past coursework (Center for $\mathrm{K}-12$ Advancement and Performance Management at ETS, 2010; Hayward \& Willett, 2014; Hern \& Snell, 2010). Many studies suggest that community colleges rely too heavily on placement tests (e.g., Bailey et al., 2015; Belfield, 2014; Hetts \& Willett, 2013; Lemay, 1994; McKinsey \& Company, 2009; Scott-Clayton, 2012). Critics argue that this overreliance has resulted in the misplacement of a large number of students (Belfield \& Crosta, 2012; Bracco et al., 2014; Hetts \& Willett, 2013; Ngo \& Melguizo, 2015; ScottClayton, 2012), with data suggesting that as many as $25 \%$ of students placed into remedial mathematics may be been severely underplaced, inasmuch as they would have likely earned at least a "B" in a transfer-level courses had they started at that level (Bailey et al., 2015; Bailey, Jeong, \& Cho, 2010; Hetts \& Willett, 2013; Scott-Clayton, Crosta, \& Belfield, 2014). Based on the most recent data available, this would translate to 66,902 California Community College students being severely misplaced ${ }^{2}$ (Skinner, 2012).

The more remedial mathematics classes students have to take, the longer they stay at a community college, and the the less likely they are to finish and graduate (Bailey, 2009; Bailey et al., 2010; Hayward, Willett, Hern, \& Snell, 2014; Hern \&

\footnotetext{
2 In the 2010-2011 academic year 350,129 students were assessed in mathematics. Fully 267,609 $(85 \%)$ of them were placed into mathematics remediation, and $25 \%$ of that would be 66,902 students.
} 
Snell, 2010). This is an issue of equity because Black, Latina/o, and first generation students are disproportionately placed into remediation (CCCCO, 2014b; Skinner, 2012), even when controlling for academic backgrounds (Kurlaender \& Larsen, 2013; Wyner, 2014). Further, Black and Latina/o students are disproportionately placed into lower levels of the remedial sequence (Hayward, C., personal communication, June 11, 2016).

Scholars and community college faculty groups argue that misplacements can be reduced by using a more robust placement mechanism (American Mathematics Association of Two-Year Colleges, 2013; Bahr et al., 2014; Grimes-Hillman, Holcroft, Fulks, Lee, \& Smith, 2014; Hodara, Smith, Melinda, \& Karp, 2012; Jenkins \& Belfield, 2014; Lemay, 1994; Scott-Clayton et al., 2014). Alternatives to placement tests include high school grade point average (GPA) (e.g., Bahr et al., 2014; Bailey et al., 2015; Belfield, 2014; Scott-Clayton, 2012; Willett et al., 2015), and the measurement of noncognitive skills (e.g., Community College Research Center [CCRC], 2013; Hays, Hayward, Purnell, \& Willett, 2014; Hetts \& Willett, 2013; Hodara, Smith, Melinda, \& Karp, 2012; Hughes \& Scott-Clayton, 2011; Jenkins \& Belfield, 2014). Noncognitive skills are the "sets of behaviors, skills, attitudes, and strategies that are crucial to [students'] academic performance in their classes, but that may not be reflected in their scores on cognitive tests" (Farrington et al., 2012, p. 2). Students' noncognitive skills are measured using noncognitive scales, which are then analyzed using noncognitive 
variables. While there is a robust set of published literature correlating and theorizing the relationship between noncognitive variables and academic performance, there is a lack of published research on how students' responses to the noncognitive scales change-if at all-once they realize that the scales will be used to determine which classes they are eligible to take.

This study examined whether students would react to these noncognitive measures in ways similar to how they react to mathematics placement tests, where certain groups of students do worse simply due to the standardized nature of the test (McKinsey Company, 2009), some students intentionally do worse for fear of being placed into a class that is beyond their skill level (Fay, Bickerstaff, \& Hordara, 2013; Fong \& Melguizo, 2015), and still others may have depressed scores because of stereotype threat (Burdman, 2015b). If these same outcomes held true for noncognitive scales, then the very thing that is being used to overcome the limitations of the placement test will have simply become an extension of that test. This study is important and timely because many community colleges across the nation are either considering or currently using noncognitive scales (e.g., Booth, Bracco, Chaplot, \& Lagunoff, 2014; Hayward \& Fagioli, 2016; Hetts \& Willett, 2013).

In fact, the California Community Colleges are currently researching the possibility of using noncognitive scales for placement (Research and Planning Group for California Community Colleges [RP Group], 2015). Thus, it is important to have a 
firm understanding of how students might behave. This research seeks to understand the impact by completing a randomized control trial where the treatment group is informed that their responses to the noncognitive scales will be used to determine what courses they are eligible to take, and the control group is told that their responses will be used to improve instruction. This quantitative study will be guided by two research questions: How does the high-stakes nature of academic placement impact student responses to noncognitive scales? How does the context, demand, characteristics, and framing of the noncognitive variables impact stcreotype threat, if at all?

\section{Problem Statement}

Mathematics courses act as a gatekeeper in the community colleges, especially for students who begin on the remediation pathway. Research suggests many reasons for this, including the high attrition rates of the remediation pathway, and problematic assessment and placement methods. Placement policies appear to have a disproportionate impact on students of color and first-generation students. The California Community Colleges system is attempting to fix some of these problems with a new method of placement that has been shown to be more accurate while simultaneously decreasing the disproportionate impact. This section will outline both the problems and the potential solution in more detail. 


\section{Gatekeeper Role of Mathematics}

There is currently a great disparity in the outcomes of community college students' completion rates between students who start at the remedial level mathematics versus those who start at the transfer level (Bailey et al., 2010; Harris, 2015; Hayward \& Willett, 2014), even after controlling for academic backgrounds (Geiser \& Atkinson, 2013; Kaufman, Agars, \& Lopez-Wagner, 2008). In the interest of equity, it behooves community colleges to have more accurate placement policies (Bailey et al., 2015). Evidence suggests that current community college placement methods are problematic inasmuch as they are prone to underplacing students, and thus do not optimize incoming students' odds of successfully completing key gatekeeper courses. This could, in part, be because current community college placement methods are not taking advantage of all available research and information that could optimize placement accuracy (e.g., Bracco et al.. 2014; Hetts \& Willett, 2013; Ngo \& Melguizo, 2015; Venezia, Bracco, \& Nodine, 2010). Current research proposes that colleges use placement approaches that increase accuracy by focusing more attention on reducing underplacement (Bahr et al., 2014; Hayward \& Willett, 2016; Hetts, 2015a; Scott-Clayton \& Stacey, 2015).

California community college students who begin mathematics at the transfer

level are nearly twice as likely to complete a degree or transfer within six years, compared to students who begin at the remedial level (Harris, 2015; Hayward, 2011). In fact, the further away from transfer-level mathematics community college students 
begin, the less likely they are to get there (Bailey et al., 2010; Hayward \& Willett, 2014), as completion rates for remedial students decrease with each additional course required (Skinner, 2012), even when the students pass their course (Hern \& Snell, 2010). In the 2013-2014 academic year, seventy-four percent (74\%) of new California community college students took a remedial course in mathematics, English, or English as a second language (Harris, 2015). Specifically looking at remedial mathematics, in the 2010-2011 academic year, $85 \%$ of incoming students started at this level (Skinner, 2012); if past trends hold, few of them will finish. A cohort of remedial mathematics students were tracked from 2003 to 2010 , and the proportion of students able to successfully complete a transfer-level mathematics course - the throughput rate ${ }^{3}$ - was only $20 \%$. The throughput rates for students beginning four levels below transfer was half that (10\%) (Skinner, 2012). More recently, a cohort starting three levels below had an even dimmer throughput rate (7\%) (Hayward et al., 2014). These statistics are particularly troublesome considering the disproportionate number of first generation, Black, and Latina/o students who begin mathematics at the remedial level (CCCCO, 2014b; Skinner, 2012).

\footnotetext{
3 "Throughput rate" is a term coined by Hayward and Willett (2014) to refer to the proportion of students able to successfully complete a transfer-level mathematics course. This term is most often used when referring to students who start coursework at the remedial level.
} 
The low throughput rates have led to advocacy groups and scholars questioning the necessity of a traditional remediation pathway to transfer-level mathematics (American Mathematics Association of Two-Year Colleges Developmental Mathematics Committee, 2013; Bailey et al., 2010; Burdman, 2015a; Hayward \& Willett, 2014; Hern \& Snell, 2010; Mery, 2011; Wong, 2014). Critics also charge that placing students in remedial mathematics is a form of tracking (Lemay, 1994; Mery, 2011 ) and a way of rationing access to transfer-level courses (Bailey et al., 2015; Burdman, 2015b). These scholars are critical of tracking because it has been shown to have long-term negative consequences (Oakes, 1985), as evidenced by the disparities in completion rates between students who start in remediation versus those who start at the transfer level. One researcher suggests that although California community colleges may be open access, transfer-level courses are not (Lemay, 1994).

The data clearly show that mathematics courses act as a gatekeeper to student success for the majority of California community college students. Part of what makes mathematics remediation a gatekeeper may in fact be a structural issue stemming from the overly restrictive methods being used to place incoming students into these courses. The next section outlines these issues.

Problems with mathematics placement. In order to enroll in a mathematics course, California Community College students must either pass a pre-requisite course or demonstrate a level of proficiency equivalent to completing the course, commonly 
known as placing out of the pre-requisite. Proficiency can be determined using numerous factors, including previous coursework, high school GPA, length of time since their last mathematics course, or performance on an placement test (Bailey et al., 2015; Grimes-Hillman et al., 2014; REL West at WestEd, 2011). When some or all of these metrics are combined with a test score to place students, the process is described as placement using multiple measures.

Individual California Community Colleges have a great deal of leeway to determine the mechanisms and criteria for placing students (California Code of Regulations, Title $5 \$ 53200,1994)$. There are few requirements, but one is that if a college uses a standardized test for placement, it must also use at least one other source of information about student capacity (i.e., multiple measures) to place students. However, evidence suggests three major problem points in the system: the number of tests available for students, placement test cut scores, and failure to implement databased multiple measures.

Number of tests available. The first problem, the number of tests available for students, stems from schools complicating student placement by having one placement test for transfer-level courses and another for remedial courses. It is reasonable to assume that the decision to have multiple placement tests options was made because the college thought it would be in the best interest of the students, but recent research suggests the opposite is true. One study found that half of students undermatch by 
taking a lower test than their academic background suggests they should take, with traditionally under-represented minorities being especially likely to choose lower level math tests than other students with similar educational backgrounds (Burdman, 2015a; CCCCO, 2014b; Hsu \& Bressoud, 2015; Kurlaender \& Larsen, 2013; Wyner, 2014). This may partially be because Black and Latina/o students tend to have lower confidence in their mathematics ability than their White counterparts (Fong \& Melguizo, 2015, as cited in Burdman, 2015b). Research suggests that this lack confidence may be associated with lack of preparation for the test (Fay et al., 2013). Another study found that students taking the lower level test may face stereotype threat, which results in lower scores (Burdman, 2015b). Stereotype threat happens when people are concerned that their actions will result in confirming a negative stereotype, such as a girl worrying that doing poorly on a mathematics test will reinforce the stereotype that girls are bad at mathematics (Picho \& Brown, 2011; Steele, 1997; Steele, Spencer, \& Aronson, 2002).

Assessment test cut scores. The second problem with placement is the test cut scores, which are used to determine if a student is allowed to take transfer-level courses. Individual colleges are allowed to choose and validate their own cut scores for determining students' placement (Student Services and Special Programs Division of the CCCCO, 2011). However, research indicates that colleges may not be well enough informed to make the best decisions about which placement test is most effective, which 
cut scores to use, or how rigorously cut-scores should be validated (Melguizo, Bos, \& Prather, 2013). Commonly-used cut scores for transfer-level mathematics may be placing students who are near the cut-score in a manner that is effectively random (Jaggars \& Stacey, 2014), with a tendency towards under-placement (Scott-Clayton et al., 2014). This may, in part, explain why there is typically only a low correlation between a students' score on the assessment test and their grade in remedial mathematics (Bahr et al., 2014; Belficld \& Crosta, 2012; Scott-Clayton, 2012). Thus, being able to make informed decisions is important because students' success in college may depend on how effective the cut scores are (Melguizo et al., 2013).

Lack of data-based multiple-measures. The third problem, failure to implement data-based multiple measures, refers to placement and assessment decisions being made by people who do not have the skills or knowledge of current and effective practices. California Community Colleges are expected to use multiple measures, but there are few requirements or resources on how to do so. Four-year institutions use multiple measures to get a big picture of the students during the application and interview processes, but most community college do not (Safran \& Visher, 2010). Many community colleges ask students a few personal questions as part of the assessment test and use the results to add and/or subtract points to the students' test score (Melguizo, Kosiewicz, Prather, \& Bos, 2014), but evidence suggests that very few students see an increase in their placement from this method (Ngo \& Kwon, 2014). Other colleges have 
counselors make placement decisions (REL West at WestEd, 2011). Of concern is research suggesting that not all people who are making decisions understand the importance of multiple measures (Melguizo et al., 2014). Community colleges are allowed to make their own decisions, but are not given the resources, guidance, tools, or support to make well-informed decisions (Bahr et al., 2014; Grimes-Hillman et al.. 2014; Melguizo et al., 2013, 2014).

It is clear that accurate placement is an issue of equity, given the stark and disproportionate throughput rates, the problematic nature of current assessment and placement methods, and the disproportionate placement of certain groups of students into lower level courses. In order to fully consider the equity implications and disproportionate impact, it is helpful to consider why so many students are placing into remedial mathematics.

Differing viewpoints. When considering the large number of students needing remedial mathematics, educators and scholars are generally in one of two camps: some see it as a student problem, while other see it as an institutional problem.

Those who believe it is a student problem feel that students place low because they are not prepared for the placement test, for the class, and/or for college in general (Grubb \& Gabriner, 2013). While this may indeed be true for some students, this viewpoint is refuted by the data indicating that both I.Q. scores and high school degree attainment have steadily increased (Hetts \& Willett, 2013; Tough, 2012). Furthermore, 
data indicate that community college students with similar academic backgrounds complete at different rates depending on their placement (Geiser \& Atkinson, 2013; Kaufman et al., 2008), suggesting that lack of preparedness is not the issue.

Conversely, some educators and scholars point to the institutions as being part of the problem. Scholars suggest that large numbers of students are placed into remedial mathematics courses because institutions choose to be over-reliant on one test when making placement decisions (e.g. Bailey et al., 2015, 2010; Belfield \& Crosta, 2012; Hetts, 2014; Hsu \& Bressoud, 2015; Hughes \& Scott-Clayton, 2011 ; Jaggars \& Stacey, 2014; Melguizo et al., 2014). Despite a requirement that these colleges use multiple measures for placement, research indicates that California Community Colleges also tend to overemphasize placement test results (REL West at WestEd, 2011). California's requirement for multiple measures stems from a settlement from a lawsuit brought by the Mexican American Legal Defense Education Fund (MALDEF), which charged that the overemphasis of placement tests was biased and unfair to Latina/o students because it failed to consider prior learning (Ngo, Kwon, Melguizo, Prather, \& Bos, n.d.; Perry, Bahr, Rosin, \& Woodward, 2010; Times Wire Services, 1991; Wiseley, 2009).

Yet, evidence suggests that the way colleges currently comply with the MALDEF requirements is still biased against certain groups of students, in that California's mandate of multiple measures does not appear to have alleviated the problems with inaccurate mathematics placement. However, a growing body of research 
suggests that an evidence-based implementation of multiple measures can result in more accurate mathematics placement (e.g.. ASCCC, 2014; Hetts \& Willett, 2013; Jaggars, Hodara, \& Stacey, 2013; Lemay, 1994; Ngo \& Kwon, 2015; Scott-Clayton et al., 2014; Scott-Clayton, 2012; Willett, Hayward, \& Dahlstrom, 2008; Willett, 2013). This new method of multiple measures has been in development at the national level (e.g., Jaggars et al., 2013; Scott-Clayton et al., 2014), in the state of California (e.g., Burdman, 2015b; Hsu \& Bressoud, 2015), and within the California Community College system (e.g., Hetts, 2014; Ngo \& Kwon, 2015; Willett, 2013). The following section will discuss California's efforts.

\section{A New Implementation of Multiple Measures}

The California Community Colleges have been working with the Research and Planning Group for California Community Colleges ${ }^{4}$ (R.P. Group) and Educational Results Partnership ${ }^{5}$ to use California Partnership for Achieving Student Success Plus ${ }^{6}$ (Cal-PASS Plus) data to develop the Multiple Measures Assessment Project (MMAP). This project is developing an easily-implementable, evidence-based version of multiple

\footnotetext{
${ }^{4}$ The RP Group works to strengthen the abilities of the California community colleges by gathering, analyzing, and acting on information to strengthen student success. http://rpgroup.org/

${ }^{5}$ http://edresults.cloudapp.net/

${ }^{6} \mathrm{Cal}-\mathrm{PASS}$ Plus (formerly Cal-PASS) is a voluntary collaboration between $\mathrm{K}-12$ and higher education institutions to gather longitudinal student data. https://www.calpassplus.org/
} 
measures intended to place students more accurately, into the highest level course where they will be successful (Willett et al., 2008).

Early MMAP results have shown positive impacts on both student success and completion (Bahr et al., 2014; Hayward \& Willett, 2016; Hetts, 2015b; Hetts \& Willett, 2013). Projections suggest this new method will increase the number of students placed into transfer-level mathematics by roughly the same proportion of students that are estimated to be severely under placed (Hetts \& Willett, 2013; Willett et al., 2015). A large part of the MMAP is using high school GPA, which has shown to be highly predictive of college success (Hodara et al., 2012; Ngo \& Kwon, 2014; Porchea, Allen, Robbins, \& Phelps, 2010; Scott-Clayton, 2012). Research suggests that GPA encompasses both testable knowledge and noncognitive skills, such as study habits (Bailey et al., 2015), perseverance (Bowen, Chingos, \& McPherson, 2009), and motivation (CCRC, 2013). Indeed, the predictive power of noncognitive variables appears to rival that of cognitive variables (Heckman \& Kautz, 2013). As such, scholars suggest that noncognitive measures may be a comparable alternative that could help avoid inaccurate placement on assessment tests. Indeed, the California Community College Chancellor's Office (CCCCO) suggests that placement "should include... study and learning skills..." (CCCCO, 2014, p. 2.3), which alludes to noncognitive skills. Research suggests that using noncognitive variables as part of the placement process can reduce placement errors (Belfield, 2014; Kaufman et al., 2008; Schmitt et 
al., 2011). Noncognitive variables may also compensate for the limitations standardized tests, especially for groups who tend to underperform, such as Black, Latina/o, and first generation students (Geiser, 2015; McKinsey \& Company, 2009a), and thus place these students into higher levels of mathematics (Boylan, 2009; Kyllonen, 2012). For example, adjustment, motivation, and perception have shown to be strong predictors of academic success for underrepresented minorities (King \& Bowman, 2006), and Black students who are able to understand and deal with racism may have better academic outcomes (Nasim, Roberts, Harrell, \& Young, 2005). First generation students' life experiences may give them successful college skills such as time management, being self-advocates (Byrd \& MacDonald, 2005), and asking for help (Karp \& Bork, 2014), some or all of which may be measured in noncognitive scales (R.P. Group, n.d.). Indeed, using noncognitive variables at the university level may increase the number of Black and Latina/o students without changing academic performance (Schmitt et al., 2011).

However, all of the published research suggesting the relationship between noncognitive predictors and academic success has been correlational, qualitative, or theoretical and as such, it is not necessarily appropriate to use noncognitive scales without further research. 


\section{Justification and Significance}

A number of U.S. community colleges, including those in California, are currently considering noncognitive scales as a way to improve placement; some institutions have already implemented them (Booth et al., 2014; Burdman, 2012; Hayward \& Fagioli, 2016; Hetts \& Willett, 2013). The general reasoning behind their use is that noncognitive variables may help overcome the limitations of the contentbased assessment tests. These limitations include: cut-scores being a vexing weak point (Belfield \& Crosta, 2012; Booth et al., 2014; Fields \& Parsad, 2012; Jaggars \& Stacey, 2014; Melguizo et al., 2015; Scott-Clayton et al., 2014; Willett, 2013); certain groups performing worse on standardized tests (Hiss \& Franks, 2014; McKinsey \& Company, 2009a); some students faking their responses by intentionally doing worse on the assessment test (Fay et al., 2013); and some students doing worse due to stereotype threat (Burdman, 2015b). Yet there has been no published research on the how the highstakes nature of academic placement impacts student responses to noncognitive scales.

There is little known about how noncognitive variables can be used for community college placement, and there is legitimate concern about the validity and reliability of their use in a high-stakes environment (Duckworth, 2016; Sinha, Oswald, Imus, \& Schmit1, 2011). Research suggests the need to validate the use of noncognitive variables for diverse community college students, including nontraditional students (Ngo \& Kwon, 2014) and those who do not typically perform well on standardized tests 
(Schmitt et al., 2011). Based on the impact of placement tests on these populations, it is possible that using noncognitive variables for placement will induce strategic behavior (Fay et al., 2013; Fong \& Melguizo, 2015) and stereotype threat, which would in turn depress results (Burdman, 2015b; Steele, 1997). Thus, before noncognitive scales are implemented as part of the assessment and placement process, it is important to understand their impact on students. This study intends to add to the literature by doing just that. 


\section{CHAPTER 2: LITERA'TURE REVIEW}

This chapter reviews the literature relevant to community college placement practices. Three strands are examined: placement practices and problems, multiple measures for placement, and noncognitive variables for placement ${ }^{7}$. Equity issues within placement practices and the limitations of current research are also discussed.

\section{Placement Practices and Problems}

Placement practices generally refer to an assessment test, but they can also include high school GPA and prior coursework (Grimes-Hillman et al., 2014). More recently, they have included noncognitive measures, such as students` study habits, study skills, and time management skills (Willett et al., 2015). Community colleges use a variety of placement methods and tools, and scholars have found inconsistencies in placement practices both nationally and locally, including within the same district. They argue that this is a result of uninformed decision-makers, test bias, poor communication about the tests to students, and the way some students react to the assessment tests, including facing stereotype threat (Walton \& Spencer, 2009) and having low confidence

\footnotetext{
${ }^{7}$ Literature for this review was compiled through multiple sources. Search terms on ERIC (EBSCO), Academic Search Complete, and Google Scholar included: stereotype threat tool, community college, mathematics, placement, and/or noncognitive. Searches for proceedings from the 2016 American Educational Research Association annual conference included the terms noncognitive mathematics, socioemotional, and/or noncognitive placement. Literature was also complied via reference lists from readings.
} 
in their own mathematics ability (Fay et al., 2013; Steele, 1997; Steele et al., 2002).

- What follows is a discussion of research on inconsistent placement and its potential causes.

\section{Inconsistent placement practices}

Recent findings suggest that a large number of community college students are being misplaced. For example, Community College Research Center (CCRC) researchers Scott-Clayton, Crosta, and Belfield (2014) examined the placement system at a statewide community college to determine if high school data were a better predictor of student success in mathematics courses than the assessment test. They concluded that roughly $25 \%$ of community college students were severely underplaced into remedial mathematics inasmuch that they could have earned at least a "B" in a transfer-level course. This suggests that there are fewer misplacements for mathematics when high school grades are used to place students. Their analysis also found that the assessment test used has a significant impact on the gender and race of students placing into both remedial and transfer-level courses, suggesting test bias. However, the researcher's sample was limited to students with high school information and who enrolled directly into transfer-level mathematics. The authors admit that the latter limits their findings because their model does not account for the effects that remediation has on students or for the potential differences in motivation between students who start in 
the transfer level and those who start in remediation. Still, there is further evidence that current placement practices are flawed.

Validation studies of placement practices have found that many students are incorrectly placed into remedial mathematics courses. For example, the seminal CCRC study (Bailey et al., 2010) of over 250,000 students at 57 Achieving the Dream community colleges across seven states found that $17 \%$ of students who were placed into remedial mathematics ignored that recommendation and started in transfer-level mathematics. These students succeeded at a rate of $72 \%$, only $7 \%$ lower than the students whose assessment test scores placed them into transfer-level mathematics. This suggests two things: that at least $17 \%$ of students were placed into remedial mathematics erroneously, and that assessment tests alone are not a valid way to determine what a student knows, or what they can learn (Hughes \& Scott-Clayton, 2011). Finding the proper cut off place for transfer-level mathematics seems to be a pressure point.

The placement decisions for students near the cut off for remedial and transferlevel mathematics are made in an especially inconsistent manner. Another CCRC study (Jaggars \& Stacey, 2014) evaluated placement at a community college with a particularly low threshold for college-level mathematics. They analyzed student success rates based on a higher, and much more common cut-score and found that students near the cut-off succeed at random rates. These findings suggest cut-scores are a problem 
point for mathematics placement. An earlier CCRC review of research (Jaggars et al., 2013) found that there is no clear cut-off that can reliably predict passing or failing in college-level mathematics. The literature suggests many reasons why using assessment tests are problematic and inconsistent.

\section{Causation of Inconsistencies In Placement Practices}

Research suggests multiple explanations for the inconsistencies in placement practices within community colleges, including decision-makers being uninformed of effective techniques, test bias, poor communication about the purpose of the tests to students, students' lack confidence in their own mathematical abilities, and stereotype threat.

Uninformed decision-makers. Scholars contend that community college placement practices are inconsistent and ineffective, in part because decision-makers do not have the necessary tools or resources. For example, Melguizo, Kosiewicz, Prather, and Bos' (2013) analyses of transcript and placement data for roughly 80,000 students at two California community colleges found that students who had similar abilities were

placed differently. The researcher's interviews with faculty, managers, and staff suggest that none of the decision-makers had the resources or information necessary to implement assessment and placement in a way that best meets students' needs. Further, some viewed multiple measures as insignificant, a finding supported by later research (Bahr et al., 2014). Melguizo and colleagues specifically point to the decision-makers 
not having the resources they need to validate assessment test cut-scores effectively. This is consistent with WestEd's (Venezia et al., 2010) earlier findings that some counselors were confused about multiple measures. These results become especially problematic when combined with the other causes of inconsistent placement practices.

Test bias. Researchers have been engulfed in controversy over the validity and purpose of assessment tests for academic admissions and placement (e.g., Bailey et al., 2010; Fong \& Melguizo, 2015; Kurlaender \& Larsen, 2013; Maloney, Schaeffer, \& Beilock, 2013; McKinsey Company, 2009; Porchea, Allen, Robbins, \& Phelps, 2010; Scott-Clayton, Crosta, \& Belfield, 2014). For example, Geiser's (2015) recent study of over 1.1 million applicants to University of California, Berkeley between 1994 and 2001 found that the best predictor of students' SAT score is their race, along with family income and parental education. This suggests that the SAT is more of a proxy for socioeconomic status than a predictor of college success. These findings are consistent with McKinsey and Company's (2009b) research, which suggests that standardized tests are problematic because White students do better than Black students, and rich students do better than poor students. These performance disparities may, in part, be explained by looking at the student side of the issues.

Communication with students. Research suggests that poor communication to students may also play a role in the inaccurate outcomes. A WestEd (Venezia et al., 2010) study of five representative California community colleges held 28 focus groups 
with 257 students who had completed the assessment test within the prior two years. They found that the majority of students knew nothing about the assessment test before taking it, and many indicated that they felt unprepared for it and uninformed about it. Most students did not realize that the assessment test would determine what classes they could take, its impact on their college credits, or the effect it could have on their college timeline. Further, few colleges provided students with the required preparation materials. Fay, Bickerstaff, and Hordara (2013) used this research to build a national survey. When distributed to focus groups of students enrolled in remedial mathematics at four community colleges, the survey revealed that the majority $(69 \%)$ did not prepare for the assessment test. A large number of students did not know that study materials were available, with returning adults being much less likely to know about them; $58 \%$ of 18-23 year olds were unaware of the resources, compared to $73 \%$ of students over the age of 23. Some students made a conscious decision not to study for fear of being placed into a class above their ability. The researchers did not delve further into the underlying causes of these students' decision, but this recent research clearly suggests that lack of mathematics confidence and/or stereotype threat could have played a role.

Math confidence and anxiety. Students' lack of mathematics confidence may partially explain inconsistent placement outcomes. Fong and Melguizo (2015) found that when California community college students were given a choice between taking an assessment test for transfer level mathematics or remedial mathematics, half took a 
lower level test than their academic background suggests they should have taken. Traditionally underrepresented minorities were more likely to choose a test lower than their ability. A researcher from the University of California, Los Angeles, Gerardo Ramirez (as cited in Burdman, 2015), suggests that students taking the lower level tests are more likely to face stereotype threat, which has been shown to lead to lower scores (Maloney et al., 2013). This may partially explain findings suggesting that when controlling for educational background, Black and Latina/o community college students are more likely to be placed in remediation (Kurlaender \& Larsen, 2013), suggesting that use of assessment tests may be biased against these ethnicities.

Stereotype threat. Stereotype threat is "a psychological phenomenon that inhibits the academic performance of individuals in domains where negative ability stereotypes about their group are highlighted" (Picho \& Brown, 2011, p. 376). Stereotype threat is not specific to any one group, and is only present when individuals find themselves worried about filling a negative stereotype. Stereotype threat can occur even if that person does not believe in the stereotype. Stanford University researcher Steele (1997) suggests that stereotype threat is one of the reasons behind the achievement gap between Black and White students, and the lack of women in the hard sciences (math, engineering, and physical sciences) compared to men. He posits that when a person is in the midst of suffering from stereotype threat, they have an emotional reaction that negatively impacts their academic performance. Similarly, 
Maloney, Schaeffer, and Beilock (2013) suggest that students suffering from both stereotype threat and mathematics anxiety do not perform well on tests because their working memory is compromised. Thus, students' assessment test scores may not be a true reflection of what they know (Burdman, 2015b), suggesting that the assessment test is biased against certain groups of students, which would in turn make assessment tests poor predictors of their knowledge.

However, in recent years stereotype threat has become controversial. Flore and Wicherts (2015) performed a meta-analysis of how stereotype threat influences girls in mathematics found no significant evidence of stereotype threat, but they did find "several signs" of publication bias ${ }^{8}$ (p. 25). Others have reached similar conclusions. Stoet and Geary (2012) performed a meta-analysis of research on the gender gap in mathematics and found that stereotype threat effect only occurred in studies where math scores were adjusted, concluding that while stereotype threat may effect some women, "the existing state of knowledge does not support the current level of enthusiasm for this as a mechanism underlying the gender gap in mathematics" (p. 93). Ganley and colleagues (2013) performed three studies with 931 female children and adolescents. They found no relationship between mathematics and stereotype threat, stating that, "stereotype threat effect only occurs in very specific circumstances, or that they are in

\footnotetext{
${ }^{8}$ Publication bias is where only research that shows statistically significant results are published, leading to a biased view of the effect-or lack thereof.
} 
fact occurring all the time" (p. 1886). Ganley et al. also suggest the relationship may be a result of publication bias. In an earlier publication, Sackett, Hardison, and Cullen (2004) suggest that Steele and Aronson's (1995) findings did not suggest that stereotype threat was eliminated, rather, the data presented by Steele and Aronson were a result of data adjustments. Sackett and colleagues argue that the findings have been widely misinterpreted. Inzlicht (2016) has worked extensively on stereotype threat, including editing a book and joining a supreme court amicus brief on the subject. He too suggests publication bias, and recently admitted, “...now I am not as certain as I once was about the robustness of the effect [of stereotype threat]" (para. 6). As one researcher put it, "Stereotype threat has been overstated, overpromoted, and oversold" (Jusim, 2015). Despite the controversy, in a recent interview Steele maintained the effect is real and can be eliminated, and suggests the lack of replication being due to a change in student behavior (Adler \& Aronczyk, 2017). This controversy aside, there are plenty of other factors that make current placement practices problematic.

Collectively, these causes for inconsistent placement may partially explain the large numbers of students who were found to be severely underplaced. The evidence also suggests the need to decrease reliance on the use of tests. Placement tools and strategies available to community college are plentiful and diverse, but few colleges have taken advantage of them. A growing body of research, discussed in the following 
section, suggests that multiple measures and noncognitive variables may be effective in balancing the shortcomings of placement tests.

\section{Multiple Measures for Placement}

This section reviews the literature on the implementation and impact of both multiple measures and noncognitive variables as predictors of academic success, as evidence suggests that both are better predictors than assessment tests.

As stated earlier, the vast majority of community colleges use assessment tests for placement (Burdman, 2015b; Parsad, Lewis, \& Greene, 2003; Skinner, 2012; Venezia et al., 2010), although many also use multiple measures for admissions and placement (Grimes-Hillman et al., 2014; REL West at WestEd, 2011). At the community colleges, multiple measures often means using a combination of high school GPA and prior coursework, in conjunction with a mathematics placement assessment test score, which tends to be given the most weight (REL West at WestEd, 2011; Willett, 2013). Scholars argue that the placement problems associated with standardized tests can be avoided by using multiple measures, especially for traditionally underrepresented minorities and first-generation students.

Scholars have found a positive relationship between multiple measures and accurate student placement. A recent retrospective analysis of California's Multiple Measures Assessment Project's (MMAP's) placement model (Willett et al., 2015) suggests that were it implemented, this new method would increase the number of 
underrepresented minority students in transfer-level mathematics by $53 \%$ and increase other students' participation by $30 \%$. Currently, there are nearly twice as many students who are not in underrepresented groups (47\%) starting in transfer-level mathematics, but under MMAP's model, this gap is predicted to decrease to $38 \%$. The increase in students starting in transfer-level mathematics would mean a $13 \%$ increase in the number of community college students completing, with a specific increase in the proportion of traditionally underrepresented minorities. Results have been so promising that the California Community College system is currently working to implement multiple measures (MMAP) as part of the common assessment (Hayward, Nguyen, \& Willett, 2015).

Some scholars argue that multiple measures are more accurate because a students' high school grade point average (GPA) has been consistently shown to be a more valid indicator of mathematics success than a single assessment test (e.g., Bailey et al., 2015; Belfield, 2014; Scott-Clayton et al., 2014; Willett et al., 2015). GPA is considered a good indicator because evidence suggests it measures both cognitive and noncognitive abilities (Hodara et al., 2012), including noncognitive skills such as motivation, perseverance (Bowen et al., 2009), and study habits (Bailey et al., 2015). The noncognitive aspect of GPA is consistent with a recent CCRC (2013) analysis suggesting that less than $15 \%$ of the variance in students' academic achievement can be explained by the assessment test and high school GPA. The researchers presume that 
the remaining $85 \%$ must be explained by something else, including noncognitive variables such as "student motivation, out-of-school commitments and stressors, and the quality of instruction and nonacademic supports provided" (p. 3). These findings, along with the results of the MMAP placement model are the impetuous behind the research performed for this study.

Using evidence-based multiple measures could result in more accurate mathematics placement. For example, Lemay (1994), a California community college counselor, performed a retrospective study of community college students' placement results and mathematics achievement. She found that intermediate algebra placement was more accurate when placement was determined using a combination of the assessment test, number of years since leaving high school, and high school GPA. More recently, Scott-Clayton's (2012) validity study of two common assessment tests found that if only using one criteria, high school GPA and coursework are a better predictor of success than assessment test scores, but that the most effective result came from using whichever result placed the student higher. Hetts and Willett's (2013) longitudinal study at a southern California community college determined that the best predictor variables are the eleventh grade California Standardized Test (CST), the student's grade in their last high school math class, and proxies for motivation, such as length of time since graduation and whether or not the student attended a local high school. Overall, what these researchers have considered are noncognitive aspects of student learning and 
achievement. These developments have ignited interest in including noncognitive variables in placement (Farrington et al., 2012).

\section{Noncognitive Variables for Placement}

Duckworth and Yeager (2015) posit that there is a "scientific consensus" that success in education and beyond "depends critically on many attributes other than cognitive ability" (p. 245). However, while scholars argue that noncognitive skills are a key to academic success and therefore should be useful in academic placement decisions (Belfield, 2014), there is little published, peer-reviewed literature on the assessment of noncognitive variables actually being used for placement. Published studies are either longitudinal correlational studies (Kaufman et al., 2008; Porchea et al., 2010) or theoretical simulations (Fong, Melguizo, \& Prather, 2015; Hayward \& Fagioli, 2016; Schmitt et al., 2011; Scott-Clayton, 2012), many of which have populations that are not easily generalizable to community college students (Byrd \& MacDonald, 2005; Day, Hanson, Maltby, Proctor, \& Wood, 2010; Komarraju, Ramsey, \& Rinella, 2012).

\section{Correlational Studies}

Longitudinal correlational studies tend to give participants noncognitive scale(s) at the beginning of the study and then follow their academic progress to correlate participants' responses with their academic progress and outcomes. For example, academic preparedness and motivation may correlate to academic achievements. Porchea, Allen, Robbins, and Phelps' (2010) longitudinal study of 4,481 students at 21 
community colleges in 13 states used the ACT Inc.'s Student Readiness Inventory (SRI) to determine the predictive value of cognitive, noncognitive, and institutional factors for student success. Their findings suggest that high school GPA, motivation, academic self-confidence, and geographic distance between college and high school are more closely correlated to earning a degree and transferring than standardized test scores. Further, when controlling for all other factors, students with higher academic selfconfidence were less likely to finish, perhaps because these students were less likely to seek out help. This suggests that standardized tests may not be a valid predictor of students' knowledge or ability to learn, whereas noncognitive skills may be.

The California community college's MMAP is considering using noncognitive scales for placement, and are completing correlational studies within that system. One such study was recently performed in a Southern California community college district (Hayward \& Fagioli, 2016). They gave all incoming students a battery of noncognitive scales, including the College Student Self-Assessment Survey, Conscientiousness, Grit, and Mindset. The largest correlation the researchers found between student responses to noncognitive scales and their academic performance was small (0.13). While the correlation is low, Hayward proposes that that it could lead to a stronger placement model (C. Hayward, personal communication, May 12, 2016) when considered with other variables. Still, the authors suggest further research is needed to determine both 
the utility of noncognitive variables and any mediating or moderating impact of their use.

\section{Theoretical Simulations}

Theoretical simulations have also shown that noncognitive variables may be good predictors of academic success. For example, a College Board (Schmitt et al., 2011) validity study compared biographical data, including background and life history, and participants' responses to noncognitive scales between current students and new applicants. The researchers found very little difference in responses between the two participant groups, suggesting that incoming students are likely to be consistent when responding, suggesting that if continuing students are truthful, then new applicants are as well. Schmitt et al. (2011) concluded that there is little evidence that noncognitive variables negatively impact any particular subgroup, but they suggest a need for further research, with special emphasis on students who do not typically perform well on standardized tests.

A more recent simulation suggests that noncognitive factors may have more to do with students' completion of remedial mathematics than their math knowledge. Fong, Melguizo, and Prather (2015) analyzed three-to-five years of academic records and assessment results for three cohorts of students who completed the remedial mathematics sequence at a large California community college district. Analysis

suggests that with the exception of arithmetic, students' ability to complete the remedial 
sequence had more to do with an individual's characteristics than with their ability to do mathematics. This indicates that NCVs can help predict success through course sequences. Further, evidence suggests that admission and placement policies can reduce disproportionate impacts, making procedures and policies for assessment and placement an issue of equity.

\section{Equity Implications}

Community college completion rates are drastically different depending on where a student is initially placed, as the more classes one needs to take, the less likely they are to earn a degree or transfer. This completion problem makes accurate placement an issue of equity, especially for historically disenfranchised students. Black and Latina/o students are disproportionately likely to attend a community college, and like first generation students, Black and Latina/o students are disproportionately placed into developmental courses, especially into the lower levels of the sequence. Combined, these develop into a perfect storm that is having a drastic impact on the completion rates of students, especially disenfranchised students. The literature discussed above suggests moving away from the placement test, and towards a robust multiple measures placement mechanism may have a positive impact on placement by increasing the number of (disenfranchised) students who are initially placed in transfer-level courses, and by extension, increasing completion rates. This suggestion is supported by research at four-year institutions. 
There is an equity gap between two- and four-year institutions in regards to both completion rates and placement. Time to completion is a problem within all higher education. Community colleges are often referred to as "Two-Year Colleges" but Bailey, Jaggars, and Jenkins (2015) suggests that is a misnomer. Their national study found that fewer than $20 \%$ of community college students finish within three years, and less than $40 \%$ complete in six years. Similarly, they found that students attending socalled "Four-Year Colleges" need at least six years, with $82 \%$ of students at selective institutions finishing in six years, but only $29 \%$ of students at non-selective institutions finished in this time. There is strong evidence to suggest that initial placement is a difference-maker. Monaghan and Attewell (2014) used national longitudinal data from the National Center for Education Statistics (Beginning Postsecondary Students) and found that when controlling for high school grades, math classes, and SAT scores, community college students were $19 \%$ more likely to be in remedial math than their four-year counterparts at non- and minimally-selective institutions. A recent review of California State University placement rules suggests that were these same rules applied to California Community College students, over $80 \%$ of incoming students would be placed into remediation for English, math, or both (National Center for Public Policy and Higher Education and The Southern Regional Education Board |NCPPHE \& SREB|, 2010). The California State University system has altered their placement 
policies since that report, but the fact remains that far too many community college students are placed into remediation.

The California Community Colleges have a crisis of equity, but they are attempting to address it through the Multiple Measures Assessment Project (MMAP), which uses robust, research-based data to make placement more accurate. There is strong evidence to suggest that noncognitive data would increase diversity in transferlevel courses by placing traditionally underrepresented populations into higher-level courses. Evidence from studies at four-year universities suggests that using a combination of cognitive and noncognitive factors can reduce the disproportionate impacts. Sinha, Oswald, Imus, and Schmitt (2011) simulated admissions policies at ten universities, including two historically black colleges, to determine how policies impact the demographic make-up of the students who are admitted. Using participants' responses to noncognitive scales, GPA, biographical data, and ACT/SAT scores from 836 incoming freshmen and class subject volunteers, the researchers found that admissions rates for each ethnic group changed depending on the weight given to each entrance criterion. This suggests that using both cognitive and noncognitive variables for admissions can reduce the disproportionate impact and increase the number of historically underrepresented groups.

Similarly, using students' background and personality characteristics may help increase the number of first-generation students. Bryd and MacDonald (2005) 
interviewed eight first-generation college students who earned an associates degree and transferred to a four-year college. Findings suggest part of what made these students successful were the skills they developed while growing up: time management, being goal-oriented, and being a self-advocate. The authors gave no suggestions for how to help current community college students succeed.

Research at community colleges has also shown that the mechanisms used for placement can have a positive impact in reducing the placement gaps between underrepresented minorities and other students (Willett et al., 2015). Evidence suggests that including noncognitive variables in academic placement may make the process more equitable for nontraditional and underrepresented students. The research performed for this study will add to the literature by testing response patterns among different types of community college students.

\section{Limitations of Current Research}

Although current research on the use of noncognitive scales in placement is promising, there are some questions that need answering before recommending or introducing their use for making placement decisions in the community colleges. For example, a large number of these studies may not be adequately transferable to California community college student because the student populations from the literature are not easily generalizable to community college students (Byrd \& MacDonald, 2005; Day et al., 2010; Komarraju et al., 2012). Further, there is a lack of 
data on how some students react to the noncognitive scales when they are used for placement.

Similarly, some of the studies on noncognitive variables are not transparent because they fail to cite references or give details about their methodology. For example, Conley (2007) argues that the literature supports four components of college readiness, but fails to cite literature beyond his own. Rather, Conley makes broad statements such as, "These findings have been confirmed in subsequent studies" (p. 14), and "other [researchers] have identified the academic behaviors and context knowledge students need" (p. 18), neither of which are followed by references. Others are absent of current research (Conley, 2011; Sedlacek, 2011). For example, Conley (2011) is the fifth edition of the original report (Conley, 2007), but a PDF comparison by this researcher revealed only minor editing, changes in terminology, and inconsequential additions. More importantly, the later edition is completely absent of current, and highly relevant research, as evidenced by the two editions having identical reference lists. Another researcher, Sedlacek (2011), makes a number of assertions with no data or citations to back them up. Further, Sedlacek is void of relevant research, some of which dispute his claims. Of particular note, in his argument for utilizing the Non-Cognitive Questionnaire (NCQ), he makes no mention of a recent meta-analysis that found the NCQ to be such an inadequate predictor that the authors recommend against its use (Thomas, Kuncel, \& Credé, 2007). As such, the NCQ is not included in this study. 
Many scholars agree that there is a need for further research regarding the utility of noncognitive variables for placement (Belfield, 2014; Booth et al., 2014; CCRC, 2013; Ngo \& Kwon, 2014; Schmitt et al., 2011). Some scholars contend that more research about the internal validity of noncognitive variables is needed before they can be used for academic placement (Duckworth \& Yeager, 2015). Scholars also argue that the nature of placement may subject certain groups to stereotype threat, thus depressing their scores (Burdman, 2015b; Steele, 1997; Walton \& Spencer, 2009; Yeager \& Walton, 2011), while other students may inflate their answers when the scales are used in a high-stakes setting (Kyllonen, 2012; Sinha et al., 2011). The research performed in this study was intentionally designed to address these concerns.

\section{Summary}

Much of the literature suggests that including noncognitive variables as part of the placement process may be beneficial to students (CCRC, 2013), especially for traditionally underrepresented students (Sinha et al., 2011), first-generation students (Byrd \& MacDonald, 2005), and students near the cut-off for transfer-level mathematics (Jaggars et al., 2013; Jaggars \& Stacey, 2014). Findings suggest that using both multiple measures and noncognitive variables may be a solution, but there is a gap in the literature when it comes to the using them for actually making placement decisions. Specifically, there is no research that considers students' reactions when they are given 
the noncognitive scales in an environment where they are told their responses will be used for placement (Farrington et al., 2012).

Theoretically, noncognitive variables may be associated with academic performance in higher education (Hayward \& Fagioli, 2016; Schmitt et al., 2011), but the results of a thorough literature review argue that there is too little empirical research to recommend that they be used in academic placement (Farrington et al., 2012). Further research is needed to fully understand the validity (Belfield, 2014; Booth et al., 2014; Hayward \& Fagioli, 2016; Kurlaender \& Larsen, 2013) and usefulness (Ngo \& Kwon, 2014; Schmitt et al., 2011) of noncognitive scales for placement, especially for non-traditional students (Farrington et al., 2012; Ngo \& Kwon, 2014) and those with assessment test scores near the cut-off for transfer-level mathematics (Belfield, 2014; Schmitt et al., 2011). Scholars argue that if noncognitive variables are used, the scales must be validated, and their use and interpretation be articulated to students (Farrington et al., 2012; Hays et al., 2014).

One's likelihood of earning a degree should not depend on erroneous and problematic placement practices. The use of noncognitive scales and variables for placement is intended to overcome the limitations of contentbased assessment tests, especially for students who historically underperform on standardized tests. Yet it is still unclear whether students will show similar reactions to the assessment tests, wherein certain groups have reacted differently, be it intentionally or unintentionally, 
because of the high-stakes nature of the test. This study seeks to add to the literature by investigating how students react to noncognitive scales when they know they may be used in a high stakes atmosphere of academic placement. 


\section{CHAPTER 3: METHODOLOGY}

This chapter discusses the procedures and methodology this study, including a review of instrumentation and data analysis. This random control trial seeks to answer the research questions: How does the high-stakes nature of academic placement impact student responses on noncognitive scales? How does the context, demand, characteristics, and framing of the noncognitive variables impact stereotype threat, if at all?

Evidence suggests that traditionally underrepresented minorities and firstgeneration students may sometimes lower their mathematics assessment test scores intentionally (Fong \& Melguizo, 2015), in part due to stereotype threat (Burdman, 2015b) and low mathematics confidence (Fay et al., 2013). This study tested to see if students have similar responses to noncognitive scales when they are used for placement. The study specifically looked for stereotype threat as a mediator and asked participants if they over- or under-represented their responses, referred to as faking. To examine this potential effect, the researcher performed quantitative, randomized control trials with deception, where the treatment group was told that their responses would be used to determine placement and the control group was told their responses would help improve instruction. 


\section{Research Design}

This randomized control trial was intended to gauge participants' reactions to noncognitive scales under a high-stakes environment. Applicants to the participating colleges were emailed an invitation to participate (Appendix B); two reminder emails were sent. Participants were randomly assigned to either the treatment group or the control group, and the message characteristics the participants received depended on which group the participant was assigned to (Appendix C). The treatment group was given high-stakes framing and was told that their responses would be used to determine course placement. The control group was given low-stakes framing and was told that their responses would help improve instruction. Participants were administered noncognitive attitudinal scales and surveys to measure stereotype threat, gather demographic information, and determine if responses were altered due to the threat of

placement. Due to the online nature of the study, consent was implied (Appendix C) and so only adults 18 years or older were allowed to participate. Participation was completely voluntary. There were two rounds of data collection: in December 2016 and June 2017. The first of which was a pilot. etails can be found in the instrumentation section of this chapter.

\section{Role of the Researcher}

The researcher has both a personal and professional interest in this topic. From a personal standpoint, I empathize with the large number of community college students 
who are placed into remediation. Coming back from a five-year educational hiatus, I had forgotten much of the math I had learned and was placed into elementary algebra, a course two levels below transfer, and far below my capability. I can empathize with misplaced and underplaced students, because like many, I passed university-level courses in both logic and statistics, in addition to having passed pre-calculus in high school. Like so many incoming community college students, I did not know that I should have, or could have, reviewed for the assessment test, and I did not have the agency to use my transcripts to challenge the placement decision. That said, as someone who enjoys mathematics, I have no doubt that this experience helped steer me toward teaching. I am now in my thirteenth year as a mathematics professor at a Northern California community college, where I am part of the decision-making body that determines how students are assessed and placed into mathematics. My doctoral research has led me to understand that my experience as a community college student is far from unique and that mathematics professors' decisions for what is best is not always in the student's best interest. I am determined to do as much as I can to help community college placement become more accurate and as such, help more students start at as high a level as possible and complete their goals.

My personal connection to the topic of study is a potential source of bias because I experienced being misplaced during my education, and because I am currently employed at one the institutions participating in the study. I see no conflict of 
interest or threats to validity because of my employment status for two reasons: first, all participants are applicants to the institution, so there is little chance that I will know any of them, and second, I will not have any direct contact with the participants, since the study is being conducted completely online, and the institution will be sending invitations on my behalf. Thus, I am confident that the research data will be analyzed in a fair and transparent manner. Still, I will take extra care to ensure that results are unbiased.

\section{Research Questions and Variables}

This study was guided by the research on how students react to assessment tests. This study will be guided by the following research questions:

1. How does the high-stakes nature of academic placement impact student responses to noncognitive scales?

2. How does the context, demand, characteristics, and framing of the noncognitive variables impact stereotype threat, if at all?

The independent variable for this study was the message characteristics that each participant received, i.e., the treatment group receiving a message with high-stakes framing. The dependent variable was the participants' responses on the noncognitive scale. 


\section{Population and Sample}

This study was intended to complement the California community colleges' Multiple Measures Assessment Project (MMAP). MMAP is researching the utility of noncognitive variables as a way to make community college placement more accurate when used in conjunction with placement and assessment and/or high school data. The noncognitive scales for this study were chosen because they are under consideration by the MMAP (RP Group, n.d.), who selected the scales based on their validity and costeffective nature (T. Willett, RP Group, personal communication, February 11, 2016). It is worth noting that there is one scale the MMAP is considering that is not included for this study: the Noncognitive Questionnaire - Revised 2 (NCQ-R2) (Ting \& Sedlacek, n.d.; Tracey \& Sedlacek, 1987). This researcher has elected not to include the NCQ-R2 because of the controversial nature of the tool (e.g., Thomas, Kuncel, \& Credé, 2007).

\section{Context}

This study received institutional review board (IRB) approval from both the participating district and San Francisco State University (protocol number X16-52). The researcher performed a field test at the participating district in order to trouble shoot both the instrument and the process. Before engaging in the full study in December 2016, minor alterations were made to the protocol and the instrument. These alterations included clarifying framing (introductory wording) and post-debriefing questions. Alterations to the protocol were also made after the first round of data collection, 
including minor phrasing changes and alterations to the number of questions participants received; all protocol changes were approved by both San Francisco State and the participating district.

Institutional participation was solicited from those where the researcher has access, most of which were in Northern California. The researcher was granted permission to recruit at two multi-college community college districts in Northern California, including one where she had existing professional connections. To solicit participation from District A, the researcher contacted the institution's research offices; at District B she worked through the chancellor's office'. At both districts, this included initiating IRB processes. Once approval was granted, the researcher worked out recruitment logistics with the individual districts, including determining the most effective times to send out invitations so as to minimize the burdens of the researcher and the institution while simultaneously maximizing the number of people in the participant pool. Invitations to participate were sent by the institution; the researcher had no direct contact with the participant pool unless they initiated contact via email.

\section{Population}

The population for this study was incoming California community college students. This study included two sample pools: students who applied for admittance in

\footnotetext{
${ }^{9}$ Two districts agreed to participate, but there were logistical issues with the recruitment emails at the second district which prevented their participation.
} 
spring 2017 and in fall 2017. The participating institutions had a varying range in the number of students, student demographics, student-counseling ratios, and rates of success and completion. Due to logistical problems, only one district was able to participate.

Eligibility criteria. Although the population for this study was California community college applicants, there are two participant groups that were excluded: minors and participants who opted out after they were debriefed (Appendix H). Minors were not included because the strictly online nature of the study did not allow for parental consent. 'The participants' age was verified at three points: before invitations were sent (participating institutions filtered applicants by age); before participation began (the kick-out question); and before data analysis began (participants' age was verified using the biodata question in Appendix G). Data from respondents who fell into any of the above categories were destroyed by the researcher.

Sample - pilot study. Invitations to participate were sent to 5,500 applicants to the District in mid-December, 2016. Two reminders were sent. The researcher received 197 responses (3.58\%), of which 100 were assigned to the treatment group, and 97 were assigned to the control group. Within the treatment group, 83 participants completed the entire protocol, all of whom affirmed their consent to participate at the end of the study. Within the control group, 70 completed the entire protocol and 66 affirmed their consent to participate at the end of the study. 
Sample - research study. Invitations to participate were sent to 7,276 fall 2017 applicants in June 2017. Three reminders were sent. The researcher received 312 responses (4.29\%), but only 179 completed the entire protocol. Of those, 168 affirmed their consent. There were 75 participants assigned to the treatment group and 93 assigned to the control group, all of whom completed the entire protocol and reaffirmed their consent to participate at the end of the study.

\section{Ethical Considerations}

Community colleges across the nation have started using noncognitive variables for academic placement, yet there has been no published or peer-reviewed research on how students' responses are impacted by the high-stakes nature of placement. Current research addresses how students perceive the assessment and placement tests (e.g., Venezia, Bracco, \& Nodine, 2010), however these studies do not specifically address noncognitive scales.

\section{Justification for Deception}

Since colleges around the nation are either considering, or are currently using noncognitive scales for placement, this research is timely and important. Before these scales are implemented as a placement measure, it is important to understand the impact they will have on student responses. This study necessarily involved deception, as there was no way to determine the impact on placement without deceiving some participants. 
Participation ended with a debriefing that revealed the deception and the true purpose of the study and allowed participants to withdraw consent (Appendix H).

\section{Research Risks}

This research had minimal physical or discomfort risk. There was a potential for psychological risk, such as anxiety as a result of the deception. This risk was relieved in the debriefing, when participants were informed of the nature of the study and the nature of the deception (Appendix H). There was a potential risk of loss of privacy, but no identifiable information was obtained. Participants were informed that they could stop participating or skip any questions at any time, with no penalty to themselves or their standing at the college. If a participant began the study but did not finish it, their responses were destroyed and were not included in the study.

The research was anonymous. No personally identifying information was collected. The researcher did not ask participants to report any information that will identify them at their institution, such as student identification numbers. The participating institutions were not informed as to who participated. Some study participants were deceived while they participated, and there is a chance that participants did not understand that the deception was part of study, but the researcher added both a debriefing and a verification of understanding to help mitigate this possibility. Participants were not harmed and were not asked for any sensitive or incriminating information. Subject risk was minimal. As such, this study was ethical. 


\section{Instrumentation}

The researcher performed a randomized posttest-only control group design (Fraenkel, Wallen, \& Huyn, 2012). The independent variable was the message characteristics to the students, namely the different instructions being given to the control group and the treatment group. The treatment group was told that their responses would be used for placement and the control group was informed that their responses would be used to improve instruction. The dependent variable was the students' responses on the noncognitive scale. Stereotype threat was measured as a potential mediator using the Social Identities Attitudinal Scale (SIAS; Picho \& Brown, 2011).

The research took place online and was hosted by the San Francisco State Qualtrics site license. Participants completed the study at a time that was convenient for them, and where they had access to the internet. The instrumentation varied depending on which group the participant participated in, and when they participated. Participants in both groups received the ten-step protocol below. Participants in each group were given slightly different protocols, as explained below. More details about each aspect of participation follow.

1. Received an email invitation to participate, with link for participation (Appendix B).

2. Received implied consent to participate in an online study (Appendix C). 
3. Verified their adult status, i.e. the "kick-out" question (Appendix C).

4. Received a message of either high-stakes framing (treatment group) or lowstakes framing (control group) (Appendix D).

5. Completed noncognitive scales (Appendix E).

6. Completed the Social Identities Attitudinal Scale (Appendix F).

7. Completed a demographic questionnaire about academic and personal background (Appendix G).

8. Received the debriefing (Appendix H).

9. Completed four follow-up questions (Appendix H).

10. Completed verification questions of understanding and consent (Appendix $\mathrm{H})$.

\section{Instrumentation Details}

Participants in the pilot should have all received the same protocol, but due to an error in Qualtrics, the treatment and groups received different protocols. The treatment group received an average of 58 questions, depending on their educational background and the noncognitive scales they received. The pilot control group, and all participants in the study received an average of 100 questions, depending on their educational background. Each of the ten steps of participation are detailed below.

Invitation to participate. The study began with emailed invitation to participate, which included a link for participation (Appendix B). The researcher had no 
direct contact with the participants, as the institutions emailed the participation pool on her behalf. Upon clicking the participation link, Qualtrics randomly assigned participants to either the control or treatment group, so assignment was determined before the study began (Fraenkel et al., 2012).

Implied consent. Next, participants received the implied consent (Appendix C). Because the study involved deception, the consent form was necessarily elusive about the purpose and background of the study, stating, "The purpose of the study is to explore ways to improve the California community colleges."

Verification of age. If the invitee agreed to participate, they first verified their age (Appendix C). Participants indicating that they were not yet 18 years old were informed that they do not qualify for participation. S.F. State refers to this as a "kick-out question." Once adult status was verified, participants were given the appropriate messaging for their group.

Message characteristics. This step is where the differentiation between the control and treatment group occurred and is where the high stakes nature is framed for the treatment group (Appendix D). To that end, the control group was given low-stakes framing, being told that the survey "will ask you about your thoughts, feelings and behaviors both in general and at school" and that responses "will help to improve instruction." They were assured that their participation "will not have any impact on your placement or your grades... and will not be reported to the college." Conversely, 
the treatment group was given high-stakes framing, being told that their responses "will help the Assessment Center determine what class(es) you should begin in and what coursework you are eligible for," and that while "your individual responses are strictly confidential... but the overall results will be reported to Admissions and Records" (i.e. placement). The wording used for both groups was adapted from a recent study at South Orange County Community College District (Hayward \& Fagioli, 2016).

Noncognitive scales. Ten noncognitive scales were part of this study. The names, abbreviation, and number of items in each scale are listed in Table 1 and the questions for each scale are in Appendix E. The treatment group in the pilot was randomly assigned a subset of noncognitive scales, but all other participants received all the scales. All instruments used one of the Likert scales listed in Table 2. Analysis of all noncognitive scales was based on the respondent's average score. That is, the numbers corresponding to each response was added up, and divided by the number of questions. Thus, the average score for each respondent followed the same Likert scale as the question responses. The validity of each scale is discussed in detail in the in the validity section. What follows is an explanation of what each noncognitive scale was intended to measure. 
Table 1.

Surveys Utilized for This Study

\begin{tabular}{|c|c|c|c|}
\hline Scale & Abbreviation & $\begin{array}{l}\text { No. of } \\
\text { Items }\end{array}$ & Likert Scale \\
\hline \multicolumn{4}{|l|}{ Noncognitive Scales } \\
\hline Academic Self-Efficacy a & ASE & 11 & A \\
\hline College Identity ${ }^{a}$ & Col-Ident & 3 & $A$ \\
\hline Teamwork $^{a}$ & Team & 5 & $A$ \\
\hline Interaction (Combined) ${ }^{a, b}$ & Interact-Comb & 9 & A \\
\hline Interaction - Communication ${ }^{a}$ & Interact-Comm & 4 & A \\
\hline Interaction - Choices ${ }^{a}$ & Interact-Choice & 5 & A \\
\hline Mindfulness (Combined) a,b.c & Mindf-Comb & 7 & $\mathrm{~B}$ \\
\hline Mindfulness - Distracted a,d & Mindf-D & 4 & B \\
\hline Mindfulness - Observing a & Mindf-Obs & 3 & $\mathrm{~B}$ \\
\hline Grit - Shortened ${ }^{c}$ & Grit & 8 & $\mathrm{C}$ \\
\hline Hope (Combined) ${ }^{b}$ & Hope-Comb & 8 & BB \\
\hline Hope - Pathways & Hope-Path & 4 & $\mathrm{BB}$ \\
\hline Hope - Agency & Hope-Agency & 4 & BB \\
\hline Conscientiousness - Concise ${ }^{c}$ & Consc & 5 & $A$ \\
\hline Mindset - Shortened ${ }^{c}$ & Mindset & 3 & A \\
\hline Social Identity Attitudes Scale & SIAS & 30 & AA \\
\hline Debriefing Questions & Debrief & 4 & $\mathrm{BB}^{\mathrm{e}} \& \mathrm{~A}^{\mathrm{f}}$ \\
\hline
\end{tabular}

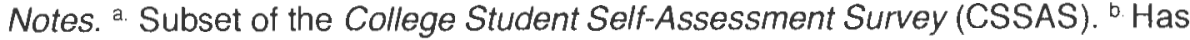
subscales that were also analyzed separately. ${ }^{c}$ Some items are reverse-coded. ${ }^{d}$ Entire scale is reverse coded inasmuch that obtaining a low score is ideal. ${ }^{e}$. Used

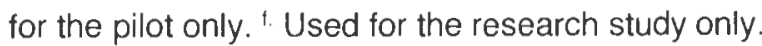


Table 2.

Likert Scales Used for This Study

\begin{tabular}{|c|c|c|c|c|c|c|c|c|}
\hline \multirow{2}{*}{ Scale } & \multirow[b]{2}{*}{1} & \multicolumn{6}{|c|}{ Point Values } & \multirow[b]{2}{*}{8} \\
\hline & & 2 & 3 & 4 & 5 & 6 & 7 & \\
\hline$A$ & $\begin{array}{l}\text { Strongly } \\
\text { disagree }\end{array}$ & Disagree & $\begin{array}{l}\text { Neither } \\
\text { agree nor } \\
\text { disagree }\end{array}$ & Agree & $\begin{array}{l}\text { Strongly } \\
\text { agree }\end{array}$ & - & - & - \\
\hline$A A$ & $\begin{array}{l}\text { Strongly } \\
\text { disagree }\end{array}$ & Disagree & $\begin{array}{l}\text { Somewhat } \\
\text { disagree }\end{array}$ & $\begin{array}{c}\text { Undecide } \\
d\end{array}$ & $\begin{array}{c}\text { Somewhat } \\
\text { agree }\end{array}$ & Agree & $\begin{array}{l}\text { Strongly } \\
\text { agree }\end{array}$ & - \\
\hline $\mathrm{B}$ & $\begin{array}{l}\text { Never or } \\
\text { rarely true }\end{array}$ & $\begin{array}{l}\text { Seldom } \\
\text { true }\end{array}$ & $\begin{array}{c}\text { Occasionally } \\
\text { true }\end{array}$ & $\begin{array}{l}\text { Frequently } \\
\text { true }\end{array}$ & $\begin{array}{c}\text { Very often } \\
\text { or always } \\
\text { true }\end{array}$ & - & - & - \\
\hline BB & $\begin{array}{l}\text { Definitely } \\
\text { false }\end{array}$ & $\begin{array}{l}\text { Mostly } \\
\text { false }\end{array}$ & $\begin{array}{l}\text { Somewhat } \\
\text { false }\end{array}$ & $\begin{array}{l}\text { Slightly } \\
\text { false }\end{array}$ & $\begin{array}{l}\text { Slightly } \\
\text { true }\end{array}$ & $\begin{array}{c}\text { Somewhat } \\
\text { true }\end{array}$ & $\begin{array}{l}\text { Mostly } \\
\text { true }\end{array}$ & $\begin{array}{c}\text { Definitely } \\
\text { true }\end{array}$ \\
\hline $\mathrm{C}$ & $\begin{array}{l}\text { Not like } \\
\text { me at all }\end{array}$ & $\begin{array}{l}\text { Not much } \\
\text { like me }\end{array}$ & $\begin{array}{l}\text { Somewhat } \\
\text { like me }\end{array}$ & $\begin{array}{c}\text { Mostly like } \\
\text { me }\end{array}$ & $\begin{array}{l}\text { Very much } \\
\text { like me }\end{array}$ & - & - & - \\
\hline
\end{tabular}

College student self-assessment survey. The College Student Self-Assessment Survey (CSSAS) was developed by the Academy for College Excellence (ACE) at Cabrillo College (Farr, Rotermund, Radwin, Robles, \& Choy, 2014). For the purposes of this study, the CSSAS was broken down into multiple separate instruments. The Academic Self-Efficacy (ASE) scale is used to determine "One's confidence in successfully completing school-related tasks and in one's ability to regulate learning and study behaviors. It also includes items related to students' hopes regarding their academic futures" (Farr et al., 2014, p. 39), where a one (strongly disagree) means the respondent has no confidence, and scores of five (strongly agree) means that they have the utmost confidence. Three of the CSSAS instruments measure college-readiness: 
College Identity (Col-Ident), Teamwork (Team), and Interacting with others (InteractComb). The last item was broken up into two sub-scales: Communication (InteractComm) and Choices (Interact-Choice). These three scales measure how one identifies "as a college student, communication skills, and aspects of personal responsibility that affect interaction with others... [and] anticipated stress and ability to handle challenging stress levels" (Farr et al., 2014, p. 39). Scores range from five (strongly agree), suggesting the student is as prepared for college as can be, to one (strongly disagree), suggesting they are not prepared for college. Two instruments measure mindfulness, Distracted (Mindf-D) and Observing (Mindf-O), by rating "one's ability to focus on tasks, and one's inner state, through observing, describing, and accepting one's actions, thoughts, and behaviors" (Farr et al., 2014, p. 39). A score of five (very often or always

, true) suggests not being mindful at all, and being easily distracted and unobservant. A score of one (never or rarely true) suggests always being mindful and being very focused and observant. The CSSAS is copyrighted, and the researcher received permission to use it.

S/hort grit. Responses to the Shortened Grit scale (Grit) show the respondents so-called grittiness (Duckworth, Peterson, Matthews, \& Kelly, 2007). Respondents achieving the highest possible score of five (very much) have a lot of grit, while those scoring one (not at all) have no grit. This scale is copyrighted and the researcher received permission to use it. 
Hope. The Hope scale (Snyder et al., 1991) will be scored based on two subscales. Half of the items measure the respondent's "pathway thinking" with a score of eight (definitely true) indicating a better ability to think about pathways (RP Group, 2015, p. 4). The other half of the questions measures the respondent's agency, where the closer the score is to eight, the more agency the respondent has. It is important to note that when originally published, the Hope scale used a four-point Likert scale, but the scale currently uses an eight-point scale. Responses range from definitely false (one) to definitely true (eight). This study will analyze the Hope scale in three ways: as one whole scale (Hope-Comb), just pathways (Hope-Path), and just agency (Hope-Agency). The Hope scale is copyrighted, but the author's website gives permission to researchers and educators to use it (Snyder, n.d.).

Unfolding five factor model conscientiousness. The Unfolding Five Factor Model Conscientiousness Scale - Concise (Consc) (Carter et al., 2014) measures conscientiousness, including competence, orderliness, dutifulness, achievement motivation, and cautiousness (RP Group, n.d.). The full scale contains 20 items, but this study used the five-item concise version under consideration by MMAP. The scale uses a five-point Likert scale from strongly disagree (one) to strongly agree (five), with higher scores indicating higher degrees of conscientiousness. This scale is open-source so the researcher does not need permission to use it (Carter et al., 2014). 
Mindset - shortened. The full Mindset Scale (Dweck, 1986) has 20 items, but this study used the shortened, three-item version (Mindset-S). This scale uses a fivepoint Likert scale, ranging from strongly disagree (one) to strongly agree (five). The higher the respondent's average, the more of a growth mindset they have. Conversely, the closer the average is to one, the more of a fixed mindset they have. This is a copyrighted scale, and the researcher received permission to use it.

Social identity attitudes scale. The sixth part is the Social Identity Attitudes Scale (SIAS) (Picho \& Brown, 2011), an attitudinal scale that was used to gauge levels of susceptibility to stereotype threat for race-, gender-, and math-identity (see Appendix F). The SIAS was used to determine if stereotype threat mediated participants' responses to the other noncognitive scales. The SIAS uses a seven-point Likert scale, where responses closest to seven (strongly agree) suggest high susceptibility to stereotype threat, and responses closer to one (strongly disagree) suggest very little or no susceptibility to stereotype threat. Participants are categorized as being in one of four profiles: Disengaged, which suggests the person has suffered from stereotype threat for so long that they have disengaged from it, high susceptibility (High SST), low susceptibility (Low SST), and no susceptibility (Unidentified). The SIAS is copyrighted and the researcher was granted permission to use it.

Background information. The seventh step of participation was a questionnaire about the participant's academic and familial background, often referred to as 
biographical data or biodata (Appendix G). Questions included participant's race, age, gender, mathematics background, high school GPA, household income, and parental education. This data was used to control for and disaggregate by participant background. Participants were also asked if they had already taken the assessment test at the college they applied to control for knowledge of the assessment and placement process. Finally, the age question was used as a secondary check to ensure all participants were adults.

Debriefing, follow-up, and verifications. The last three steps were the debriefing, follow-up questions, and verification questions (Appendix $H$ ). The debriefing revealed the true nature of the study. Participants in the treatment group were informed that they were deceived, and they were assured that their responses would not be used for course placement, and would not be reported to the college. Participants in the control group were also informed that some participants were deceived. All participants were assured that their responses would be kept completely confidential and would not have any impact on their standing at the college to which they applied, or at San Francisco State University. After being informed that the responses would have no impact, participants in both groups were asked follow-up questions to see if they believed the deception, and/or if they gave inflated or deflated answers. The study ended with two verification questions. The first was to determine if participants 
understood the nature of the study, which served as a check for understanding. The second question verified participants' consent.

\section{Validity}

The validity of this random control trial, both internal and external, is based on the randomized nature of the study design and the validity of the selected instruments.

\section{Internal Validity}

The entire protocol was field tested at a three-college district to check for potential threats to internal validity and to trouble shoot any technical problems with sending the invitations. The field test was done with current students, so as to assure people in the participant pool would not be included in the field test.

Additionally, the large sample size and randomized, posttest-only design of the study will control for potential threats to internal validity, including testing threat, "subject characteristics, maturation, and statistical regression" (Fraenkel et al., 2012, p. 271). The large sample size is expected to control for mortality threat, but the researcher will report mortality rates for transparency. Further, all instruments have been shown to be both reliable and valid.

Noncognitive scales. All scales have been verified for internal validity. The CSSAS scale was verified by the CCRC (ACE, 2014). These items have also shown to have good reliability, as evidenced by Cronbach's Alpha ranging from 0.57 to 0.89 , with a mean of 0.75 (RP Group, 2015). The short Grit scale (Grit-S) (Duckworth et al., 
2007) has been shown to be both reliable and valid in subsequent studies (Duckworth $\&$ Yeager, 2015), with one study finding a Cronbach's Alpha of 0.73 (RP Group, 2015). The Hope scale (Snyder et al., 1991) has been shown to have internal validity and reliably, with multiple studies finding Cronbach's alpha of at least 0.80 (RP Group, 2015). The UFFM-I-C (Carter et al., 2014) takes five questions from the 20-item UFFM-I scale, which have been shown to have internal validity with a Cronbach's alpha of 0.63 (RP Group, 2015). Finally, the Mindset scale - shortened (Mindset-S) has been shown to have a Cronbach's alpha of 0.63 (RP Group, 2015).

Social identities attitudes scale. The SIAS has been tested for internal validity and reliability (Picho, 2011; Picho \& Brown, 2011) and has been used in subsequent research (e.g., Guillory, 2014; Smith \& Cokley, 2016). The question order has been changed from the original scale to avoid a feeling of redundancy, but the change does not invalidate the results (K. Picho, personal correspondence, August 29, 2016).

\section{External validity}

This study has external validity because it was completed for two sets of applicants (spring 2017 and fall 2017). Moreover, the large sample size and randomized, experimental methodology give it generalizability. To reach a near-normal sample, researchers should have at least 40 participants per variable, per institution (Fraenkel et al., 2012). The district that participated has three institutions, suggesting a need for at least 120 participants. This research had a total of 296 eligible participants, 
141 from the pilot and 155 from study, suggesting that the data from each round has external validity.

\section{Data Analysis Procedures}

Data analysis was completed using IBM's SPSS predictive analytics software. The researcher followed the "rigorous quantitative data analysis procedures" outlined by Creswell and Plano Clark (2010, p. 204): prepare data for analysis, clean data, recode data as necessary, explore the data by conducting descriptive analyses and checking for trends, analyze the data using statistical tests, represent the data, interpret the results, and validate both the data and the results.

The statistical tests used for data analysis were based on Hoy and Adams (2015), Laerd Statistics (2015), and Cobb (2008). SPSS assistance came from Laerd Statistics (2015) and Lund and Lund (2015). Analysis included measures of central tendencies, measures of variability, and inferential statistics such as comparisons of means, correlations, and regression. The data from the pilot and the research study were analyzed separately. In both cases, the data were first analyzed as one large set. The first test performed was independent samples t-tests to check for differences by F1 visa status. Once it was established that there was little difference between the domestic and international students, the researcher removed the international students from the study to eliminate any mitigating variables. 
The data set was then reevaluated with just the domestic students and disaggregated by study group. For all statistical tests, assumptions were verified following Laerd Statistics (2015), statistical significance was determined using twotailed $95 \%$ confidence intervals, and findings were checked for Family Wise Error Rates using post-hoc analysis suggested by Cobb (2008) and Laerd Statistics (2015). Post-hoc analysis included Tukey HSD, Dunnet's T3, or Bonferroni, depending on the test being performed and whether or not the relationship met the assumption of homogeneity of variance. Testing of statistical significance between correlation coefficients of two independent samples was performed by using Lowry's (2017) online tool. What follows are details of how those were performed, along with details of how each data set was analyzed.

\section{Detailed Explanation of Analysis Procedures}

A number of independent samples t-tests were performed. In all cases, the data were checked for outliers ${ }^{10}$ and extreme outliers ${ }^{11}$ via visual inspection of boxplots, and outliers $^{12}$ were removed before continuing analysis. Normality of distribution was determined using the Shapiro-Wilk test for normality, with significance $p>0.05$, but the test was continued if this assumption was violated, as the data set was believed to be

\footnotetext{
${ }^{10}$ Data points that are more than one-and-a-half box lengths away from the edge of their box.

11 Data points that are more than three box-lengths away from the edge of their box.

${ }^{12}$ Outliers and extreme outliers will be referred to collectively using the term outliers.
} 
robust enough (Laerd Statistics, 2015). Homogeneity of variances was determined by Levene's test for equality of variances with significance $p>0.05$. If the assumption of homogeneity was met, then the t-test statistic was reported, otherwise the Welch's t-test statistic was reported.

For analysis of variance, both one-way and two-way ANOVAs were performed. For one-way ANOVA, outliers were determined by visual inspection of boxplots and were removed before continuing analysis. Normality of distribution was determined using the Shapiro-Wilk test for normality, with significance $p>0.05$, but the test was continued regardless of normality, as the data set was believed to be robust enough. Homogeneity of variances was determined by Levene's test for equality of variances with significance $p>0.05$. If the assumption of homogeneity was met, then the ANOVA F statistic was given and Tukey HSD was used for post hoc analysis. Otherwise, the robust test of equality of mean was reported using Welch's F statistic, in which case post hoc testing utilized Dunnet's T3.

For two-way ANOVA, outliers were determined by visual inspection of boxplots of residuals, and outliers were removed for analysis. The data presented in Chapter Four indicate how many outliers were present. Normality of distribution was determined using the Shapiro-Wilk test for normality with significance $p>0.05$; the test was continued even if the data was not normal. Homogeneity of variances was determined by Levene's test for equality of variances with significance $p>0.05$. If the 
assumption of homogeneity was met, then the F statistic was given, else Welch's F was given. In both cases, post hoc analysis was based on Bonferroni simple main effects.

For analysis of covariance, ANCOVA tests were performed. The assumption of linearity was determined by visual inspection of scatterplots. Homogeneity of regression was determined by slopes of (independent variable)*(covariant) with significance $\mathrm{p}>0.05$. Normality was determined by within-group residuals, with Shapiro-Wilk significance $p>0.05$. Homoscedasticity was determined by visual inspection of scatterplots. Homogeneity of variance was determined by Levene's, $\mathrm{p}>0.05$. Outliers were determined by standardized residuals. All ANCOVA tables include both the F statistic for the covariate, and the F statistic for the independent variable after adjustment for covariate. the test was discontinued for relationships that failed to meet the assumptions of linearity or homogeneity of regression (Laerd Statistics, 2015).

Findings were checked for confounding variables. Both data sets were checked for significant biographical differences between study groups. This check included high school GPA, college GPA, years since last math class, age, parent's education, family income, ethnicity, and college applied to. Any significant results between study groups were then checked as potentially confounding variables for significant findings. Note that the number participants of each ethnicity were too small to analyze on their own, so ethnic groups were collapsed into three categories: traditionally Underrepresented 
Minorities (URM), which consisted of Black, Latina/o, Pacific Islander, Filipina/o, and Native Americans; non-Underrepresented Minorities (non-URM), which consisted of White and Other Asians; and Unsure, which consisted of South Asian, Southeast Asian, Multi- or Bi-Racial, and Other. What follows is a more detailed explanation for how the data were analyzed for each round.

\section{Pilot Data Analysis}

There were problems with the protocol for the pilot study and the research questions could not be analyzed. Specifically, within the treatment group participants were randomly assigned a noncognitive scale, but no scales received enough responses to allow for analysis. At the same time, the control group, participants received all the noncognitive scales. Since both the research questions from this study required a comparative analysis of noncognitive variables between groups, the researcher was unable to study them. However, all other survey questions were able to be analyzed, including susceptibility to stereotype threat and faking so a data exploration was performed with the available information.

The pilot data set was first analyzed in aggregate form as a whole set, followed by a disaggregated analysis of the treatment and control groups. As this was exploratory research, Type-I errors were not a concern (Cobb, 2008). This exploration included descriptive statistics, correlations, comparisons of means, analysis of variation. and cross tabs to check for trends. The researcher looked for trends in the data across 
variables and found that whether or not a participant took an assessment test impacted responses within the treatment group. After this discovery, data was re-analyzed with a focus on the assessment test as a potential mediator. This secondary analysis included descriptive statistics, correlations, comparisons of means, and analysis of variance. Data was also analyzed in aggregate form, looking for differences between ethnicity, income, first-generation status, institution applied to, and GPAs in order to check for potential disproportional impacts between the treatment and control groups.

\section{Research Study Data Analysis}

The research study data were analyzed with two objectives: to address the research questions and check for a relationship with the assessment test. Analysis included descriptive statistics, correlations, analysis of variance, comparison of means, and multivariate regression to analyze the simultaneous impact of multiple factors on the dependent variable. All findings were checked for Family Wise Errors using posthoc analysis. The data were first analyzed in aggregate form, followed by a disaggregated analysis of the treatment and control groups. Participant responses were analyzed while controlling for ethnicity, academic preparation, parent's educational background, socioeconomic status, and institution applied to. When using mean and standard deviation, the researcher checked for sensitivity to ensure that outliers were not skewing the data. Finally, the analysis was used to determine potential disproportional impacts within the treatment and control groups. The disaggregation and the differences 
between the control and treatment groups was used to analyze differences in responses on the noncognitive scales in order to answer the research questions and to analyze whether or not the assessment test was a mediator.

\section{Study Limitations}

This protocol was set up with the best of intentions to decrease potential limitations, but as the cliché goes, hindsight is always $20 / 20$ and as data analysis begun, the researcher became aware of a number of protocol issues that add limitations to the data. Specifically, there are a number of limitations which limited comparability between the pilot treatment and control groups. Further, there are limitations on generalizability due to the ways in which questions were posed.

First, there were problems with the pilot study that prohibited the researcher from analyzing participant responses on the noncognitive scales for that data set, meaning that the research questions could not be answered for the round one data. Specifically, the control group received a different protocol than the treatment group. Each group should have been randomly assigned a set of roughly eight noncognitive questions, but due to an error in the Qualtrics protocol, the control group was given the full set of noncognitive scales in a random order. This means the control group received all 59 noncognitive questions instead of the eight or so planned questions. Had this error not occurred, the data would still be problematic as the as the method of randomly assigning noncognitive scales meant that no single scale received enough responses to 
illicit statistically significant results. Moreover, this error inadvertently doubled the protocol for the control group, who received an average of 110 questions, compared to the treatment group, who received an average of 58 questions. This difference in protocols may have impacted on how participants reacted to the debrief questions, as responses to follow-up questions differ depending on the number of survey questions. That is to say, the comparison of how the pilot treatment and control groups responded on the debrief responses are not completely reliable due to the differing protocols.

There was a limitation with regard to the value of the debrief questions themselves. Regarding faking, the control and treatment groups were given different questions. The control group was asked to respond to direct questions about whether or not they increased or decreased their answers (e.g., "I gave higher answers than were true"), whereas the treatment group was given the caveats of placement (e.g., "I gave higher answers than were true because I was worried about being placed to low"). This means two things: it is unclear if the treatment group was responding to the first part of the statement or the second, or both, and responses between treatment and control may not be completely comparable. In retrospect, the questions about faking given to the treatment group may have been more illuminating if they had they been asked as four questions: e.g., did you change your answers? Were you worried about being placed too high/low? Regarding the deception check questions, the second question, "I was especially worried about math placement" was intended to be a follow-up to the 
question, "When I answered I was worried by responses would be used for course placement." However, some participants may have interpreted the math placement question as a stand-alone question.

Information about assessment tests is also limited. The protocol asked if participants had taken an assessment test prior to participation, but it failed to ask which specific assessment test was taken, or if the participant was using other means for placement (e.g., transcripts). Thus, there is no way to know if participants were responding to having taken (or not taken) a specific assessment test, or assessment tests in general, such as the A.C.T. or S.A.T.

The small sample size limits analysis of stereotype threat, as there were few participants who were found to have High SST or Disengaged.

There was also a limitation on how international students were identified. When gathering participants' background information, the protocol asked if participants were "applying to the college with an F1 Visa" (see Appendix G). However, this visa is not the only means by which international students attend college in the United States. The researcher removed international students from analysis, but the analysis of so-called "domestic" participants could include international students who are studying with a different type of visa.

Finally, as with all data analysis, there is a chance of Family Wise Errors rates, but the researcher's use of post-hoc analysis accounts for any potential errors, false 
positives, or Type I errors. In chapter four, the narrative calls out significant findings that are believed to be Type I errors.

The next chapter will report the findings from this study, followed by the final chapter, which will discuss the findings and make recommendations for next steps. 


\section{CHAPTER 4: REPORT OF FINDINGS}

This was a random control trial of incoming California Community College students to see how the initial framing of a noncognitive survey impacted responses. It sought to answer the research questions: How does the high-stakes nature of academic placement impact student responses on noncognitive scales? How does the context, demand, characteristics, and framing of the noncognitive variables impact stereotype threat, if at all? This chapter will report on the findings, starting with an overview of the participant backgrounds, followed by reports for each research question, and a report of unexpected findings ${ }^{13}$.

\section{Research Study Background}

In order to study the two research questions, the control group was given lowstakes framing, being informed, "This survey will ask you about your thoughts, feelings, and behaviors both in general and at school," and that responses "will help to improve instruction". They were assured that their participation "will not have any impact on your placement or your grades... and will not be reported to the college". Conversely, the treatment group was given high-stakes framing, being told that their responses "will help the Assessment Center determine what class(es) you should begin

\footnotetext{
${ }^{1.3}$ In the interest of readability, the majority of data tables are included in Appendix A.
} 
in and what coursework you are eligible for," and that while "individual response are strictly confidential... the overall results will be reported to Admissions and Records" (i.e., placement; see Appendix D for full text).

The major findings suggest that initial framing played a role in participant responses and lowered responses on some noncognitive variables, but that the act of having taken a placement test was also a moderator of student behavior and whether or not students believed the initial framing. Susceptibility to stereotype threat appeared to have a statistically significant ${ }^{14}$ relationship with some participants' responses on the noncognitive scales, although there was evidence that initial framing was not related. Finally, while participants were generally honest, those who did change their answers did so in a manner that was inconsistent, more so when given high stakes framing.

This chapter will give a detailed report of the study findings. It will start with an overview of the pilot study findings, followed by a report of the findings of the research study. This will include participant demographics, data relevant to research question one, data in relation to question two, a report of unexpected outcomes, and a summary.

\section{Pilot Study}

The pilot was conducted with spring applicants in December 2016, roughly one month before spring 2017 classes began. Within the California Community Colleges,

${ }^{14}$ The terms significant and statistically significant will be used interchangeably. 
spring applicants are more likely to be non-traditional college students, and the pilot participants fit that general profile. There were 141 domestic applicants who completed the entire protocol, with roughly $57 \%(\mathrm{n}=81)$ of them having had taken a placement test prior to participation, albeit there was no data collected on which test(s) participants took. Based on the district's registration dates, it is probable that participants had registered for classes before participating. The treatment and control groups of the pilot were similar in their backgrounds. Both groups were predominately females; half were under age 25 , and a sizeable proportion (23\%) were at least 40 years old. The treatment group had a larger portion of traditionally Underrepresented Minorities (URMs; Black, Latina/o, Pacific Islander, Native American, and Filipina/o). The control group had statistically significantly higher family incomes, high school GPAs, and college GPAs.

\section{Validation of Deception (Pilot)}

An independent sample t-test suggests that participants in the treatment group believed the high stakes framing they were given, $\mathrm{t}_{73}=5.770, \mathrm{p}<0.001$ (Figure 1), as the treatment group was significantly more worried that their response would be used for course placement $(\bar{x}=2.49, \mathrm{sd}=2.216)$ compared to the control group $(\bar{x}=1, \mathrm{sd}=0.0)$. There was evidence that this difference was not related to family income, $F_{1,130}=14.062$, $p<0.001$, or ethnicity $F_{2.131}=11.119, p<0.01$. There was no evidence of a relationship with college GPA or institution. 


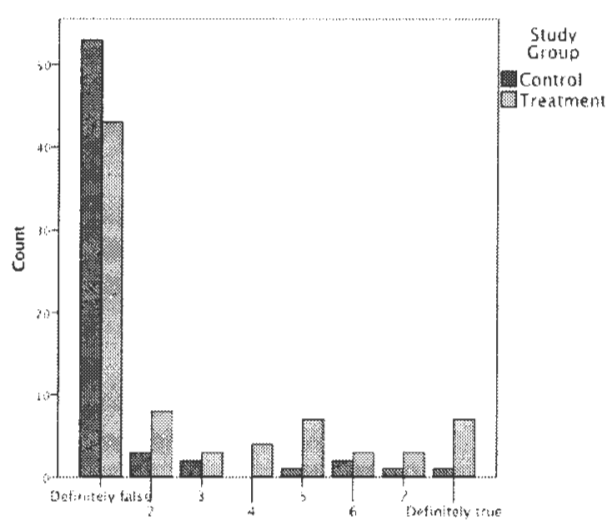

Figure 1. (Pilot) Distribution of belief in high stakes framing by study group. Treatment group participants were significantly more likely to believe their responses would be used for placement.

Framing and assessment tests (Pilot). During the exploratory data analysis of the pilot, it became apparent that there was a relationship between participants' belief that responses would be used for placement and whether or not they took an assessment test before participating in this study $\mathrm{t}_{80}=6.277, \mathrm{p}<0.001$ (Figure 2). Pilot participants who had taken an assessment test prior to study participation $(\mathrm{N}=81)$ were significantly more likely to believe that their responses would be used for placement $(\bar{x}=2.56$, $\mathrm{sd}=2.230)$, compared to participants who had not taken an assessment test $(\mathrm{N}=60$; $\bar{x}=1.00, \mathrm{sd}=0.00$ ). Among the latter, those who believed their responses would be used for placement were outliers.

To check if these results were related to the initial framing, an ANOVA was run using four dummy variables: Control-No Assessment Test $(\mathrm{N}=46)$; Control-Assessment Test $(\mathrm{N}=37)$; Treatment-No Assessment Test $(\mathrm{N}=31)$; and Treatment-Assessment Test $(\mathrm{N}=41)$. There is evidence of a significant difference between groups, $\mathrm{F}_{3,119}=23.522$, 
$\mathrm{p}<0.001$ (Figure 3). Excluding outliers, there was a significant difference in the belief of high stakes framing Treatment-Test $(\bar{x}=3.33, \mathrm{sd}=2.440)$ compared to the three other groups $(\bar{x}=1.00, \mathrm{sd}=0.0)$, a mean difference of 2.333, $\mathrm{p}<0.001$ (Dunnett's T3).

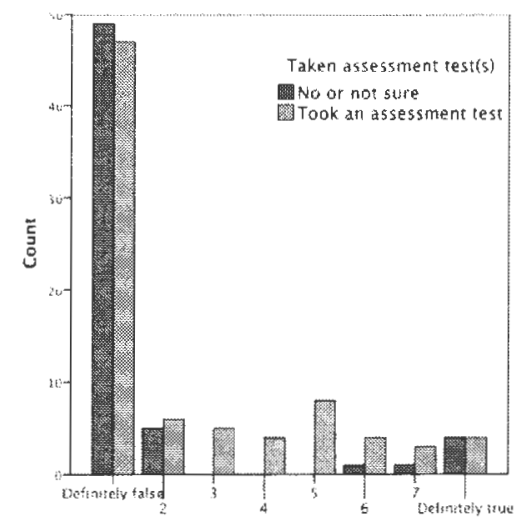

Figure 2. (Pilot) Distribution of belief in high stakes framing by taken assessment test. Participants who took a placement test were significantly more likely to believe their responses would be used for placement.

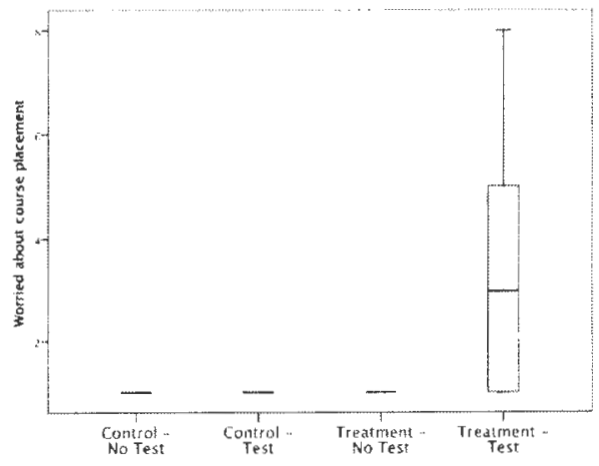

Figure 3. (Pilot) Boxplots of Belief in high stakes framing by study group and assessment test (outliers removed). Participants in the treatment group who had taken an assessment test were significantly more likely to believe their responses would be used for placement. 


\section{Faking (Pilot)}

At the end of the survey, participants were given four debriefing questions, two of which were related to faking. The treatment group was asked to respond to the questions, "I gave lower answers than were true because I was worried about being placed too high," (Decreased Answers) and "I gave higher answers than were true because I was worried about being placed too low" (Increased Answers). The control group was asked to respond to, "I gave lower answers than were true" (Decreased Answers), and "I gave higher answers than were true" (Increased Answers).

Participants who reported faking were outliers, as the mean responses were quite low for both decreasing answers $(\bar{x}=1.43, \mathrm{sd}=1.16)$ and increasing answers $(\bar{x}=1.57$, $\mathrm{sd}=1.52$ ). However, among those participants who adjusted their answers, there was a moderately positive correlation between decreasing and increasing answers, $r=.517$, $\mathrm{p}<0.001, \mathrm{~N}=141$ (Figure 4). After removing outliers, comprised solely of participants who only reported increasing their answers, the relationship between increasing and decreasing answers became very strong, $r=.913, p<0.001, N=130$. 


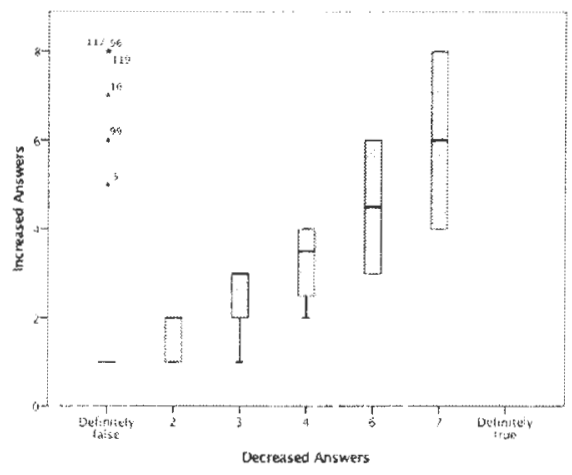

Figure 4. (Pilot) Boxplots of Increased Answers by Decreased Answers. There was a very strong, positive relationship between increasing and decreasing answers.

There is evidence that pilot participants given high stakes framing were significantly more unreliable in their answers. In the control group, participants reported low amounts of decreasing answers $(\bar{x}=1.33, \mathrm{sd}=1.00)$ and increasing answers $(\bar{x}=1.68, \mathrm{sd}=1.78)$, and there was only a weak relationship between increasing and decreasing answers, $r=.324, \mathrm{p}<0.05, \mathrm{~N}=63$ (Figure 5). However, after the outliers were removed, the correlation nearly tripled, becoming very strong, $r=0.928, p<0.001, N=57$. The treatment group also reported low levels of decreasing answers $(\bar{x}=1.51, \mathrm{sd}=1.28)$ and increasing answers $(\bar{x}=1.49, \mathrm{sd}=1.29)$, but had a significantly stronger correlation between the two, $\mathrm{r}=739, \mathrm{p}<0.001, \mathrm{~N}=78$ (Figure 6) compared to the control (Fisher $\mathrm{r}$ to- $z$ transformation, $z=3.53, p<0.001$ ). There was no evidence of relationships with ethnicity or institution and faking. 


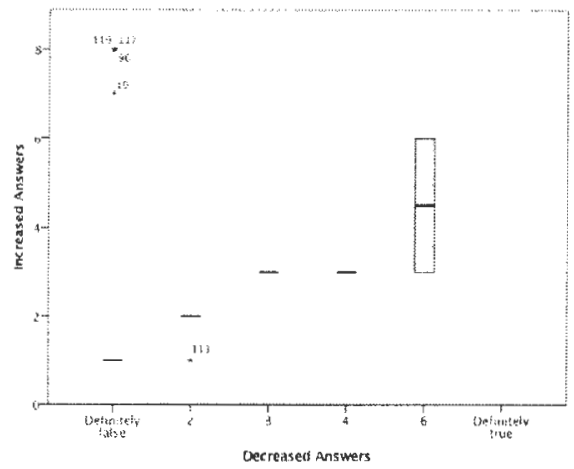

Figure 5. (Pilot, control) Boxplots of Increased Answers by Decreased Answers. There was a weak, positive relationship between increasing and decreasing answers within the control group. This relationship became very strong after outliers were removed.

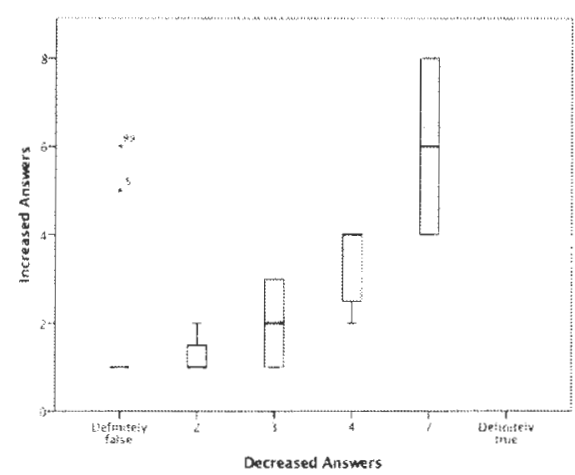

Figure 6. (Pilot, treatment) Boxplots of Increased Answers by Decreased Answers. There was a strong, positive relationship between increasing and decreasing answers within the treatment group. This relationship became very strong after outliers were removed.

Faking and Susceptibility to Stereotype Threat. The pilot data were further analyzed to check for a relationship between study group and susceptibility to stereotype threat. An independent samples t-test by study group found no statistically significant difference between the treatment and control groups. As there was earlier evidence of a significantly difference in correlations between increasing and decreasing 
answers across study groups, each group was analyzed separately, but these too produced no significant results.

Within the treatment group, one-way ANOVAs were attempted to check for a relationship between susceptibility to stereotype threat and faking. All tests were inconclusive because there was zero variance between groups, and so Welch's F could not be calculated; post hoc analysis was not significant.

Within the treatment group, a one-way ANOVA was attempted to check for a relationship between SST Identities and faking. All relationships had outliers, and once the outliers were removed, all relationships became constant, with no apparent faking of any kind, $M=1, s d=1$. Thus, ANOVA could not be performed. The control group showed no significant correlations between faking and susceptibility to stereotype threat, as determined by Pearson's correlations.

\section{Pilot Summary}

There is evidence that treatment group believed the high stakes framing, and that having taken an assessment test significantly increased the likelihood of believing that responses would be used for placement. In general, pilot group participants were honest and reported low levels of faking, but those who did fake, did so inconsistently in that they reported both decreasing and increasing their answers. This inconsistency was significantly more likely among the group given high stakes framing. Tests for 
relationships between faking and susceptibility to stereotype threat were inconclusive. The rest of this chapter will present the findings from the research study.

\section{Study Participant Demographics}

This section will outline the demographics of each round and consider any significant differences between study groups. Data for the research study was collected in June 2017 and consisted of fall 2017 applicants within a three-college California community college district. Fall applicants to the California Community Colleges tend to be more traditional college students, and this participant group was as well. Participants were surveyed roughly six to ten weeks before fall 2017 classes began. Based on district registration dates, it is unlikely that any participants had registered for classes prior to participation. The participant pool included both domestic and international applicants, with the latter self-identifying as applying with $\mathrm{F} 1$ visas $(\mathrm{n}=13)$, but analysis was completed with only domestic applicants $(\mathrm{N}=155)$ in order to minimize confounding variables. In general, the treatment and control groups had fairly similar backgrounds (Table 3). Both groups were predominantly female and under the age of 25 . They had roughly the same number of traditionally Underrepresented Minorities (Black, Latina/o, Pacific Islander, Native American, and Filipina/o), although the control group appears to include a larger percentage of nonUnderrepresented Minorities (White or Other Asian). 
Table 3.

Participant Background

\begin{tabular}{|c|c|c|c|}
\hline Item & $\begin{array}{c}\text { Combined } \\
N=155\end{array}$ & $\begin{array}{c}\text { Treatment } \\
\mathrm{n}=72\end{array}$ & $\begin{array}{c}\text { Control } \\
\mathrm{n}=83\end{array}$ \\
\hline \multicolumn{4}{|l|}{ Biographical Background } \\
\hline Female & $70 \%$ & $68 \%$ & $71 \%$ \\
\hline $18-24$ years old & $68 \%$ & $68 \%$ & $68 \%$ \\
\hline $40+$ years old & $10 \%$ & $8 \%$ & $11 \%$ \\
\hline Underrepresented Minority a & $39 \%$ & $40 \%$ & $37 \%$ \\
\hline Non-Underrepresented Minority b & $40 \%$ & $35 \%$ & $45 \%$ \\
\hline \multicolumn{4}{|l|}{ Household Background } \\
\hline Parent(s) have no higher ed. experience & $27 \%$ & $27 \%$ & $28 \%$ \\
\hline Parent holds Bachelor's Degree or higher & $39 \%$ & $38 \%$ & $40 \%$ \\
\hline Lower or Lower Middle Class & $39 \%$ & $42 \%$ & $36 \%$ \\
\hline Middle Class & $45 \%$ & $38 \%$ & $29 \%$ \\
\hline \multicolumn{4}{|l|}{ Educational Background } \\
\hline Attended High School & $98 \%$ & $99 \%$ & $98 \%$ \\
\hline Attended a California High School c & $88 \%$ & $87 \%$ & $88 \%$ \\
\hline High School GPA 3.0 to 4.0 c. d & $70 \%$ & $63 \%$ & $76 \%$ \\
\hline Previous College Experience & $41 \%$ & $42 \%$ & $40 \%$ \\
\hline College GPA 3.0 to $4.0^{\circ}$ & $78 \%$ & $72 \%$ & $84 \%$ \\
\hline Last math Class within last 2 years & $67 \%$ & $68 \%$ & $69 \%$ \\
\hline Last math class $5+$ years ago & $18 \%$ & $15 \%$ & $17 \%$ \\
\hline \multicolumn{4}{|l|}{ District Background } \\
\hline Applied to Diablo Valley College c & $62 \%$ & $61 \%$ & $63 \%$ \\
\hline Taken an Assessment Test & $50 \%$ & $57 \%$ & $45 \%$ \\
\hline
\end{tabular}

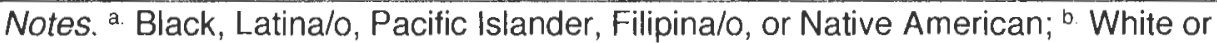
Other Asian. c. Percentage based on number of people responding to the questionall other percentages are based on the total number of participants. ${ }^{d}$ Statistically significant difference between groups.

The treatment group had a slightly larger proportion of lower, lower middle class, and middle-class participants. Nearly all participants attended high school, mostly in California. The majority applied to Diablo Valley College (DVC), and the treatment group had a larger proportion who had taken a placement test prior to participating in 
the study. The data suggests the two groups had significant difference in High School GPAs (Figure 10). The control group had significantly higher high school GPAs, $\mathrm{t}_{116}=3.875, \mathrm{p}<0.001$, tending towards a 3.0 to 3.49 GPA $(\bar{x}=4.43, \mathrm{sd}=0.722)$, compared to the treatment group's 2.5 to 2.9 GPA average $(\bar{x}=3.82, \mathrm{sd}=1.072)$. Thus, High School GPA, ethnicity, and institution will be considered as potentially confounding variables.

\section{Noncognitive Variables and High Stakes Academic Placement}

This section addresses the first research question: How does the high-stakes nature of academic placement impact student responses on noncognitive scales? The researcher compared participant responses to check for a relationship between the highstakes framing given to the treatment group and noncognitive scales. First, the data were analyzed to check for a relationship between the treatment group and a belief in high stakes framing.

\section{Validation of Deception}

Participants were given a deception check question at the end of the survey by responding to the question, "When I answered, I thought that my responses would be used for course placement." An independent sample t-test, revealed significant differences between the treatment and control group, $\mathrm{t}_{109}=3.406, \mathrm{p}<0.001$ (Figure 7). The treatment group was significantly more likely to believe their responses would be used for course placement $(\bar{x}=1.96, \mathrm{sd}=1.127, \mathrm{~N}=72)$ compared to the control group 
$(\bar{x}=1.44, \mathrm{sd}=.626, \mathrm{~N}=83)$, suggesting that the average treatment group participant was more likely to have believed the deception.

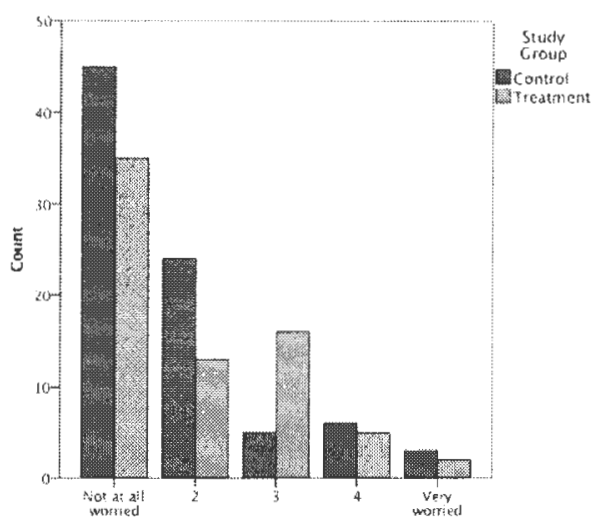

Figure 7. Distribution of belief in deception by study group. The treatment group was significantly more likely to believe their responses would be used for course placement.

During analysis, it became apparent that there was a relationship between participants' belief that responses would be used for placement and whether or not they had taken a placement test before participating in this study, $\mathrm{t}_{120}=2.587, \mathrm{p}<0.05$ (Figure 8). Participants who had not taken a placement test were significantly more likely to believe their answers would be used for placement $(\bar{x}=1.96, \mathrm{sd}=1.160, \mathrm{~N}=73)$ compared to those who had taken a test $(\bar{x}=1.55, \mathrm{sd}=.722, \mathrm{~N}=75)$, a mean difference of 0.412 . In this way, not having taken an assessment test also served as a high stakes event. 


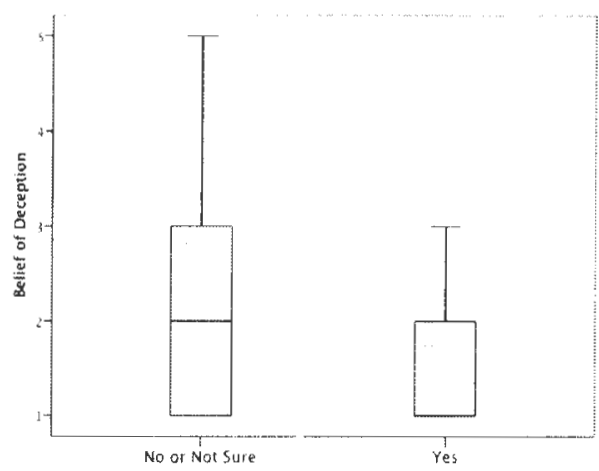

Figure 8. Boxplots of belief that responses would be used for placement by taken assessment test. Participants who had not taken an assessment test were significantly more likely to believe their responses would be used for placement.

To check for a relationship between high stakes framing and taking an assessment test, a one-way ANOVA was run using four dummy variables: Control-No Assessment Test ( $\mathrm{N}=46)$, Control-Assessment Test $(\mathrm{N}=37)$, Treatment-No Assessment Test $(\mathrm{N}=31)$, and Treatment-Assessment Test $(\mathrm{N}=41)$. The data suggest there was an interaction, $F_{3.76}=4.407, \mathrm{p}<0.01$ (Figure 9). The Treatment-No Test group was significantly more likely to believe their responses would be used for placement $(\bar{x}=2.27, \mathrm{sd}=1.258)$ compared to the Control-Test group $(\bar{x}=1.47, \mathrm{sd}=.560)$, a mean difference of $0.794, p<0.01$ (Dunnett's T3). 


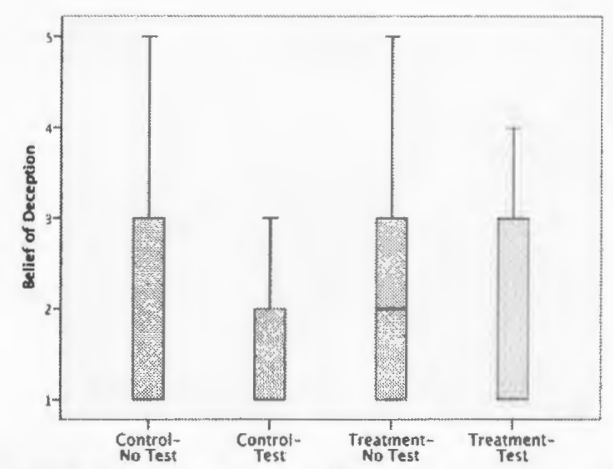

Figure 9. Boxplots of belief that responses would be used for course placement by study group and taken assessment test (outlier removed). Participants in the treatment group who had not taken an assessment test were significantly more likely to believe their response would be used for placement compared to the control group participants who had taken an assessment test.

\section{Noncognitive Variables and High Stakes Framing}

Multiple statistical tests were performed for the entire data set to check for a relationship between the framing and the noncognitive scales. First, an independent samples t-test was performed to determine whether there were statistically significant differences on the noncognitive variables across study groups or across the placement test (Table 4). There were significant differences across five noncognitive variables: Academic Self Efficacy (ASE), College Identity, Teamwork, Hope-Combined, and Hope-Agency. 
Table 4.

Independent Samples T-Test of Noncognitive Variables

\begin{tabular}{lcccc}
\hline \multirow{2}{*}{ Variable } & \multicolumn{2}{c}{ by Study Group } & \multicolumn{2}{c}{ by Placement Test } \\
\cline { 2 - 6 } $\mathrm{t}$ & $-2.003^{*}$ & 153 & -0.556 & 153 \\
\hline ASE & -0.261 & 153 & $1.981^{*}$ & 148 \\
College Identity & $-2.304^{*}$ & 153 & 0.686 & 152 \\
Teamwork & -1.132 & 153 & 0.347 & 149 \\
Interact-Combined & -0.769 & 151 & -0.508 & 149 \\
Interact-Comm & -0.690 & 151 & 0.155 & 149 \\
Interact-Choice & 0.55 & 153 & -1.134 & 144 \\
Mindf D & -1.435 & 152 & -0468 & 153 \\
Mindf Obs & -0.518 & 153 & -0.593 & 153 \\
Grit & $-2.271^{*}$ & 146 & -0.842 & 149 \\
Hope-Combined & -1.059 & 153 & 0.294 & 150 \\
Hope-Path & $-2.037^{*}$ & 148 & -0.754 & 153 \\
Hope-Agency & -1.257 & 153 & 0.505 & 151 \\
Consc & -0.475 & 153 & 1.040 & 153 \\
Mindset & & & & \\
\hline Notes. ${ }^{*} p<0.05$ (2-tailed). & & &
\end{tabular}

The full data set was then re-analyzed using one-way ANOVA to check for a joint relationship between noncognitive variables, high-stakes framing, and placement tests using the four dummy variables from above (Table 5). One variable was statistically significant: Teamwork.

These five noncognitive variables were analyzed to determine if the differences were due to the high stakes, or if the difference was due to the confounding variables of high school GPA, ethnicity, or the institution participants applied to. 
Table 5.

One-Way ANOVA of Noncognitive Variables by Study Group and Assessment Test

\begin{tabular}{|c|c|c|c|c|c|}
\hline \multirow{2}{*}{ Variable } & \multicolumn{3}{|c|}{ Test Assumptions } & \multirow{2}{*}{$\begin{array}{c}F \\
\text { Statistic }^{d}\end{array}$} & \multirow{2}{*}{$d f$} \\
\hline & Outliers $^{\mathrm{a}}$ & Normal & Homog. ${ }^{c}$ & & \\
\hline ASE & No & Yes & Yes & 1.627 & 3,151 \\
\hline College Identity & Yes & Yes & Yes & 1.208 & 3,147 \\
\hline Teamwork & Yes & Yes & Yes & $3.280^{\star}$ & 3,149 \\
\hline Interact-Comb & Yes & Yes & Yes & 0.410 & 3,148 \\
\hline Interact-Comm & Yes & Yes & Yes & 0.693 & 3,151 \\
\hline Interact-Choice & No & No & Yes & 0.289 & 3,149 \\
\hline Mindf-Distracted & Yes & Yes & No & 0.281 & 3,80 \\
\hline Mindf-Observing & No & Yes & Yes & 0.690 & 3,151 \\
\hline Grit & Yes & Yes & Yes & 0.027 & 3,149 \\
\hline Hope-Comb & Yes & No & Yes & 2.081 & 3,147 \\
\hline Hope-Path & Yes & Yes & No & 1.928 & 3,79 \\
\hline Hope-Agency & Yes & No & Yes & 1.443 & 3,146 \\
\hline Conscientious & Yes & No & Yes & 0.916 & 3,149 \\
\hline Mindset & No & No & Yes & 1.329 & 3,151 \\
\hline
\end{tabular}

Notes. ${ }^{a}$. Determined by visual inspection of boxplots. ${ }^{b}$ Normal distribution determined by Shapiro-Wilk, $p>0.05 .{ }^{c}$ Homogeneity of variances determined by Levene's, $p>0.05$.

d. If assumption of homogeneity met, ANOVA $F$ is given, else Welch's $F$ is given.

${ }^{*} p<0.05$.

Academic Self Efficacy (ASE). There is evidence to suggest that high-stakes

framing had a negative effect on responses to Academic Self Efficacy (ASE). The mean scores between the treatment group $(\bar{x}=3.722$, sd $=0.5824)$ and the control group $(\bar{x}=3.912, \mathrm{sd}=0.5935)$ may appear similar, but there was a statistically significant difference, $\mathrm{t}_{153}=2.003, \mathrm{p}<0.05$ (Figure 10). There was no evidence of a relationship with ethnicity, $F_{2,134}=.470, p>.05$, or institution, $F_{4.134}=.919, p>.05$, but there was evidence of a relationship with high school GPA. 


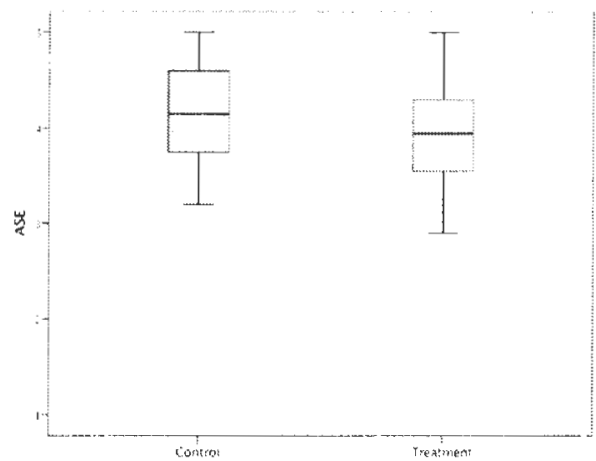

Figure 10. Boxplots of Academic Self Efficacy (ASE) by study group. Participants in the treatment group had significantly lower scores than the control group.

Analysis of the two-way ANOVA suggests that high school GPA accounted for $11.4 \%$ of participants' responses, $F_{4,136}=4.364, p<0.01$, partial $\eta^{2}=114$. Results from ANCOVA of study group over noncognitive variables, with covariate high school GPA indicate controlling for high school GPA, there was no significant difference between study groups and response on Academic Self Efficacy, $F_{1,142}=2.775, p>.05$ (Figure 11). This suggests that high school GPA explains more variance in ASE than study group, $F_{1,142}=12.614, p<0.01$, partial $\eta^{2}=0.082$. This could indicate that the relationship between study group and ASE is overwhelmed by high school GPA. 


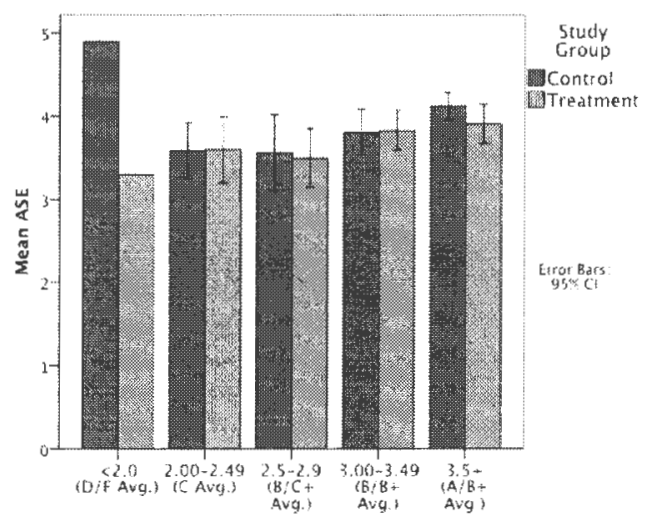

Figure 11. Mean Academic Self Efficacy (ASE) score by high school GPA, disaggregated by Study Group. The relationship between ASE and high school GPA overwhelmed the difference between study groups.

Academic Self Efficacy and Income. There data were also checked for a relationship between Academic Self Efficacy and Family Income. There was no evidence of a relationship with in the control group, but the treatment group showed a moderately positive relationship between ASE and family income $(r=.428, p<0.001)$. Figure 12 illustrates that within the treatment group, as family income increased, ASE scores also increased. This suggests that in a high-stakes environment, ASE is sensitive to income. A linear regression analysis was conducted to check the extent of the relationship between ASE and family income. 


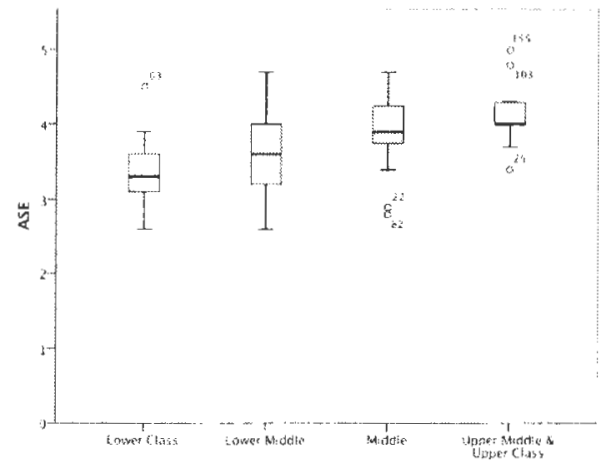

Figure 12. (Treatment) Boxplots of Academic Self Efficacy (ASE) by Family Income. There was a moderately positive relationship between family income and score on ASE.

Family income predicted statistically significant responses on Academic Self Efficacy, $F_{1,65}=14.564, p<0.001$. Analysis suggests that there was a statistically significant relationship, with family income accounting for $18.3 \%$ of the variation in treatment group responses on the ASE scale, with an adjusted $R^{2}=17.0 \%$, a medium effect size (Cohen, 1988). This suggests that a linear regression could be used to predict participants' responses on ASE in a high-stakes situation, using the following equation:

$$
\mathrm{ASE}_{\text {High Stakes }}=3.103+0.261 \times(\text { Family Income })
$$

There was no linear relationship between Academic Self Efficacy, high school GPA, and family income, but there was evidence to suggest a relationship between ASE and susceptibility to stereotype threat (SST), which will be discussed in a later section.

College Identity. College Identity was the only noncognitive variable that had a significant relationship with placement tests across the entire data set, $\mathrm{t}_{148}=1.981$, $\mathrm{p}<0.05$ (Figure 13). Participants who had taken a placement test scored higher on 
College Identity $(\bar{x}=3.66, \mathrm{sd}=.879, \mathrm{~N}=78)$ compared to those who had not taken an assessment test $(\bar{x}=3.35, \mathrm{sd}=1.041, \mathrm{~N}=77)$, a mean difference of 0.312 . There was no evidence that ethnicity or institutional choice was related to these findings. Two-way ANOVA found no interaction between College Identity, having taken a placement test, and ethnicity, $\mathrm{F}_{2.139}=.217, \mathrm{p}>.05$, or for institution, $\mathrm{F}_{2,135}=2.099, \mathrm{p}>.05$. It is worth noting that College Identity was not significant when analyzed with ANOVA using the four dummy variables, $\mathrm{F}_{3.147}=1.208$, $\mathrm{p}>0.05$ (see Table 5), and post hoc analysis was not significant for any interactions.

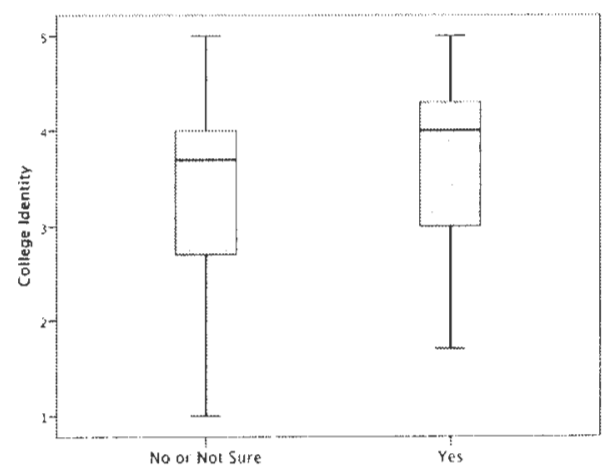

Figure 13. Boxplots of College Identity by taken assessment test (outliers removed). Participants who had not taken an assessment test had significantly lower scores.

Teamwork. There was evidence that high stakes framing had a negative relationship with Teamwork (Figure 14). An independent samples t-test by study group, $\mathrm{t}_{153}=2.304, \mathrm{p}<0.05$ (Table 4), revealed that the control group scored significantly higher on Teamwork $(\bar{x}=4.243, \mathrm{sd}=.4889)$ than the treatment group $(\bar{x}=4.033, \mathrm{sd}=.6439)$.

There was no evidence of a relationship between Teamwork, study group, and ethnicity, 
$\mathrm{F}_{2,141}=.331, \mathrm{p}>0.05$. However, there was evidence that Teamwork had interactions with high school GPA, institution, and the placement test.

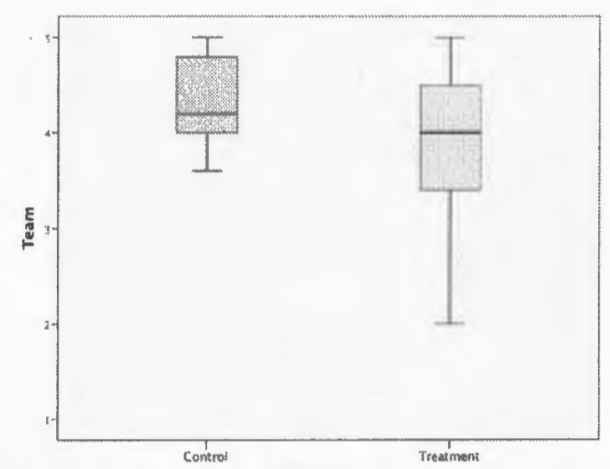

Figure 14. Boxplots of Teamwork by study group. The Treatment group had significantly lower scores than the control group.

Results from a two-way ANOVA provide evidence that study group and high school GPA were jointly related to Teamwork, $F_{4,136}=3.222, p<0.05$, partial $\eta^{2}=.087$ (Figure 15). This suggests that the interaction of study group and high school GPA was responsible for $8.7 \%$ of participants' response. An analysis of simple main effect reveals a statistically significant difference in mean Teamwork scores among participants with high school GPA 3.0 to $3.49, \mathrm{~F}_{1,136}=8.984, \mathrm{p}<0.01$, partial $\eta^{2}=.062$. In this GPA range, the participants given high stakes framing scored significantly lower on Teamwork $(\bar{x}=3.95, \mathrm{~N}=21)$ compared to the control group $(\bar{x}=4.47, \mathrm{~N}=20)$, a mean difference of $0.518(\mathrm{p}<0.01)$. This is a wider gap between the treatment and control group compared to the whole data set. Thus, there was evidence that the high stakes 
framing had a negative impact for participants with a 3.0 to 3.49 average high school GPA.

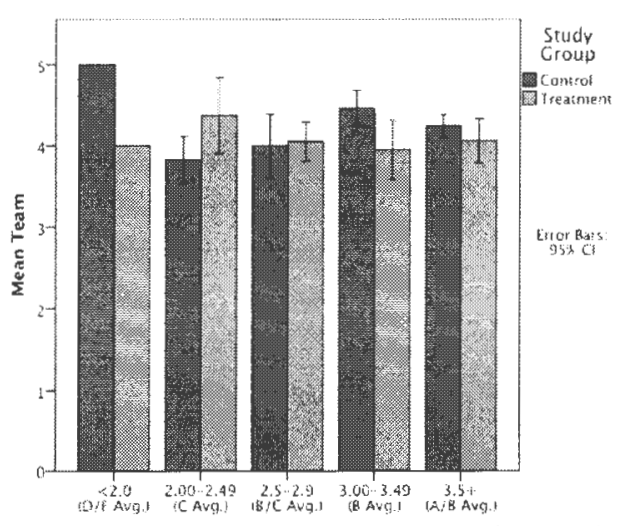

Figure 15. Mean Teamwork by high school GPA, disaggregated by study group. The difference between the treatment and control group was significant for the 3.0 to 3.49 GPA range.

There was evidence to suggest that institution may also be related to Teamwork, albeit only with one college in particular. While there was no significant interaction with the group as a whole, $F_{2,137}=.577, \mathrm{p}>0.05$, an analysis of simple main effect of study group on Teamwork suggests a relationship with applicants to Diablo Valley College, $F_{1,137}=6.397, p<0.05$, partial $\eta^{2}=.045$ (Figure 16). DVC applicants given high stakes framing scored significantly lower on Teamwork $(\bar{x}=4.015, \mathrm{~N}=40)$ compared to those given low stakes framing $(\bar{x}=4.288, \mathrm{~N}=52)$, a mean difference of $0.273, \mathrm{p}<0.05$. 


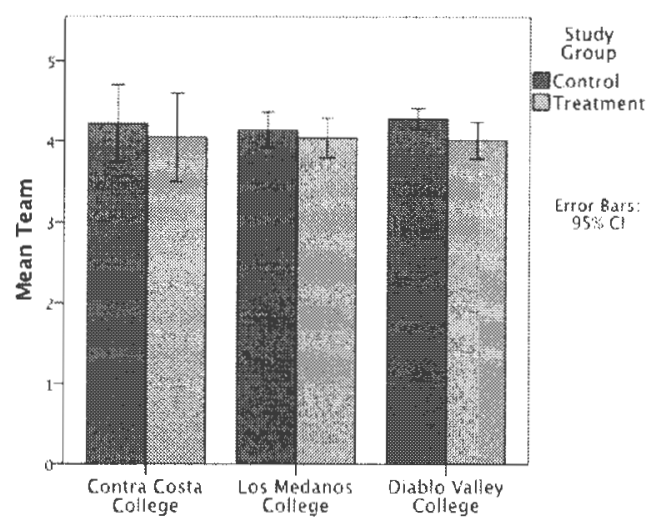

Figure 16. Mean Teamwork by institution, disaggregated by study group. The difference between treatment and control was significant for Diablo Valley College applicants.

Finally, there was evidence that high stakes framing and having taken a placement test was related to responses on Teamwork, $F_{3,149}=3.280, p<0.05$ (Figure 17). Specifically, of the participants who had taken an assessment test, those given high stakes framing-- the Treatment-Test group--scored significantly lower on Teamwork $(\bar{x}=4.01, \mathrm{sd}=.635, \mathrm{~N}=41)$ compared to those given low stakes framing, the Control-Test group $(\bar{x}=4.38, \mathrm{sd}=.470, \mathrm{~N}=37)$, a mean difference of $0.369, \mathrm{p}<0.05$ (Tukey HSD). Two-way ANOVA of assessment test over Teamwork provided no evidence of a relationship with ethnicity, $F_{6.135}=0.840, p>.05$, or institution, $F_{6,135}=0.726, p>.05$. This provides evidence to suggest that the high stakes framing had a negative relationship with Teamwork. 


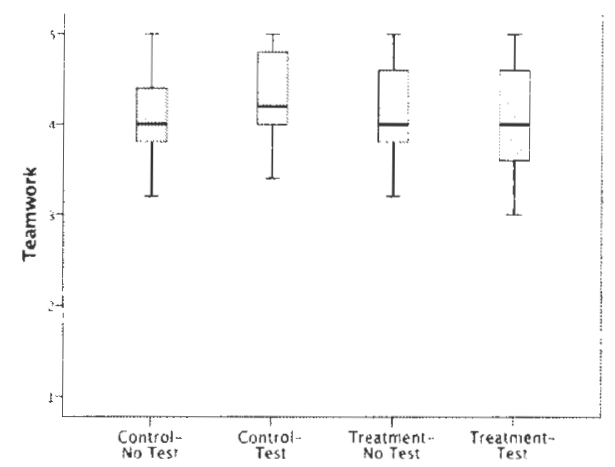

Figure 17. Boxplots of Teamwork by study group and taken assessment test (outliers removed). Treatment group participants who had taken an assessment test scored significantly lower on Teamwork compared to Control group participants who had taken an assessment test.

Hope-Combined. Independent samples t-test (see Table 4) suggests that framing may have had a negative effect on Hope-Combined, $\mathrm{t}_{146}=2.271, \mathrm{p}<0.05$ (Figure 18). The treatment group scored significantly lower $(\bar{x}=6.32, \mathrm{sd}=.939)$ compared to the control group $(\bar{x}=6.64, \mathrm{sd}=.803)$. There was no evidence of an interaction with high school GPA, $F_{4.136}=0.369, p>0.05$, or with ethnicity, $F_{2.135}=0.582, p>0.05$, but there was evidence of an interaction with a specific institution.

While there was no evidence of the entire data set having an interaction with institution, $F_{2.138}=0.379, p>0.05$, an analysis of simple main effects of study group on Hope-Combined appear to be related to Diablo Valley College, $F_{1,138}=4.296, p<0.05$, partial $\eta^{2}=0.030$ (Figure 19). Fall applicants to DVC given high stakes framing scored significantly Iower on Hope-Combined $(\bar{x}=6.067, \mathrm{~N}=39)$ compared to the other DVC applicants $(\bar{x}=6.504, \mathrm{~N}=52)$, a mean difference of $0.437, \mathrm{p}<0.05$. This was a larger difference than observed across the entire data set. 


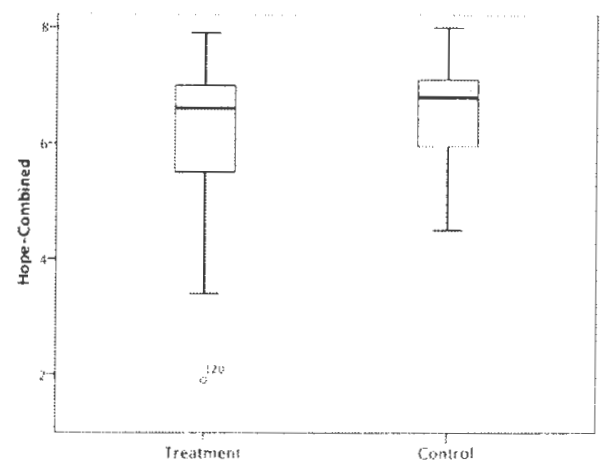

Figure 18. Boxplots of Hope-Combined by study group. The treatment group had significantly lower scores than the control group.

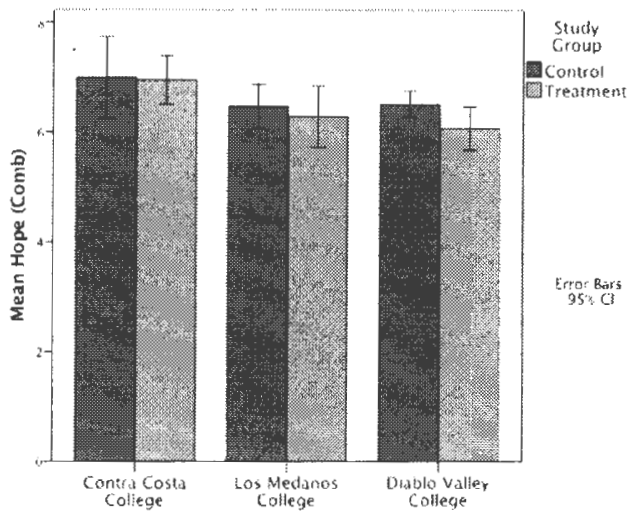

Figure 19. Mean Hope-Combined by institution, disaggregated by study group (outliers removed). The difference between treatment and control is significant for Diablo Valley College.

Hope-Agency. An independent sample t-test (Table 4) suggests a relationship between study group and Hope-Agency, $\mathrm{t}_{148}=2.037, \mathrm{p}<0.05$ (Figure 20). The treatment group scored significantly lower on Hope-Agency $(\bar{x}=6.17, \mathrm{sd}=1.174)$ compared to the control group $(\bar{x}=6.55, \mathrm{sd}=1.076)$. Results from ANCOVA suggest that Hope-Agency scores are related to high school GPA. While two way ANOVA gave no evidence of the entire data set interacting with ethnicity, $F_{2.134}=1.104, p>0.05$, or institution, $F_{2.139}=.615$, 
$p>0.05$, there was evidence of relationships within a specific ethnicity and a specific institution.

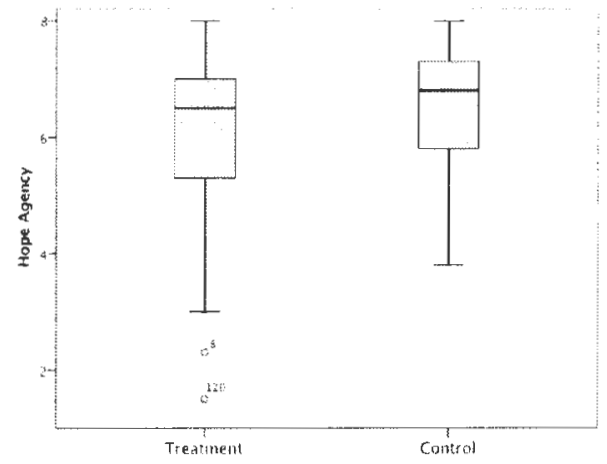

Figure 20. Boxplots of Hope-Agency by study group. The treatment group had significantly lower scores than the control group.

'There was evidence of a relationship with high school GPA and Hope-Agency (Figure 21). ANCOVA suggests that controlling for high school GPA, there was no significant difference between study groups and response on Hope-Agency, $F_{1,142}=2.312, p>.05$. Controlling for study group there was a weak, positive relationship between high school GPA and Hope-Agency $(r=.220, p<0.01)$. ANCOVA suggests that high school GPA explains more variance in Hope-Agency than study group, $F_{1.141}=8.984, p<0.01$, partial $\eta^{2}=0.060$ (Figure 14). This could indicate that the relationship between Hope-Agency and study group is overwhelmed by high school GPA, especially given the significant differences in high school GPA between study groups. 


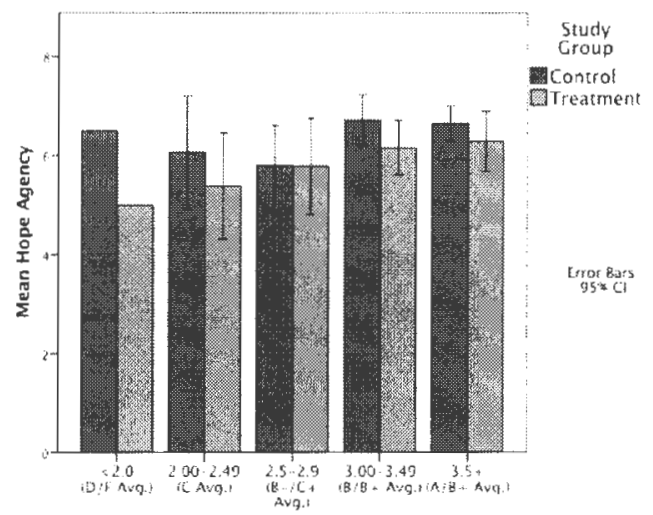

Figure 21. Mean Hope-Agency by High School GPA, disaggregated by study group. The relationship between high school GPA and Hope-Agency may overwhelm the differences between study groups.

An analysis of simple main effects of study group on Hope-Agency suggest significant differences among Non-Underrepresented Minorities (White and other Asian), $\mathrm{F}_{1,134}=5.092, \mathrm{p}<0.05$, partial $\eta^{2}=0.037$ (Figure 22). Within this ethnic category, participants who were given high stakes framing scored significantly lower on HopeAgency $(\vec{x}=5.938, \mathrm{~N}=24)$ than those given low-stakes framing $(\vec{x}=6.679, \mathrm{~N}=33)$, a mean difference of $0.741, \mathrm{p}<0.05$. This was a larger difference than observed across the entire data set.

Simple main effect also suggests a significant difference among Diablo Valley College applicants, $F_{1,139}=6.512, p<0.05$, partial $\eta^{2}=.045$ (Figure 23). DVC Applicants who were given high stakes framing were significantly lower on Hope-Agency $(\bar{x}=5.803, \mathrm{~N}=39)$ compared to those given low stakes framing $(\bar{x}=6.490, \mathrm{~N}=52)$, a mean 
difference of $0.688, \mathrm{p}<0.05$ (Bonferroni). This too was a larger difference than observed across the entire data set.

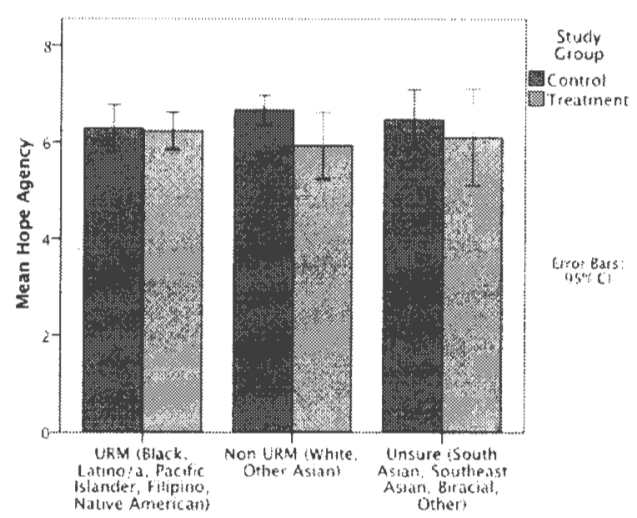

Figure 22. Mean Hope-Agency by ethnicity, disaggregated by study group (outliers removed). The difference between treatment and control is significant for Non-Underrepresented Minorities.

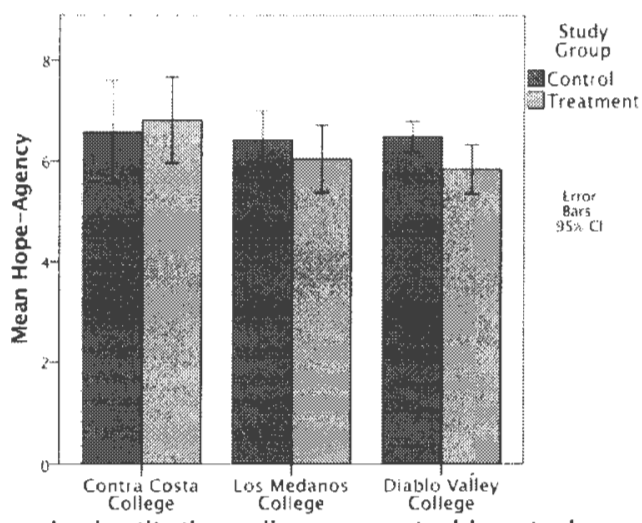

Figure 23. Mean Hope-Agency by institution, disaggregated by study group. The difference between treatment and control is significant for Diablo Valley College applicants.

The significant difference in Hope-Agency scores observed within the nonUnderrepresented minorities and Diablo Valley College could, in part, be due to demographic factors within the three institutions, as Diablo Valley College has a larger number of White and Asian students than the other two institutions. Alternatively, the 
differences across the entire data set could be a factor of the significant differences between ethnicity and institution.

\section{Summary, Research Question One}

The first research question of this study was: How does the high-stakes nature of academic placement impact student responses on noncognitive scales? There is strong evidence to suggest that the high-stakes nature of placement had a negative impact on responses to five noncognitive scales: Academic Self Efficacy, College Identity, Teamwork, Hope-Combined, and Hope-Agency. The first three items are subsets of the College Student Self-Assessment Survey (CSSAS).

Across the whole data set, Academic Self Efficacy appeared to have a negative relationship with high stakes framing, but there was evidence that relationship disappeared after controlling for high school GPA. In addition, ASE may be sensitive to family income in a high stakes scenario, as income accounted for $18 \%$ of participant's ASE score, with scores increasing as family income increased.

College Identity was sensitive to the placement process, with participants who had taken a placement test scoring higher on the College Identity scale.

Teamwork appears to be the most sensitive variable to the high stakes nature of plcaement. There is strong evidence to suggest that Teamwork scores are lower in a high stakes situation, be it high stakes framing or being given high stakes framing after taking a placement test. Institutional factors were also related to Teamwork, with high 
stakes framing having a larger negative impact at one particular institution than overall. Finally, Teamwork was sensitive to high school GPA, with high stakes framing having a negative impact among participants with a 3.0 to 3.4 high school GPA.

Finally, the Hope scale appears to be sensitive to high stakes framing and institution. High stakes framing had a negative impact on Hope-Combined at one particular institution. High stakes framing also had a negative relationship with Hope Agency at one particular institution, and within specific ethnicities. Across the whole data set, Hope-Agency appeared to have a negative relationship with high stakes framing, but there was evidence that relationship disappeared after controlling for high school GPA.

More research is necessary to fully understand the interactions between noncognitive variables, institution, ethnicity, and high school GPA.

\section{Stereotype Threat as a Moderator}

This section addresses the second research question of this study: How does the context, demand, characteristics, and framing of the noncognitive variables impact stereotype threat, if at all? Susceptibility to stereotype threat (SST) was measured for Math Identity, Ethnic Identity, and Gender Identity. Participants were categorized as being in one of four profiles (Table 6): Disengaged, which suggests the person has suffered from stereotype threat for so long that they have disengaged from it, high susceptibility (High SST), low susceptibility (Low SST), and Unidentified, which 
suggests the person has no known susceptibility to stereotype threat. For analysis purposes, High SST and Disengaged were grouped together, as neither profile had enough data points on their own.

Table 6

Participants' Susceptibility to Stereotype Threat

\begin{tabular}{lccc}
\hline \multicolumn{1}{c}{ Variable } & $\begin{array}{c}\text { Combined } \\
\mathrm{N}=155\end{array}$ & $\begin{array}{c}\text { Treatment } \\
\mathrm{n}=72\end{array}$ & $\begin{array}{c}\text { Control } \\
\mathrm{n}=83\end{array}$ \\
\hline $\begin{array}{l}\text { SST Math Identity } \\
\quad \text { Unidentified }\end{array}$ & $45 \%$ & $51 \%$ & $40 \%$ \\
$\quad$ Low SST & $41 \%$ & $39 \%$ & $42 \%$ \\
$\quad$ Disengaged or High SST & $14 \%$ & $10 \%$ & $18 \%$ \\
SST Gender Identity & & & \\
$\quad$ Unidentified & $67 \%$ & $75 \%$ & $60 \%$ \\
$\quad$ Low SST & $19 \%$ & $17 \%$ & $22 \%$ \\
$\quad$ Disengaged or High SST & $14 \%$ & $8 \%$ & $18 \%$ \\
SST Ethnic ldentity & & & \\
$\quad$ Unidentified & $52 \%$ & $58 \%$ & $47 \%$ \\
$\quad$ Low SST & $37 \%$ & $32 \%$ & $41 \%$ \\
$\quad$ Disengaged or High SST & $11 \%$ & $10 \%$ & $12 \%$ \\
\hline
\end{tabular}

Note. All percentages have been rounded.

The data were first analyzed to check for a relationship between susceptibility to stereotype threat and responses on the noncognitive scales within the entire data set (within-group comparison), followed by an analysis to check for a relationship between susceptibility to stereotype threat, framing, and responses to noncognitive variables (between-group comparison). 


\section{Within Group Comparison}

The full data set was analyzed using one-way ANOVAs to check for a relationship between prevalence of susceptibility to stereotype threat (SST) and the noncognitive scales (Table 7).

Table 7.

One-Way ANOVA ${ }^{a . b, c, d}$ of Stereotype Threat Identities Across Noncognitive Variables

\begin{tabular}{lcccccc}
\hline \multirow{2}{*}{ Variable } & \multicolumn{3}{c}{ SST Math ldentity } & \multicolumn{2}{c}{ SST Ethnic ldentity } & \multicolumn{2}{c}{ SST Gender Identity } \\
& F & df & $F$ & df & $F$ & df \\
\hline ASE & 1.336 & 2,151 & 0.142 & 2,149 & 1.013 & 2,147 \\
College Identity & $5.669^{\star \star}$ & 2,150 & $16.791^{\star \star \star}$ & 2,48 & $17.498^{\star \star \star}$ & 2,55 \\
Teamwork & 1.192 & 2,150 & 0.281 & 2,151 & .894 & 2,150 \\
Interact-Combined & 0.361 & 2,149 & 0.252 & 2,150 & .521 & 2,149 \\
Interact-Comm & 2.936 & 2,66 & 1.734 & 2,149 & 1.662 & 2,150 \\
Interact-Choice & 1.793 & 2,148 & 0.359 & 2,150 & 1.235 & 2,150 \\
Mindf Distracted & 2.406 & 2,53 & 2.067 & 2,40 & 1.772 & 2,149 \\
Mindf Observing & 0.507 & 2,152 & $3.353^{\star}$ & 2,150 & 0.258 & 2,152 \\
Grit & 2.449 & 2,152 & 2.331 & 2,41 & $6.644^{\star \star}$ & 2,150 \\
Hope-Combined & 2.780 & 2,55 & 1.311 & 2,150 & 0.844 & 2,149 \\
Hope-Path & 2.607 & 2,151 & 2.015 & 2,149 & 0.544 & 2,150 \\
Hope-Agency & $9.995^{\star \star \star}$ & 2,62 & $7.264^{* \star}$ & 2,46 & 1.355 & 2,149 \\
Conscientiousness & 2.205 & 2,152 & 0.472 & 2,41 & 2.487 & 2,152 \\
Mindset & $4.771^{\star}$ & 2,152 & 2.010 & 2,152 & 0.066 & 2,152 \\
\hline
\end{tabular}

Notes. ${ }^{\text {a }}$ Outliers determined by visual inspection of boxplots; outliers were removed for analysis. ${ }^{b}$ Normal distribution determined by Shapiro-Wilk, $p>0.05 .{ }^{c}$. Homogeneity of variances determined by Levene's, $p>0.05$. ${ }^{d}$. If assumption of homogeneity met, $F$ statistic is given, else Welch's $F$ is given. ${ }^{*} p<0.05,{ }^{* \star} p<0.01,{ }^{\star * *} p<0.001$.

Five scales were related to the stereotype threat identities: College Identity,

Mindfulness-Observing, Grit, Hope-Agency, and Mindset. College Identity was related to all three SST identities, Hope-Agency was related to both Math and Ethnic Identities, 
Mindfulness-Observing was related to Ethnic Identity, Grit was related to Gender Identity, and Mindset was related to Math Identity. In most cases, participants with some sort of susceptibility scored higher on the noncognitive scale than those with no known susceptibility (Unidentified). All significant relationships were checked for relationships between ethnicity or institution and the noncognitive scores using two-way ANOVAs, first with the focal variable of SST Identity and moderator Ethnicity, the second using institution as a moderator. Findings are presented with each respective noncognitive variable.

College Identity. There was a significant relationship between College Identity and all three stereotype threat profiles. There was also evidence of an interaction with traditionally underrepresented minorities and applicants to Diablo Valley College.

College Identity and SST Math Identity. There was a statistically significant difference on responses to College Identity between all three SST Math Identity profiles, $\mathrm{F}_{2.150}=5.669, \mathrm{p}<0.01$ (Figure 24). Unidentified scored lower than participants with some form of SST Math Identity. The biggest difference was between Unidentified $(\bar{x}=3.17, \mathrm{sd}=1.081, \mathrm{~N}=70)$ and Disengaged/High SST Math $(\bar{x}=3.86, \mathrm{sd}=.954, \mathrm{~N}=22)$, a mean difference of $0.689, \mathrm{p}<0.05$ (Tukey HSD). The Unidentified group also scored significantly lower than the Low SST Math $(\bar{x}=3.63, \mathrm{sd}=.892, \mathrm{~N}=61)$, a mean difference of $0.460, p<0.05$ (Tukey HSD). There was no evidence of a relationship with ethnicity, $\mathrm{F}_{4.138}=.917, \mathrm{p}>.05$, or with institution, $\mathrm{F}_{4.139}=.591, \mathrm{p}>.05$. 


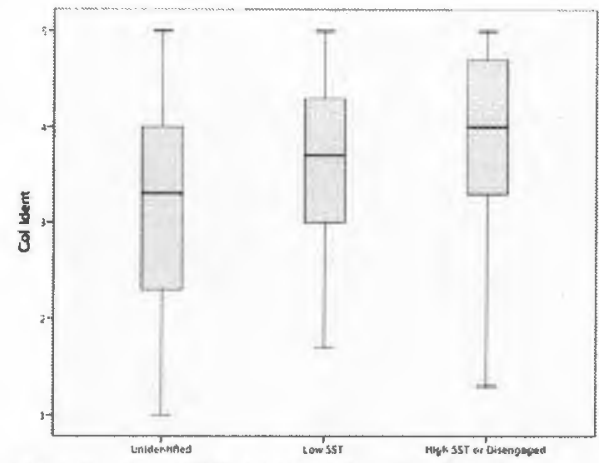

Figure 24. Boxplots of College Identity by SST Math Identity (outliers removed). Unidentified scored significantly lower than the other profiles.

College Identity and SST Ethnic Identity. There is evidence of a relationship between College Identity and SST Ethnic Identity, $F_{2,48.072}=16.791$, $p<0.001$ (Figure 25). Participants with no known susceptibility to stereotype threat for Ethnic Identity scored significantly lower on College Identity $(\bar{x}=3.07, \mathrm{sd}=1.087, \mathrm{~N}=81)$ than Disengaged/High SST Ethnic $(\bar{x}=4.15, \mathrm{sd}=.672, \mathrm{~N}=16)$, a mean difference of 1.078, $\mathrm{p}<0.001$ (Dunnett's T3). The Unidentified group also scored significantly lower than Low SST Ethnic $(\bar{x}=3.81, \mathrm{sd}=.763, \mathrm{~N}=56)$, a mean difference of $0.739, \mathrm{p}<0.001$ (Dunnett's T3). While there is no evidence that either ethnicity or institution played roles across the entire data set, there is evidence of a relationship within specific ethnicities and institutions. 


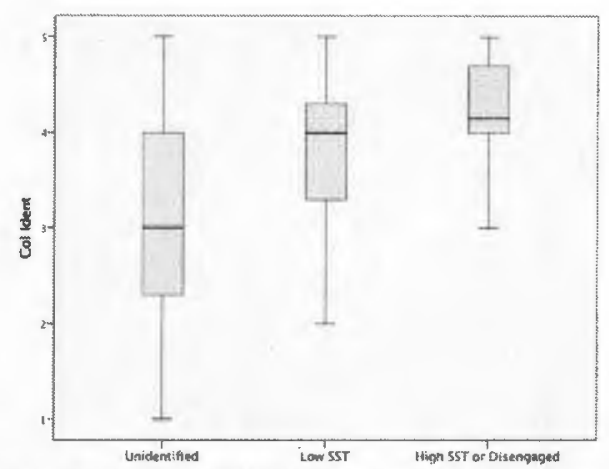

Figure 25. Boxplots of College Identity by SST Ethnic Identity (outliers removed). Participants with no susceptibility (Disengaged) scored significantly lower than the other profiles.

College Identity scores were significantly different among two ethnicities: traditionally Underrepresented Minorities (URM; Black, Latina/o, Pacific Islander, Filipino/a, Native American), and participants classified as unsure (South Asian, Southeast Asian, Biracial, and other), $\mathrm{F}_{2,138}=8.807, \mathrm{p}<0.001$, partial $\eta^{2}=0.113$ (Figure 26). Among Underrepresented Minorities, Unidentified scored significantly lower $(\bar{x}=2.735, \mathrm{~N}=17)$ than both Low SST Ethnic $(\bar{x}=3.766, \mathrm{~N}=32)$ and Disengaged/High SST Ethnic $(\bar{x}=4.218, \mathrm{~N}=11)$. These were mean differences of $1.000(\mathrm{p}<0.01)$ and 1.483 $(p<0.001)$, respectively (Bonferroni). Similarly, simple main effect suggests significant differences in College Identity scores among the ethnicities categorized as Unsure, $F_{2,139}=4.421, p<0.05$, partial $\eta^{2}=0.060$. Within this group, Unidentified scored significantly lower on College Identity $(\bar{x}=3.020, \mathrm{~N}=15)$ compared to Low SST Ethnic $(\bar{x}=4.125, \mathrm{~N}=8)$, a mean difference of $1.105, \mathrm{p}<0.05$ (Bonferroni). 


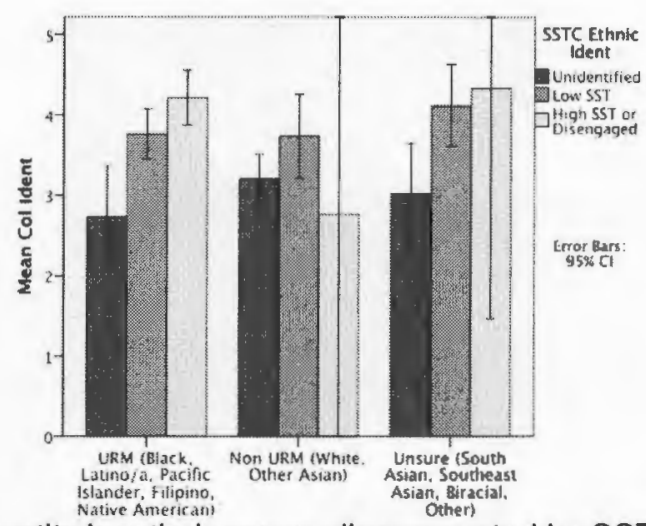

Figure 26. Mean College Identity by ethnic group, disaggregated by SST Ethnic Identity. Scores were significantly different within Underrepresented Minorities and within the Unsure group. Within URMs, Unidentified scored significantly lower than both other profiles. Within Unsure, Unidentified scored significantly lower than Low SST.

Simple main effect of SST Ethnic Identity on College Identity suggests an interaction with Diablo Valley College, $F_{2,133}=10.151, p<0.001$, partial $\eta^{2}=0.132$ (Figure 27). Unidentified scored significantly lower $(\bar{x}=3.058, \mathrm{~N}=52)$ compared to those with some form of SST Ethnic Identity. Applicants with Low SST Ethnic $(\bar{x}=3.794$, $\mathrm{N}=33$ ) scored an average of .736 points higher than Unidentified ( $<<0.01$, Bonferroni), and applicants with Disengaged or High SST Ethnic $(\bar{x}=4.680, \mathrm{~N}=5)$ scored an average of 1.622 points higher than Unidentified ( $\mathrm{p}<0.01$, Bonferroni). 


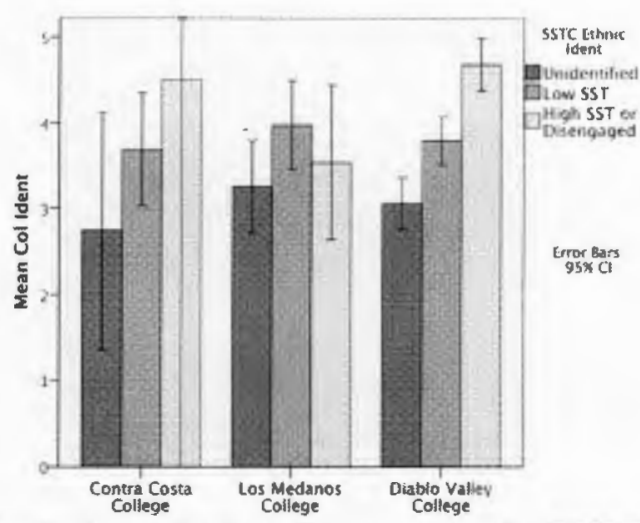

Figure 27. Mean College Identity by institution, disaggregated by SST Ethnic Identity (outliers removed). Scores were significantly different among applicants to Diablo Valley College, with Unidentified scoring significantly lower than both other profiles.

College Identity and SST Gender Identity. College Identity was related to susceptibility to stereotype threat for Gender Identification, $F_{2,55}=17.498, p<0.001$ (Figure 28). There was also evidence of a relationship with ethnicity and institution.

Disengaged/High SST Gender scored significantly higher on College Identity $(\bar{x}=4.17, \mathrm{sd}=.601, \mathrm{~N}=20)$ compared to both other SST profiles. The largest difference was between Disengaged/High SST Gender and Unidentified $(\bar{x}=3.20 \mathrm{sd}=1.089$, $\mathrm{N}=104$ ), a mean difference of $0.966, \mathrm{p}<0.001$ (Dunnett's T3). Disengaged/High SST Gender also scored significantly higher than Low SST Gender $(\bar{x}=3.86, \mathrm{sd}=.653$, $\mathrm{N}=29$ ), a mean difference of $0.660, \mathrm{p}<0.001$ (Dunnett's T3). Across the entire data set, there was no evidence of a relationship between SST Gender, College Identity, and ethnicity, $F_{3,134}=.232, p>.05$, or with institution, $F_{3,137}=.110, p>.05$, but there was a relationship among specific ethnicities and with a specific institution. 


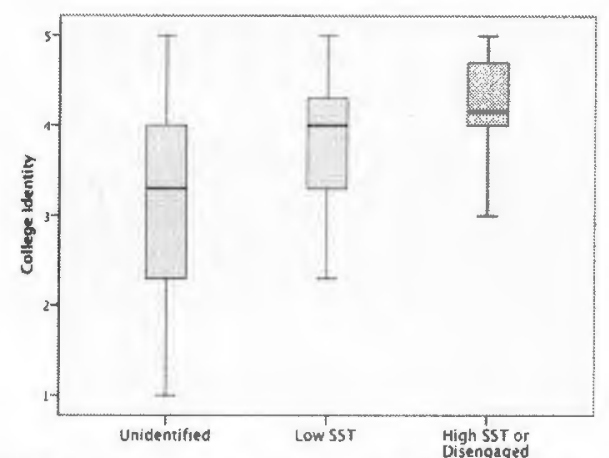

Figure 28. Boxplots of College Identity by SST Gender Identity (outliers removed). Disengaged or High SST scored significantly higher than both other profiles.

Simple main effect of stereotype threat susceptibility for Gender Identity across College Identity suggests there were significant difference in responses among traditionally Underrepresented Minorities, $F_{2,134}=7.132, p<0.01$, partial $\eta^{2}=0.096$ (Figure 29). Underrepresented Minorities who were Unidentified scored significantly lower $(\bar{x}=3.142, \mathrm{~N}=31)$ than the those with some type of susceptibility. The largest difference was with Disengaged or High SST Gender $(\bar{x}=4.214, N=14)$, with a mean difference of 1.072, $\mathrm{p}<0.01$ (Bonferroni). Low SST Gender also scored significantly higher $(\bar{x}=4.100, N=10)$ than Unidentified, a mean difference of $0.958, p<0.05$ (Bonferroni).

There was also a significant institutional differences in College Identity scores among applicants to Diablo Valley College, $F_{2,137}=4.704, p<0.05$, partial $\eta^{2}=0.064$ (Figure 30). Within this group, Unidentified scored significantly lower on College 
Identity $(\bar{x}=3.170, \mathrm{~N}=60)$ than Disengaged/High SST Gender $(\bar{x}=4.060, \mathrm{~N}=10)$, a mean difference of $0.908, \mathrm{p}<0.05$ (Bonferroni).

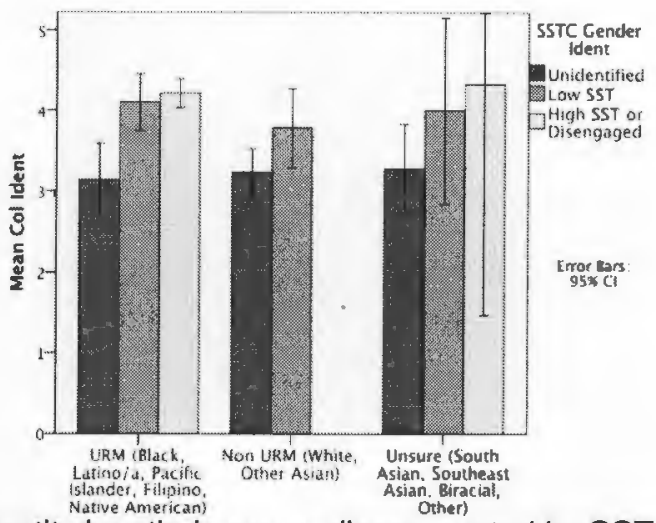

Figure 29. Mean College Identity by ethnic group, disaggregated by SST Gender Identity (outliers removed). The scores were significantly different within Underrepresented Minorities, with Unidentified scoring significantly lower than both other profiles.

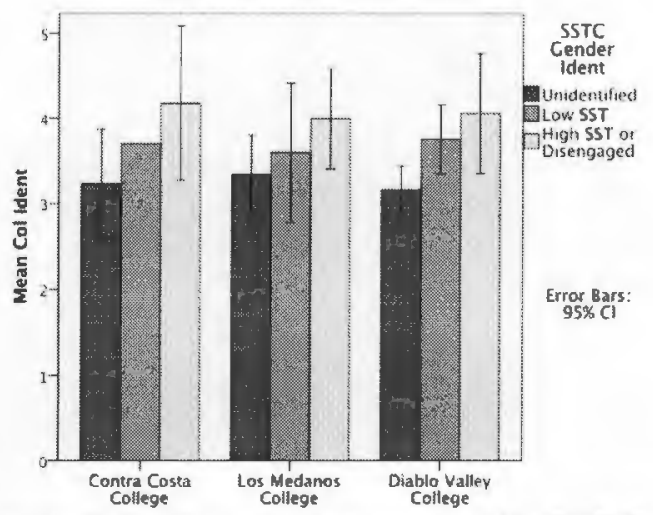

Figure 30. Mean College Identity by institution, disaggregated by SST Gender Identity. Scores were significantly different within applicants to Diablo Valley College, with Disengaged/High SST scoring significantly higher than Unidentified.

Mindfulness-Observing. There was evidence of a relationship between Mindfulness-Observing and susceptibility to stereotype threat for Ethnic Identity. The 
data also suggest an interaction with traditionally underrepresented minorities (URM) and applicants to Diablo Valley College.

There was a significant difference on Mindfulness-Observing between participants with some form of SST Ethnic Identity, $F_{2,150}=3.353, p<0.05$ (Figure 31). Disengaged/High SST Ethnic scored significantly higher on Mindfulness-Observing $(\bar{x}=3.65, \mathrm{sd}=.869, \mathrm{~N}=16)$ compared to Low SST Ethnic $(\bar{x}=2.99, \mathrm{sd}=1.031, \mathrm{~N}=57), \mathrm{a}$ mean difference of $0.664, \mathrm{p}<0.05$ (Tukey HSD). Across the whole data set, there was no evidence of an interaction with ethnicity, $F_{4,139}=1.260, p>.05$, or with Institution, $F_{4,139}=2.293, p>.05$. However, there was evidence of a relationship with a specific ethnicity and a specific college.

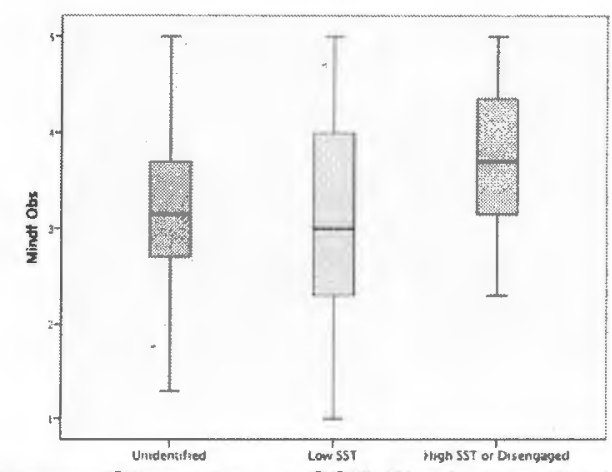

Figure 31. Boxplots of Mindfulness-Observing by SST Ethnic Identity (outliers removed). Disengaged/High susceptibility scored significantly higher than participants with Low susceptibility.

Simple main effects of SST Ethnic Identity on Mindfulness-Observing were significant for traditionally Underrepresented Minorities, $\mathrm{F}_{2,139}=3.452, \mathrm{p}<0.05$, partial $\eta^{2}=0.047$ (Figure 32). URMs with Disengaged/High SST Ethnic scored significantly 
higher on Mindfulness-Observing $(\bar{x}=3.764, \mathrm{~N}=11)$ than the Unidentified participants $(\bar{x}=2.812, \mathrm{~N}=17)$, a mean difference of $.952, \mathrm{p}<0.05$ (Bonferroni).

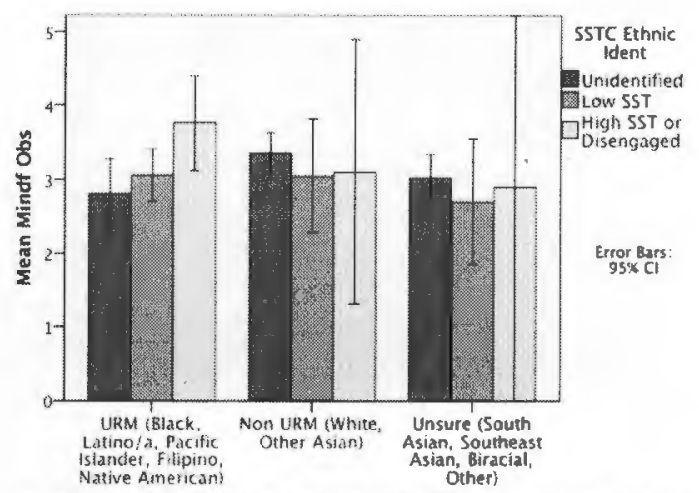

Figure 32. Mean Mindfulness-Observing by ethnic group, disaggregated by SST Ethnic Identity. The difference between stereotype threat identities is significant within Underrepresented Minorities, with Disengaged/High SST scoring significantly higher than Unidentified.

Simple main effects of SST Ethnic Identity on Mindfulness-Observing were also significant for applicants to Diablo Valley College, $\mathrm{F}_{2,139}=5.462$, $\mathrm{p}<0.001$, partial $\eta^{2}=0.073$ (Figure 33). Within this group, Disengaged/High SST Ethnic scored significantly higher on Mindfulness-Observing $(\bar{x}=4.350, \mathrm{~N}=6)$ compared to both other groups. The difference was largest between Disengaged/High SST and Low SST Ethnic $(\bar{x}=2.948, \mathrm{~N}=33$ ), a mean difference of $1.402, \mathrm{p}<0.01$ (Bonferroni). Unidentified also scored significantly lower $(\bar{x}=3.102, N=78)$ than Disengaged/High SST, with the mean difference of $1.248, \mathrm{p}<0.01$ (Bonferroni). It is possible that these findings are spurious, and a product of the larger proportion of applicants to Diablo Valley College. Alternatively, this finding could be a result of demographics, as Diablo Valley College has a larger proportion of White and Asian students compared to the other institutions. 


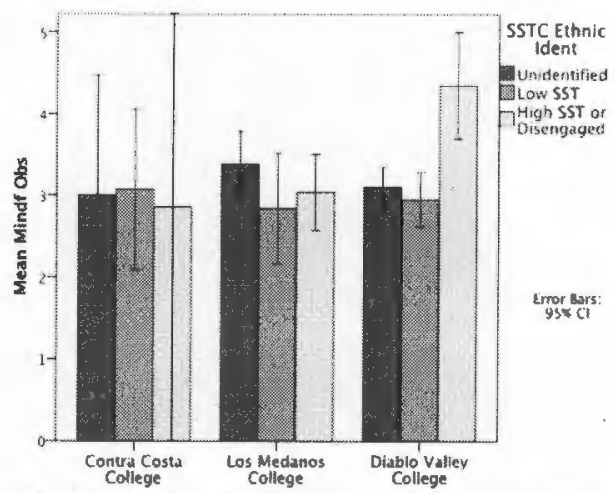

Figure 33. Mean Mindfulness-Observing by institution, disaggregated by SST Ethnic Identity. Scores were significantly different within applicants to Diablo Valley College, with Disengaged/High SST scoring significantly higher than both other groups.

Grit. There was evidence of a relationship between Grit and susceptibility to stereotype threat for Gender Identity $F_{2,150}=6.644, p<0.01$ (Figure 34). There was also evidence that this relationship interacted with both ethnicity and institutional choice.

Participants with Low SST Gender $(\bar{x}=3.03, \mathrm{sd}=.519, \mathrm{~N}=28)$ scored significantly lower on Grit compared to the other two profiles. The largest difference was with Disengaged or High SST ( $\bar{x}=3.59, \mathrm{sd}=.778, \mathrm{~N}=21)$; Unidentified had slightly lower scores $(\bar{x}=3.46, \mathrm{sd}=.605, \mathrm{~N}=104)$. These were mean differences of 0.562 and 0.436, respectively ( $<<0.01$, Tukey HSD). Across the whole data set there was no evidence of an interaction with ethnicity, $F_{3,140}=1.911, p>.05$, or institution, $F_{3,134}=1.558, p>.05$, although the data suggest an interaction with a specific ethnicity and a specific institution. 


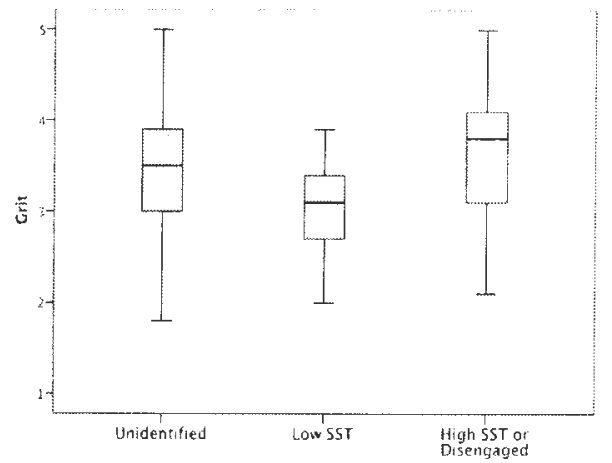

Figure 34. Boxplots of Grit by SST Gender Identity (outliers removed). Low SST scored significantly lower than both other stereotype threat profiles.

Simple main effects of SST Gender Identity on Grit suggest a significant interaction among the ethnicities classified as Unsure (South Asian, Southeast Asian, multi-ethnic, and other), $F_{2.140}=3.274, p<0.05$, partial $\eta^{2}=0.045$ (Figure 35). Unidentified significantly lower $(\bar{x}=3.263, \mathrm{~N}=19)$ than Disengaged/High SST $(\bar{x}=4.267$, $\mathrm{N}=3$ ), a mean difference of $1.004, \mathrm{p}<0.05$ (Bonferroni). However, given the small $\mathrm{N}$ value of the Disengaged/High SST group, it is possible that this is a spurious result.

Simple main effects of SST Gender Identity on Grit suggest a significant interaction among applicants to Los Medanos College, $\mathrm{F}_{2.134}=3.895, \mathrm{p}<0.05$, partial $\eta^{2}=0.055$ (Figure 36 ). Within this group, Low SST Gender scored significantly higher on Grit $(\bar{x}=2.967, \mathrm{~N}=26)$ than Disengaged/High SST $(\bar{x}=3.983, \mathrm{~N}=6)$, a mean difference of 1.017, $\mathrm{p}<0.05$ (Bonferroni). Again, given the small $\mathrm{N}$ value of the Disengaged/High SST group, it is possible that this is also a spurious result. 


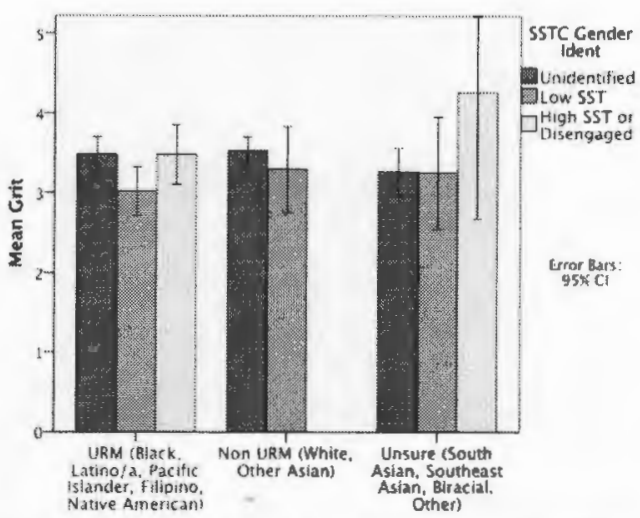

Figure 35. Mean Grit by ethnicity, disaggregated by SST Gender Identity. Scores are significantly different within the Unsure group, with Unidentified scoring significantly lower than Disengaged/High SST.

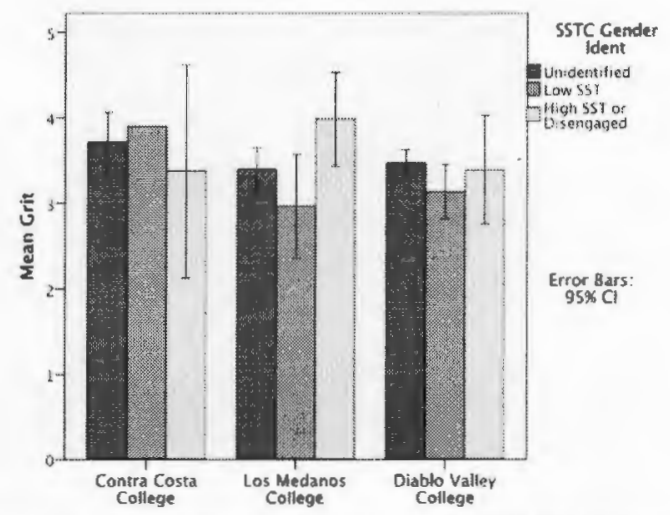

Figure 36. Mean Grit by institution, disaggregated by SST Gender Identity. Scores are significantly different within applicants to Los Medanos College, with Low SST scoring significantly higher than Disengaged/High SST.

Hope-Agency. There was evidence of a relationship between Hope-Agency and susceptibility to stereotype threat for both Math and Ethnic Identities. The data also suggest an interaction with traditionally Underrepresented Minorities (URM).

Hope-Agency and SST Math Identity. There were significant relationships between Hope-Agency and SST Math Identity, $F_{2,62}=9.995, p<0.001$ (Figure 37). 
Unidentified scored nearly a full point lower $(\bar{x}=6.11, \mathrm{sd}=1.289, \mathrm{~N}=69)$ than Disengaged/High SST Math $(\bar{x}=7.06, \mathrm{~d}=.609, \mathrm{~N}=17)$, a mean difference of 0.949 , $\mathrm{p}<0.001$ (Dunnett's T3). Across the whole data set there was no evidence of an interaction with ethnicity, $F_{4.134}=2.395, p>.05$, or institution, $F_{4.132}=1.547, p>.05$, but the data suggest an interaction with a specific ethnicity.

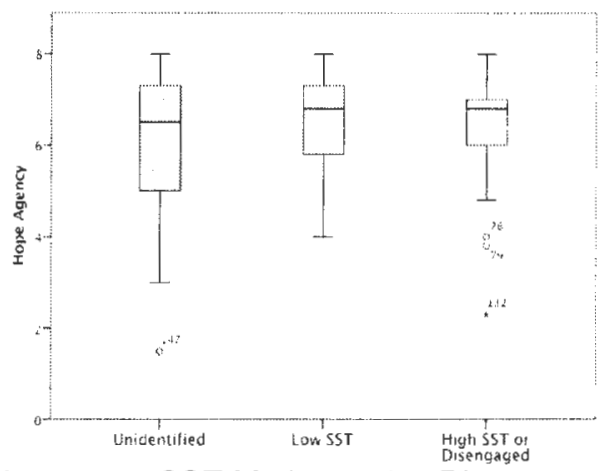

Figure 37. Boxplots of Hope-Agency by SST Math Identity. Disengaged/High SST scored significantly higher than Unidentified.

Simple main effects of SST Math Identity on Hope-Agency suggest a significant difference on mean Hope-Agency among Non-Underrepresented Minorities (White and other Asian), $F_{2,134}=3.995, p<0.05$, partial $\eta^{2}=0.056$ (Figure 38). Low SST Math scored significantly higher $(\bar{x}=6.867, \mathrm{~N}=27)$ than Unidentified $(\bar{x}=5.971, \mathrm{~N}=28)$, a mean difference of 0.895, $\mathrm{p}<0.05$ (Bonferroni). 


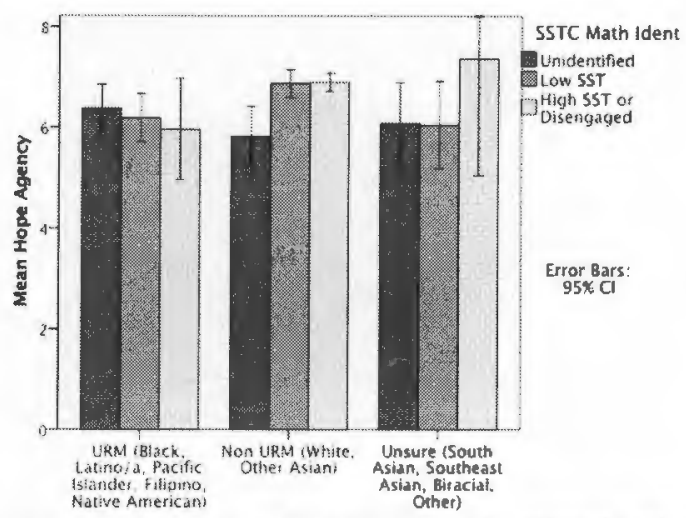

Figure 38. Mean Hope-Agency by ethnicity, disaggregated by SST Math Identity. Scores were significantly different within Non-Underrepresented Minorities, with Low SST scoring significantly higher than Unidentified.

Hope-Agency and SST Ethnic Identity. There was a significant difference in responses on Hope-Agency across all three SST Ethnic Identity profiles, $F_{2,46}=7.264$, $\mathrm{p}<0.01$ (Figure 39). Disengaged/High SST Ethnic scored significantly higher on HopeAgency $(\bar{x}=7.05, \mathrm{sd}=.624, \mathrm{~N}=13)$ than both other profiles. The largest difference in scores was between Disengaged/High SST and Unidentified $(\bar{x}=6.23, \mathrm{sd}=1.255, \mathrm{~N}=80)$, a mean difference of $0.821, \mathrm{p}<0.05$ (Dunnett's T3). There was a smaller difference between Disengaged/High SST and Low SST Ethnic $(\bar{x}=6.36, \mathrm{sd}=1.118, \mathrm{~N}=57)$, a mean difference of $0.692, p<0.05$ (Dunnett's T3). There was no evidence of a relationship with ethnicity, $F_{4,135}=1.520, p>0.05$, or institution, $F_{4,136}=1.161, p>0.05$. 


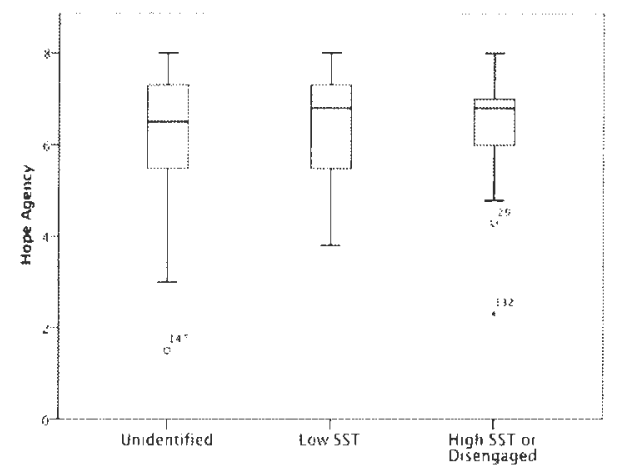

Figure 39. Boxplots of Hope-Agency by SST Ethnic Identity. Disengaged/High SST scored significantly higher than both other profiles.

Mindset. There was evidence of a relationship between Mindset and SST Math Identity, $F_{2,152}=4.771, \mathrm{p}<0.05$ (Figure 40). Unidentified scored significantly lower on Mindset $(\bar{x}=3.71, \mathrm{sd}=.605, \mathrm{~N}=70)$ compared to Low SST Math $(\bar{x}=4.04, \mathrm{sd}=.575$, $\mathrm{N}=63$ ), a mean difference of $0.329, \mathrm{p}<0.01$ (Tukey HSD). Across the whole data set there was no evidence of an interaction with ethnicity, $F_{4,136}=.691, p>.05$, or institution, $\mathrm{F}_{4,133}=.400, \mathrm{p}>.05$, but the data suggest an interaction with traditionally Underrepresented Minorities and Diablo Valley College.

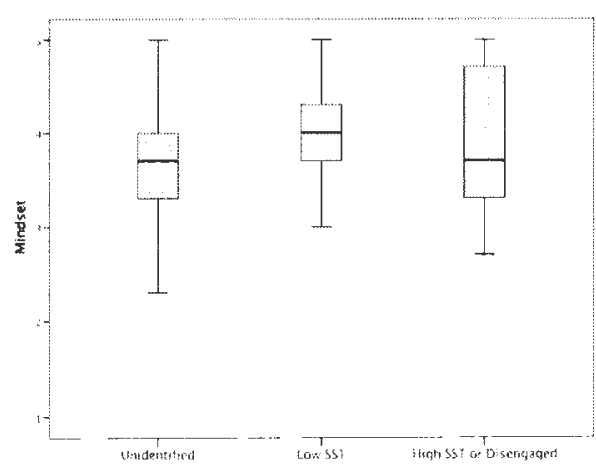

Figure 40. Boxplots of Mindset by SST Math Identity profiles. Participants with Low susceptibility scored significantly higher than participants with no known susceptibility (Unidentified). 
An analysis of simple main effects of SST Math Identity on Mindset suggests an interaction with Underrepresented Minorities, $F_{2,136}=3.423$, $p<0.05$, partial $\eta^{2}=0.048$ (Figure 41). URMs with no known susceptibility scored significantly lower on Mindset $(\bar{x}=3.645, \mathrm{~N}=22)$ than URMs with Low SST Math $(\bar{x}=4.108, \mathrm{~N}=24)$, a mean difference of $0.463(\mathrm{p}<0.05)$. Within non-URM participants (White and Other Asian), the simple main effect was also significant, $F_{2,136}=3.218, p<0.05$, partial $\eta^{2}=0.045$, but the mean differences were not. This suggests a type one error.

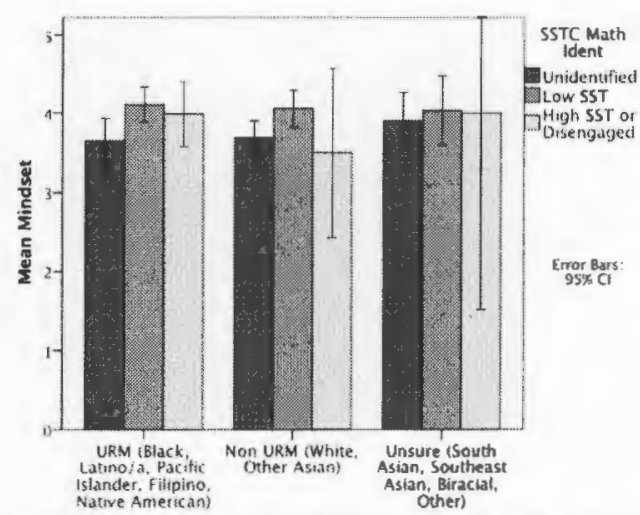

Figure 41. Mean Mindset by ethnicity, disaggregated by SST Math Identity (outliers removed). Scores were significantly different within Underrepresented Minorities, with Unidentified scoring significantly lower than Low SST Math.

Simple main effect suggests responses on Mindset were significantly different among applicants to Diablo Valley College, $\mathrm{F}_{2,139}=3.693, \mathrm{p}<0.05$, partial $\eta^{2}=0.050$ (Figure 42). Unidentified scored significantly lower on Mindset $(\bar{x}=3.726, \mathrm{~N}=37)$ than Low SST Math $(\bar{x}=4.085, \mathrm{~N}=39)$, a mean difference of $0.359, \mathrm{p}<0.05$. 


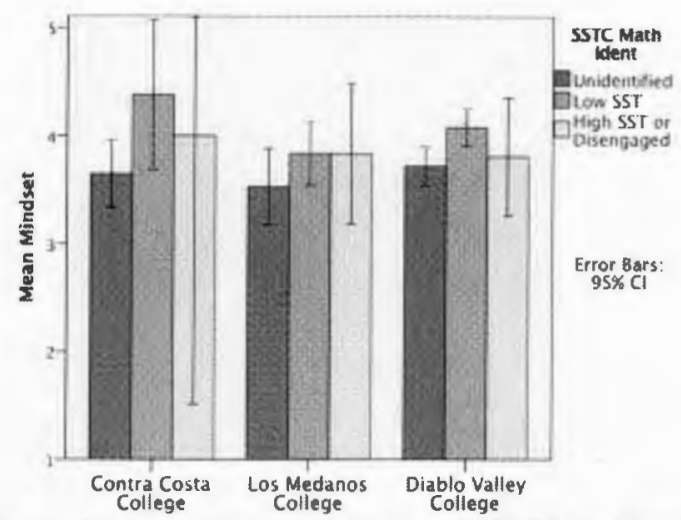

Figure 42. Mean Mindset by institution, disaggregated by SST Math Identity. Scores were significantly different within applicants to Diablo Valley College, with Unidentified scoring significantly lower than Low SST Math.

\section{Between-Group Comparison}

The previous section studied the relationship between noncognitive scales and susceptibility to stereotype threat in general; this section seeks to understand if there was a relationship between high stakes framing, noncognitive scales, and susceptibility to stereotype threat. To do this, the data were first analyzed to check for a relationship between susceptibility to stereotype threat (SST) and framing. Next, the data were analyzed to check for relationships between study group, susceptibly to stereotype threat, and noncognitive variables.

Findings from independent sample t-tests suggest that there were no significant differences in susceptibility to stereotype threat for Math Identity, $\mathrm{t}_{153}=1.765, \mathrm{p}>0.05$, or SST Ethnic Identity, $\mathrm{t}_{153}=1.247, \mathrm{p}>0.05$. However, there was a significant difference with SST Gender Identity, $\mathrm{t}_{76}=5.910, \mathrm{p}<0.001$ (Figure 43 ). There were significantly more participants with some form of SST Gender Identity in the control group. The 
control group tended to lean more towards Low SST Gender, whereas the treatment group had a very strong tendency towards Unidentified SST.

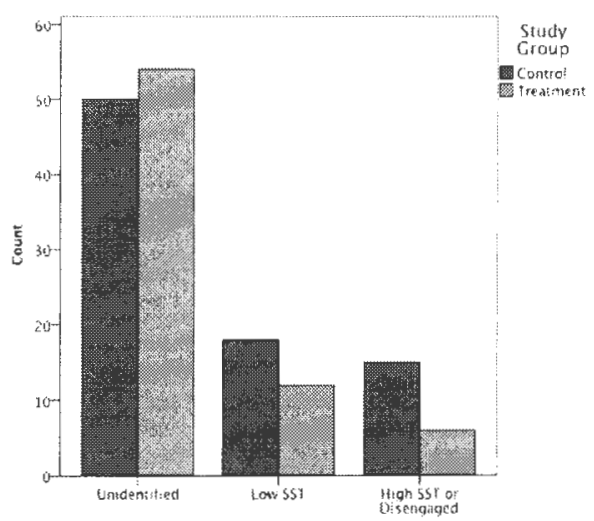

Figure 43. Distribution of SST Gender Identity by study group. The prevalence of susceptibility to stereotype threat for Gender Identity was more prevalent within the control group.

The data were then analyzed using ANCOVA to determine if any of the three stereotype threat identities were moderators for participants' responses on any of the noncognitive scales (Table 8). For this analysis, study group was the independent variable, the noncognitive scale was the dependent variable, and the stereotype threat identity was the covariate. There were only two noncognitive variables with significant interactions: Academic Self Efficacy (ASE) and College Identity. 
Table 8.

ANCOVA a.b.c.de. of Noncognitive Variables by Study Group with Covariate SST Identities

\begin{tabular}{|c|c|c|c|c|c|c|c|c|c|}
\hline \multirow{3}{*}{ Variable } & \multicolumn{3}{|c|}{ SST Math Identity } & \multicolumn{3}{|c|}{ SST Ethnic Identity } & \multicolumn{3}{|c|}{ SST Gender Identity } \\
\hline & $\mathrm{Fg}$ & $\mathrm{F}^{\mathrm{h}}$ & $d f$ & $\mathrm{Fg}$ & $\mathrm{F}^{\mathrm{h}}$ & $d f$ & $\mathrm{Fg}$ & $\mathrm{Fh}^{\mathrm{h}}$ & $d f$ \\
\hline & $\begin{array}{l}\text { SST } \\
\text { Math }\end{array}$ & $\begin{array}{l}\text { Study } \\
\text { group }\end{array}$ & & $\begin{array}{c}\text { SST } \\
\text { Ethnic }\end{array}$ & $\begin{array}{l}\text { Study } \\
\text { group }\end{array}$ & & $\begin{array}{c}\text { SST } \\
\text { Gender }\end{array}$ & $\begin{array}{l}\text { Study } \\
\text { group }\end{array}$ & \\
\hline ASE & $\mathrm{i}$ & - & & .001 & $3.960^{\star}$ & 1,152 & .356 & $4.290^{\star}$ & 1,152 \\
\hline College Identity & $9.013^{\star \star}$ & .025 & 1,152 & $20.475^{\star \star \star}$ & .032 & 1,152 & $16.826^{\star \star \star}$ & .181 & 1,152 \\
\hline Teamwork & k & - & - & k & - & - & .592 & 3.594 & 1,151 \\
\hline Inter-Combined & 1.344 & .450 & 1,151 & .657 & .567 & 1,151 & .496 & .496 & 1,151 \\
\hline Inter-Comm & .918 & .718 & 1,151 & 2.183 & .715 & 1,151 & 1.387 & .606 & 1,151 \\
\hline Inter-Choice & .579 & .329 & 1,150 & .045 & .443 & 1,150 & .017 & .489 & 1,150 \\
\hline Mindf-Distracted & .007 & .004 & 1,152 & .168 & .009 & 1,152 & .332 & .023 & 1,152 \\
\hline Mindf-Observing & .666 & 1.253 & 1,152 & .038 & 1.485 & 1,152 & 261 & 1.302 & 1,152 \\
\hline Grit & 1.252 & .124 & 1,152 & .990 & .173 & 1,152 & .088 & .313 & 1,152 \\
\hline Hope-Combined & 2.773 & 2.267 & 1,151 & .474 & 2.758 & 1,151 & .274 & 3.030 & 1,151 \\
\hline Hope-Path & 3.504 & .232 & 1,151 & .898 & .413 & 1,151 & .007 & .544 & 1,151 \\
\hline Hope-Agency & 2.640 & 2.573 & 1,150 & j & - & - & k & - & - \\
\hline Consciousness & j & - & - & 1.729 & 1.257 & 1,152 & .180 & 1.353 & 1,152 \\
\hline Mindset & 3.590 & .043 & 1,152 & .926 & .141 & 1,152 & .080 & .175 & 1,152 \\
\hline \multicolumn{10}{|c|}{ 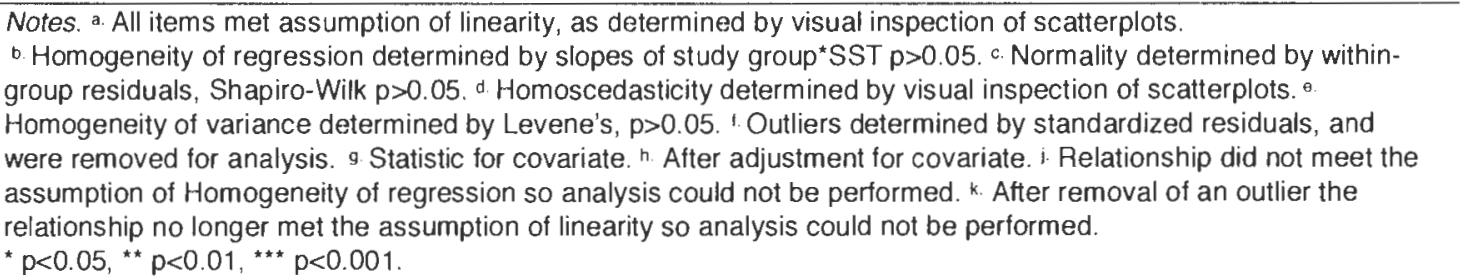 } \\
\hline
\end{tabular}

Academic Self Efficacy. Earlier analysis found a significant difference in Academic Self Efficacy (ASE) across study groups (see Table 4). ANCOVA of study group over ASE with covariate of stereotype threat identity suggests that the interaction between study group and ASE was not related to stereotype threat (Table 8), as the findings for both SST Ethnic Identity and Gender Identity were both insignificant. Thus, 
there is no evidence that SST Ethnic or SST Gender Identities changed the interaction between ASE and the initial framing.

College Identity. Earlier analysis provided no evidence that framing was related to College Identity (see Table 4), although there was evidence of a relationship between College Identity and all three stereotype threat identities (see Table 7). However, ANCOVA of study group over College Identity with covariate of stereotype threat identities (Table 8) provides evidence that the relationships between College Identity and the stereotype threat identities did not change the relationship with study group. Put another way, there was no significant difference between study groups after controlling for SST Math Identity $\mathrm{F}_{1.152}=0.025, \mathrm{p}>0.05$; after controlling for SST Ethnic Identity, $F_{1.152}=0.032, p>0.05 ;$ or after controlling for SST Gender Identity, $F_{1,152}=0.181, p>0.05$. That is to say, there is evidence that stereotype threat identity was not a moderator for College Identity.

\section{Summary, Research Question Two}

There was no evidence of an interaction between framing and stereotype threat for Mindfulness-Observing, Grit, Hope-Agency, and Mindset. There was evidence that framing did not interact with stereotype threat identity and College Identity. There was further evidence that neither SST Ethnic Identity nor SST Gender Identity adjusted responses on Academic Self Efficacy (ASE). However, there was strong evidence to suggest a relationship between stereotype threat and many noncognitive variables in 
general. Table 9 summarizes the significant interactions between the noncognitive scales and each stereotype threat identity, including relationships with confounding variables.

Table 9.

Relationships of Noncognitive Variables and Stereotype Threat Identities

\begin{tabular}{|c|c|c|c|}
\hline \multirow{2}{*}{$\begin{array}{l}\text { Noncognitive } \\
\text { Variable }\end{array}$} & \multicolumn{3}{|c|}{ Susceptibility to Stereotype Threat Identity } \\
\hline & SST Math Identity & SST Ethnic Identity & SST Gender Identity \\
\hline College Identity & $\begin{array}{c}\text { Unid. } \ll \text { Dis./High } \\
\text { Unid. }<\text { Low }\end{array}$ & $\begin{array}{c}\text { Unid. } \ll \text { Dis./High } \\
\text { Unid. }<\text { Low } \\
\text { Institution } \\
\text { Ethnicity }\end{array}$ & $\begin{array}{c}\text { Unid. } \ll \text { Dis./High } \\
\text { Low } \ll<\text { Dis./High } \\
\text { Ethnicity }\end{array}$ \\
\hline $\begin{array}{l}\text { Mindfulness- } \\
\text { Observing }\end{array}$ & - & $\begin{array}{c}\text { Low } \ll \text { Dis./High } \\
\text { Institution } \\
\text { Ethnicity }\end{array}$ & - \\
\hline Grit & - & 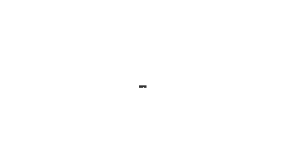 & $\begin{array}{l}\text { Low < Unid. } \\
\text { Low }<\text { Dis./High } \\
\text { Institution } \\
\text { Ethnicity }\end{array}$ \\
\hline Hope-Agency & $\begin{array}{c}\text { Unid. } \ll \text { Dis./High } \\
\text { Ethnicity }\end{array}$ & $\begin{array}{c}\text { Unid. } \ll \text { Dis./High } \\
\text { Low }<\text { Dis./High }\end{array}$ & - \\
\hline Mindset & $\begin{array}{l}\text { Unid. < Low } \\
\text { Institution } \\
\text { Ethnicity }\end{array}$ & - & - \\
\hline
\end{tabular}

Notes. Unid. mean Unidentified; Low means Low SST; Dis./High means Disengaged/High SST. < indicates mean difference of 0.5 or less; < indicates mean difference of more than 0.5 . Institution indicates sensitivity at the institutional level; Ethnicity indicates sensitivity to some ethnicities. - indicates no evidence of an interaction between the two variables.

In the general context of noncognitive variables, notwithstanding study group, multiple noncognitive variables were related to stereotype threat: College Identity, 
Mindfulness-Observing, Grit, Hope-Agency, and Mindset. In every interaction between noncognitive variables and susceptibility to stereotype threat, participants classified as having no susceptibility (Unidentified) scored lower than participants with some form of susceptibility to stereotype threat.

While there was no evidence of interactions with ethnicity and institution across the whole data set, most noncognitive variables that had a significant interaction with stereotype threat also had a relationship with a specific institution and/or specific ethnicities. With regard to relationships with institutions, College Identity was sensitive to applicants to Diablo Valley College when interacting with SST Ethnic Identity and SST Gender Identity. Mindfulness-Observing was sensitive to Diablo Valley College when interacting with SST Ethnic Identity. Mindset was sensitive to Diablo Valley College when interacting with SST Math Identity. And Grit was sensitive to Los Medanos College when interacting with SST Gender Identity.

With regard to the relationship with ethnicities, College Identity was sensitive to Underrepresented Minorities when interacting with SST Ethnic Identity and SST Gender Identity, and sensitive to the Unsure ethnicities (South Asian, Southeast Asian, Biracial, and Other) when interacting with SST Gender Identity. MindfulnessObserving was sensitive to Underrepresented Minorities when interacting with SST Ethnic Identity. Hope-Agency was sensitive to Non-Underrepresented Minorities when interacting with SST Math Identity. Mindset was sensitive to Underrepresented 
Minorities when interacting with SST Math Identity. And Grit was sensitive to Unsure when interacting with SST Gender Identity.

The findings that participants with some form of susceptibility to stereotype threat scored better on a task are contrary to the literature suggesting that people suffering from stereotype threat tend to perform worse, especially in a high stakes environment. This finding suggests a need for further research, and so the data were analyzed to check for faking among participants, with a specific interest in any relationships between faking and susceptibility to stereotype threat. The next section will address this.

\section{Faking}

At the end of the study, participants were given four debriefing questions, two of which were related to faking. The questions were phrased slightly differently for each study group. The treatment group was asked to respond to the questions, "I gave lower answers than were true because I was worried about being placed too high" (Decreased Answers) and "I gave higher answers than were true because I was worried about being placed too low" (Increased Answers). The control group was asked to respond to, "I gave lower answers than were true" (Decreased Answers) and "I gave higher answers than were true" (Increased Answers).

The literature suggests that people suffering from stereotype threat score worse on standardized tests (see Chapter 2), but this study found participants with 
susceptibility to stereotype threat scored significantly higher on a number of noncognitive scales compared to participants with no susceptibility. This lead the researcher to consider faking as a possible explanation of the higher scores. This section seeks to understand what role, if any, faking played in relation to responses on noncognitive scales. As the data for both susceptibility to stereotype threat and faking were collected in both the pilot and the research study, they were both analyzed to determine if differences exist between the two rounds. The data were also analyzed to check for relationships between faking and ethnicity, as well as institution applied to. Each round was analyzed both as a whole (within group comparison) and disaggregated by study group (between group comparison). Susceptibility to stereotype threat (SST) was then considered as a potential mediator with faking. The data from the pilot were reported earlier; what follows is the data relevant to the research study.

\section{Within Group Comparison}

Across the research study, participants reported very low levels of faking, with very low reported levels of decreasing answers $(\bar{x}=1.51, \mathrm{sd}=.778)$ and increasing answers $(\bar{x}=1.64, \mathrm{sd}=1.00)$. A Pearson correlation revealed a strong, positive statistically significant relationship between the two, $r=.729, p<0.001, N=154$ (Figure 44). This was a significantly higher correlation than observed in the pilot (Fisher r-to-z transformation (Lowry, 2017), $\mathrm{z}=3.01, \mathrm{p}<0.01,2$-tailed). After removing outliers, the correlation became very strong, $\mathrm{r}=1.00, \mathrm{p}<0.001$. This suggests that while participants 
overall reported very little faking, the more likely one was to increase their answers, the more likely they were to decrease them as well. Multiple analyses were performed to check for a relationship between ethnicity or institution and increasing or decreasing answers. There was no evidence of a relationship between faking and institution, but there were relationships between faking and ethnicity.

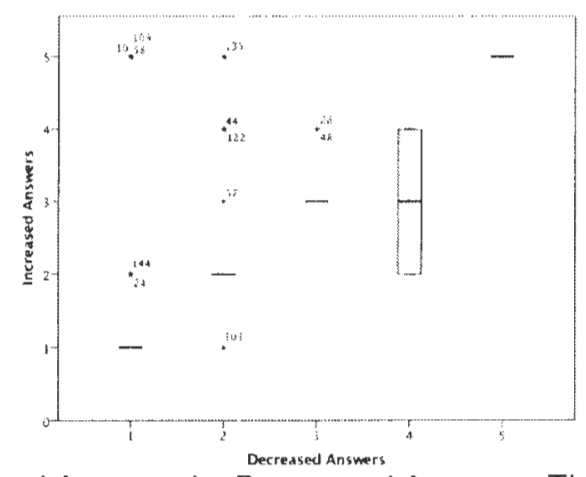

Figure 44. Boxplots of Increased Answers by Decreased Answers. There was a strong, positive relationship between increasing and decreasing answers. This relationship became very strong after removing outliers.

There is evidence of a relationship between ethnicity and decreasing answers. The Welch's F statistic could not be calculated due to at least one group having zero variance, but post hoc analysis was significant across ethnicity (Figure 45). On average, participants in the ethnic group Unsure (South Asian, Southeast Asian, Biracial, and other) were significantly less likely to decrease their answers $(\bar{x}=1.00, \mathrm{sd}=0.00, \mathrm{~N}=21)$ compared to both other groups. The largest difference was between Unsure and Underrepresented Minorities $(\bar{x}=1.58, \mathrm{sd}=.755, \mathrm{~N}=57)$ a mean difference of 0.579 , $\mathrm{p}<0.01$ (Dunnett's T3). The Unsure group was also significantly less likely to decrease 
their answers compared to Non-Underrepresented Minorities $(\bar{x}=1.40, \mathrm{sd}=.613, \mathrm{~N}=62)$, a mean difference of $0.403, p<0.001$ (Dunnett's T3).

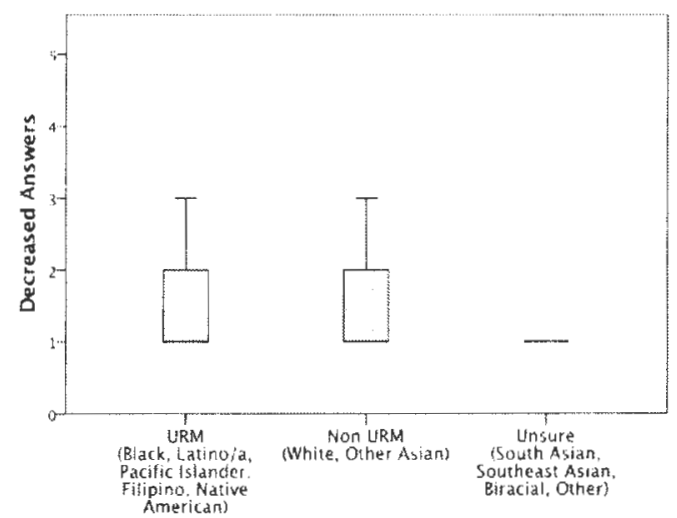

Figure 45. Decreased answers by ethnicity (outliers removed). Participants in the Unsure group were significantly less likely to decrease their answers compared to all other ethnicities.

There was also evidence of a relationship between increasing answers and ethnicity. Welch's F statistic could not be calculated due to at least one group having zero variance, but post hoc analysis of increased answers across ethnicity suggest a significant difference between ethnicities (Figure 46). The Unsure group was significantly less likely to increase their answers $(\bar{x}=1.00, \mathrm{sd}=0.00, \mathrm{~N}=20)$ compared to both Underrepresented Minorities $(\bar{x}=1.54, \mathrm{sd}=.727, \mathrm{~N}=52)$, and Non-Underrepresented Minorities $(\bar{x}=1.42, \mathrm{sd}=.645, \mathrm{~N}=60)$. These were mean difference of $0.538, \mathrm{p}<0.01$ and 0.417, $\mathrm{p}<0.001$, respectively (Dunnett's T3). 


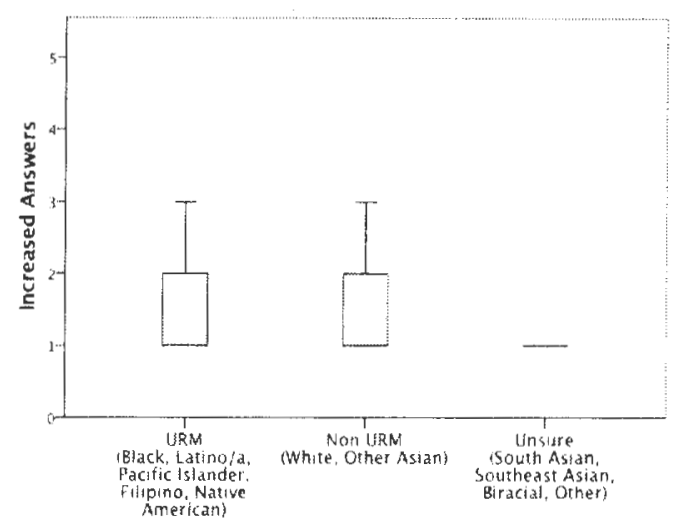

Figure 46. Increased answers by ethnicity (outliers removed). Participants in Unsure group were significantly less likely to decrease their answers compared to all other ethnicities.

\section{Between Group Comparisons}

An independent sample t-test was performed and found no relationship between study group and decreasing answers, $\mathrm{t}_{144}=1.467, \mathrm{p}>0.05$, or increasing answers, $t_{137}=0.784, p>0.05$. However, an analysis of each individual study group suggests that the relationship between increasing and decreasing answers was stronger within the treatment group than the control. This finding was consistent with the pilot study.

Control group. In general the control group was honest (Figure 47), reporting low levels of decreasing answers $(\bar{x}=1.51, \mathrm{sd}=.832)$ and increasing answers $(\bar{x}=1.66$, $\mathrm{sd}=1.039$ ). At the same time, there was a strong, positive relationship between increasing and decreasing answers $(r=651, \mathrm{p}<0.01, \mathrm{~N}=83)$. This was a significantly stronger relationship than observed in the pilot control group (Fisher r-to-z transformation $\mathrm{z}=-2.58, \mathrm{p}<0.01,2$-tailed). Removing outliers, the relationship became very strong $(\mathrm{r}=.962, \mathrm{p}<0.001, \mathrm{~N}=77)$. There was no evidence of an interaction between 
faking and institution or ethnicity within the control group. Indeed, after removing outliers, both increasing and decreasing answers were constant across all ethnicities.

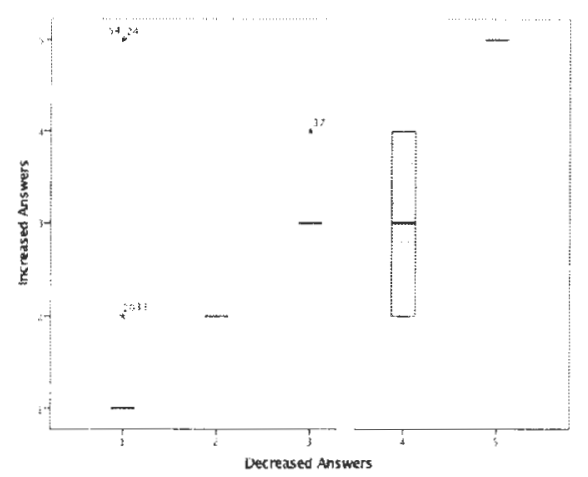

Figure 47. (Control) Boxplots of Increased Answers by Decreased Answers. There was a strong, positive relationship between increasing and decreasing answers. This relationship became very strong after removing outliers.

Treatment group. Like the control, the treatment group reported low levels of decreasing answers $(\bar{x}=1.51, \mathrm{sd}=.715)$ and increasing answers $(\bar{x}=1.62$, sd $=.962)$. There was a very strong, positive relationship between increasing and decreasing answers, $\mathrm{r}=.846, \mathrm{p}<0.001, \mathrm{~N}=71$ (Figure 48). Removing outliers, the correlation became even stronger, $\mathrm{r}=1.000, \mathrm{p}<0.001, \mathrm{~N}=63$. A Fisher $\mathrm{r}-\mathrm{to}-\mathrm{z}$ transformation suggests that both correlations are significantly stronger than the control group: with outliers, $\mathrm{z}=2.83$, $\mathrm{p}<0.001$, and without, $z=10.52, \mathrm{p}<0.001$ (2-tailed). The relationship was not significantly different from the pilot treatment group. There was no evidence of an interaction with institution, but there was evidence of an interaction with ethnicity. 


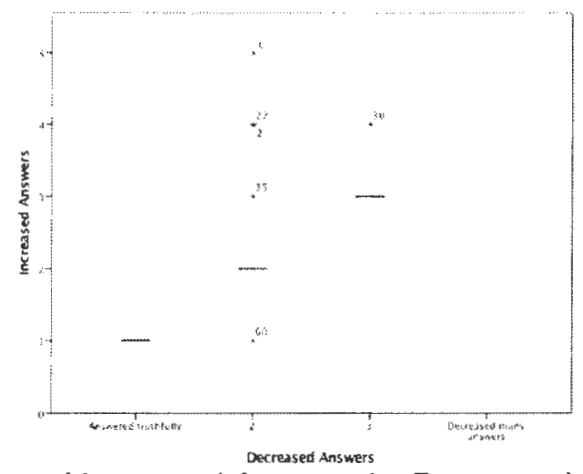

Figure 48. (Treatment) Boxplots of Increased Answers by Decreased Answers. There was a very strong, positive relationship between increasing and decreasing answers. This relationship became very strong after removing outliers. These were significantly stronger relationships than the control.

There is evidence to suggest that certain ethnicities may be more prone to faking given high stakes framing. One-way ANOVAs were performed to check for a relationship between ethnicity and faking within the treatment group. The Welch's F statistic could not be calculated due zero variance, but post hoc analysis suggests significant differences in faking across the ethnic groups (Figure 49). Specifically, participants classified as Unsure were significantly less likely to decrease their answers $(\bar{x}=1.00, \mathrm{sd}=0.00, \mathrm{~N}=13)$ than both Underrepresented Minorities $(\bar{x}=1.66, \mathrm{sd}=.814$, $\mathrm{N}=29)$ and Non-Underrepresented Minorities $(\bar{x}=1.52, \mathrm{sd}=.653, \mathrm{~N}=25)$. These were mean differences of $0.655(\mathrm{p}<0.01)$ and $0.520(\mathrm{p}<0.01)$, respectively (Dunnett's T3). 


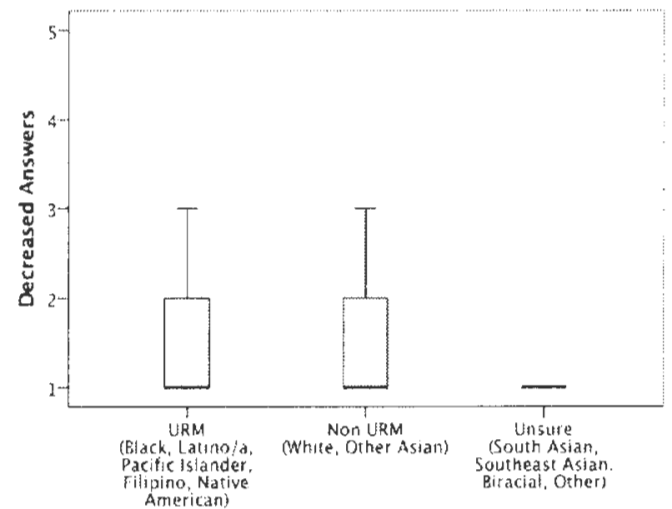

Figure 49. (Treatment) Decreased answers by ethnicity (outliers removed). Participants in the Unsure group were significantly less likely to decrease their answers compared to the other ethnicities.

Post hoc analysis also suggests a significant difference in increasing answers across ethnic groups (Figure 50). Participants classified as Unsure were also significantly less likely to increase their answers $(\bar{x}=1.00, \mathrm{sd}=0.00, \mathrm{~N}=13)$ compared to both underrepresented minorities $(\bar{x}=1.83, \mathrm{sd}=1.071, \mathrm{~N}=29)$ and non-underrepresented minorities $(\bar{x}=1.50, \mathrm{sd}=.722, \mathrm{~N}=24)$. These were mean differences of $0.828(\mathrm{p}<0.01)$ and $0.500(\mathrm{p}<0.01)$, respectively (Dunnett's T3). Given the small $\mathrm{N}$ within the Unsure ethnic grouping, it is possible that these findings are spurious. 


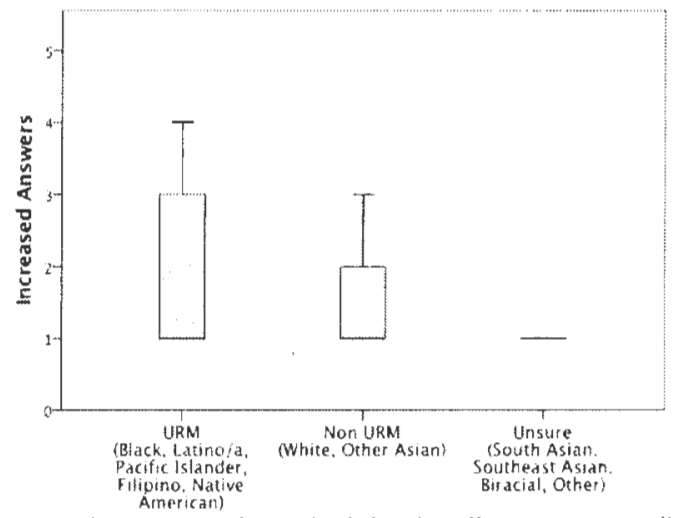

Figure 50. (Treatment) increased answers by ethnicity (outliers removed). Participants in the Unsure group were significantly less likely to increase their answers compared to the other ethnicities.

Although these interactions between faking and ethnicity occurred within the treatment group, there is strong evidence to suggest that they were not related to high stakes framing. ANCOVA of ethnicity over decreased answers, with covariate study group suggests that the framing did not adjust the associations between ethnicity and decreasing answers, $F_{2.143}=3.846, p<0.05$. Findings were similar for increased answers, $\mathrm{F}_{2.140}=5.523, \mathrm{p}<0.01$. These findings could spurious due to the treatment group having a slightly larger proportion of participants classified as Unsure compared to the control group ( $25 \%$ compared to $18 \%)$.

\section{Faking and Stereotype Threat}

Overall, there was little faking reported, but findings in relation to research question two raised concerns that participants with some form of susceptibility to 
stereotype threat were more prone to faking. This section attempts to check for a relationship between susceptibility to stereotype threat and faking.

One-way ANOVAs were performed with the entire data set to check for a relationship between faking and the three SST Identities; no relationships were statistically significant in terms of the F statistic or post hoc analysis. Pearson correlations were performed with and without outliers. In both cases, few correlations were significant, and those that were had very small relationships, with values no more than $r=0.28$. Thus, there was no evidence of a relationship between faking and stereotype threat within the group as a whole. The data was analyzed separately as earlier analysis revealed different relationships for faking within each study group and a statistically significant difference in prevalence of SST Gender Identity.

Control group. Within the control group, a one-way ANOVA suggests a relationship between faking and SST Ethnic and Gender identities (Table 10). There was no evidence of a relationship between faking and SST Math Identity, either in terms ANOVA F statistic or post-hoc analysis. 
Table 10

(Control Group) ANOVA of Faking by Stereotype Threat Identities

\begin{tabular}{|c|c|c|c|c|c|}
\hline \multirow{2}{*}{ Variable } & \multicolumn{3}{|c|}{ Test Assumptions } & \multirow{2}{*}{$\begin{array}{c}\text { F } \\
\text { Statistic d }^{\text {d }}\end{array}$} & \multirow{2}{*}{ df } \\
\hline & Outliers $^{a}$ & Normalb & Homog. & & \\
\hline \multicolumn{6}{|l|}{ SST Math Identity } \\
\hline Decreased Answers & Yes & No & Yes & .424 & 2,73 \\
\hline Increased Answers & Yes & No & Yes & .494 & 2,74 \\
\hline \multicolumn{6}{|l|}{ SST Ethnic Identity } \\
\hline Decreased Answers & Yes & No & No & $\mathrm{e}$ & - \\
\hline Increased Answers & Yes & No & No & $3.622^{*}$ & 2,21 \\
\hline \multicolumn{6}{|l|}{ SST Gender Identity } \\
\hline Decreased Answers & Yes & No & No & e & - \\
\hline Increased Answers & Yes & No & No & $3.837^{*}$ & 2,25 \\
\hline \multicolumn{6}{|c|}{ 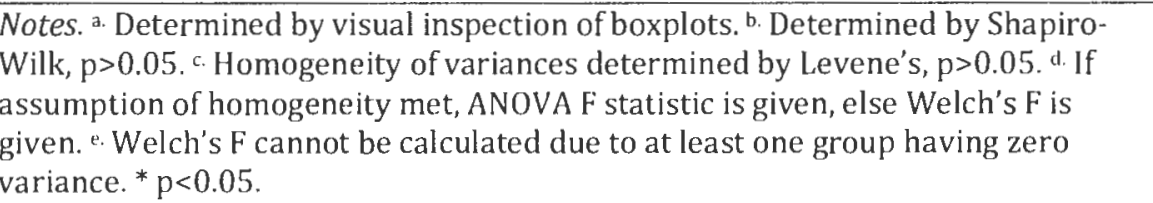 } \\
\hline
\end{tabular}

SST Ethnic Identity. There is evidence to suggest that participants with Low SST Ethnic were more prone to decreasing their answers (Figure 51). While Welch's F statistic for SST Ethnic Identity and Decreased Answers could not be calculated due to at least one group zero variance, post hoc analysis suggests that participants with Low SST Ethnic scored significantly higher on Decreased Answers ( $\bar{x}=1.48, \mathrm{sd}=.712, \mathrm{~N}=33$ ) than Unidentified $\bar{x}=1.00, \mathrm{sd}=.000, \mathrm{~N}=29$ ), a mean difference of 0.485 , $\mathrm{p}<0.01$ (Dunnett's T3).

The statistical significance of SST Ethnic and Increased Answers may be a Type I error, as Welch's $F$ was statistically significant, $F_{2,21}=3.622, p<0.05$, but post-hoc analysis (Dunnett's T3) was not significant for any relationship. 


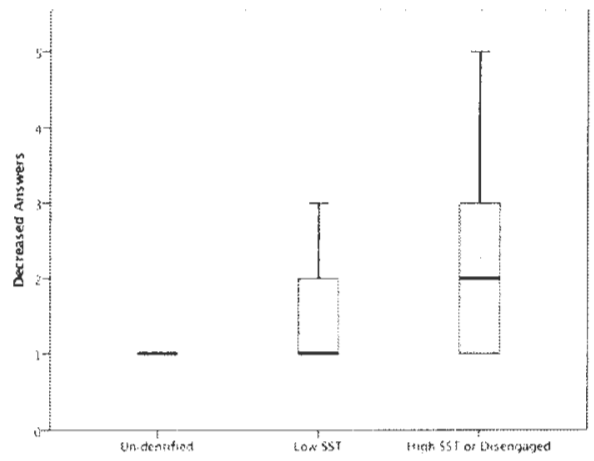

Figure 51. (Control) Boxplots of Decreased Answers by SST Ethnic Identity (outliers removed). Participants with no susceptibility (Unidentified) were significantly less likely to decrease their answers compared to participants with Low susceptibility.

SST Gender Identity. There is evidence to suggest that participants with some form of susceptibility to stereotype threat of Gender Identity are more likely to decrease their answers. Welch's F statistic for SST Gender Identity and Decreased Answers could not be calculated due to at least one group zero variance, but post hoc analysis suggests that participants with some form of susceptibility to stereotype threat were more prone to decreasing answers (Figure 52). Low SST Gender scored significantly higher on Decreased Answers $(\bar{x}=1.61, \mathrm{sd}=.778, \mathrm{~N}=18)$ than Unidentified $(\bar{x}=1.00$, $\mathrm{sd}=.000, \mathrm{~N}=37$ ), a mean difference of $0.611, \mathrm{p}<0.05$ (Dunnett's 'T3). Disengaged/High SST Gender also scored significantly higher on Decreased Answers $(\bar{x}=1.54, \mathrm{sd}=.660$, $\mathrm{N}=13$ ) than Unidentified, a mean difference of $0.537, \mathrm{p}<0.05$ (Dunnett's T3). 


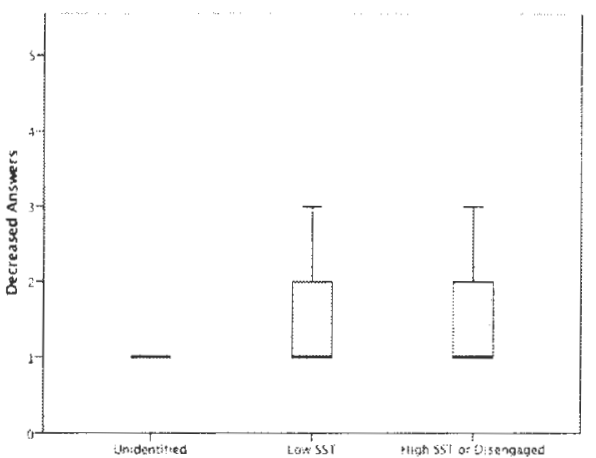

Figure 52. (Control) Boxplots of Decreased Answers by SST Gender Identity (outliers removed). Participants with no susceptibility were significantly less likely to decrease their answers compared to the other participants.

The relationship between SST Gender Identity and Increased Answers may be spurious or a Type I error, as Welch's F was statistically significant, $F_{2.25}=3.837$, $\mathrm{p}<0.05$, but post-hoc analysis (Dunnett's T3) was not significant for any relationship.

Treatment group. A one-way ANOVA was completed to check for a relationship between faking and the SST Identities. No relationships were statistically significant. Correlations were then run, and again nothing was statistically significant. Thus, there is no evidence of a relationship between susceptibility to stereotype threat and faking within the treatment group.

\section{Summary, Faking}

There is evidence that in general, fall applicants were honest, but if someone was going to change their answers, they were likely to both increase and decrease their answers. There was strong evidence to suggest that the high stakes framing makes this even more likely. There is further evidence to suggest that some ethnic groups may be 
less prone to faking, and that susceptibility to stereotype threat may increase the likelihood of decreasing answers among participants with SST Ethnic and SST Gender Identities.

\section{Final Analysis Summary}

There was strong evidence to suggest that the high stakes nature of assessment and placement was had a negative impact on many participants, even outside the realm of the actual placement test. The level of the impact differed depending on the situation. In the pilot study of spring applicants, when given a high-stakes framing, participants who had already taken an assessment test strongly believed that their responses would be used for course placement; any other participants were outliers. Conversely, in the study of fall applicants, participants given a high stakes framing who had not taken a placement test were more likely to believe the framing than participants who had taken a placement test and were given low stakes framing.

Some noncognitive variables were sensitive to high stakes situations. Three noncognitive scales are sensitive to high-stakes framing: Academic Self Efficacy (ASE), Teamwork, and College Identity. Participants given high stakes framing had significantly lower scores on ASE and Teamwork, which in some cases was compounded by participants' background. Given high stakes framing, those with lower

family incomes scored lower on ASE, and those with a high school GPA of 3.0 to 3.45 scored lower on Teamwork. There was evidence that high school GPA overwhelmed 
the differences between study group on both ASE and Hope-Agency. Both College Identity and Teamwork interacted with the placement test. Participants who has taken a placement test scored higher on College Identity, and given high stakes framing, they scored lower on Teamwork.

There was no evidence that stereotype threat susceptibility itself was a moderator, there was also evidence to suggest a relationship between that susceptibility to stereotype threat in general for five noncognitive variables: College Identity, Mindfulness-Observing, Hope-Agency, Grit, and Mindset. In all cases, participants with some form of stereotype threat susceptibility scored higher on these noncognitive scales. Every noncognitive variable that was sensitive to stereotype threat also had an interaction with ethnicity, and all but one (Hope-Agency) had an interaction with institution.

There was also evidence that susceptibility to stereotype threat played an indirect role vis-à-vis faking. In general, participants were honest and reported low levels of faking, but those who did fake, did so inconsistently by both increasing and decreasing their scores. This was especially true for participants given high stakes framing. There was evidence of a relationship between decreasing answers and susceptibility to stereotype threat for Ethnic and Gender Identities. While much of the literature indicates people who are susceptible to stereotype threat may scores lower on tests, this study did not find that to be true for these noncognitive variables. This could 
be an example of the controversy around stereotype threat, or it could be a factor of the small sample size, especially within the High SST and Disengaged categories. Further research is necessary to determine the extent of the relationship between susceptibility to stereotype threat and faking, and how much of the difference on noncognitive scales is a result of that interaction. 


\section{CHAPTER 5: DISCUSSION AND RECOMMENDATIONS}

"[W]hen seriously underprepared students have only a tiny chance of getting a degree, something must change." (Wyner, 2014, p. 61)

This study was born out of a concern that U.S. community colleges were currently using or considering using noncognitive variables for academic placement (e.g., Booth, Bracco, Chaplot, \& Lagunoff, 2014; Hayward \& Fagioli, 2016; Hetts \& Willett, 2013; R.P. Group, 2015; Willett et al., 2015) without an understanding of how students would react to these scales in a high-stakes setting. Of particular concern was that students would react to noncognitive variables in the same way the react to any placement test, where certain groups of students do worse simply due to the nature of the test (McKinsey Company, 2009), and some intentionally do worse for fear of being placed in a class beyond their skill level (Fay et al., 2013; Fong \& Melguizo, 2015), while still others do worse due to stereotype threat (Burdman, 2015b; Maloney et al., 2013). While the use of noncognitive variables for placement often stems from a desire to overcome the limitations of content-based assessment tests, the researcher was concerned that noncognitive variables had the potential to become an extension of the placement test inasmuch that students may react in a similar manner. With that in mind, this study was guided by two research questions: How does the high-stakes nature of academic placement impact student responses on noncognitive scales? How does the 
context, demand, characteristics, and framing of the noncognitive variables impact stereotype threat, if at all? This chapter will discuss the hypothesized relationships between these two questions, discuss the findings from the research questions, and discuss the implications, including recommendations for future policies and research.

\section{Hypothesized Relationships}

The researcher hypothesized two outcomes as a result of the high-stakes framing, theorizing that the high-stakes framing would impact participant responses in both a positive and negative manner, illustrated in Figure 53 by the green (bottom) and red (top) paths respectively.

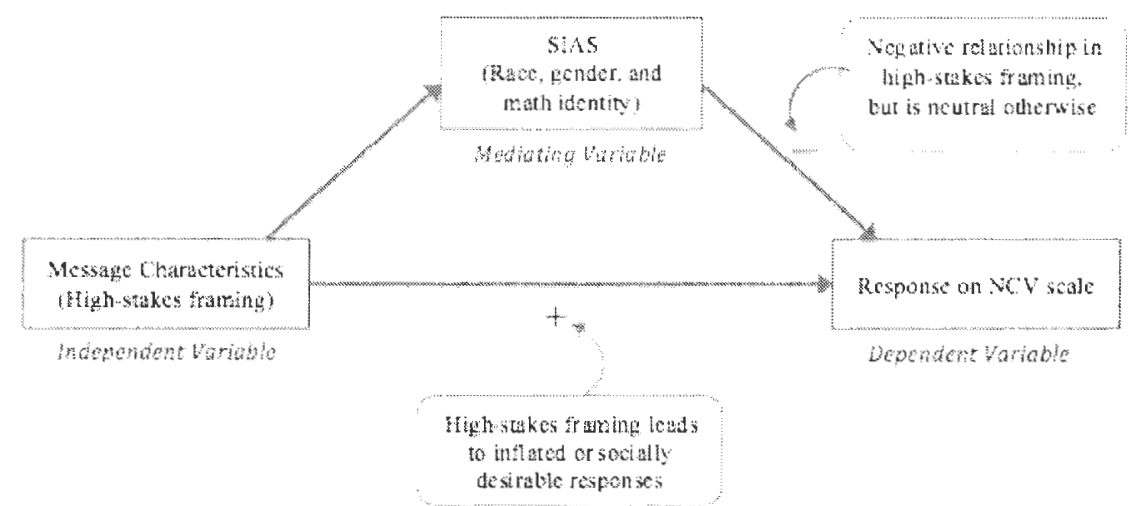

Figure 53. Hypothesized relationships between the variables. The green arrows (bottom) represent the hypothesized negative relationship as a result of high-stakes framing, and the red arrows (top) represent the hypothesized positive relationship as a result of high-stakes framing.

The researcher's first hypothesis was that participants in the treatment group would be more prone to inflating their scores by giving higher answers than was accurate and/or more prone to giving socially desirable responses, represented by the 
green (bottom) arrows in Figure 51. This researcher hypothesized that treatment group participants with stronger academic backgrounds would be more likely to report faking.

The second hypothesis, represented by the red path (top), was based on the literature suggesting that stereotype threat would be a potential mediating variable, where participants with some form of susceptibility to stereotype threat would likely have lower answers due to the threat of stereotype threat. For this study, stereotype threat susceptibility was measured for Ethnic, Gender, and Mathematics Identity using the Social Identities Attitudinal Scale (SIAS; Picho \& Brown, 2011). The researcher hypothesized that there would be a negative relationship between the SIAS and the dependent variable for the treatment group, inasmuch that the high-stakes framing given to the treatment group would have a negative relationship with noncognitive scales in relation to the control group. The researcher also hypothesized that treatment group participants who were Black, Latina/o, or had weaker academic backgrounds would be more likely to show this negative relationship. These conjectures were based on the researcher's theory that when noncognitive scales are used for placement, participants would react in a manner similar to the placement test. That is to say, the researcher hypothesized that stereotype threat would intervene and be responsible for how the independent variable and the dependent variable were related (Baron \& Kenny, 1986). 


\section{Discussion of Findings}

Analysis suggested that the researcher's hypotheses were each partially correct. While faking and giving socially desirable answers was not common in either treatment or control groups, when faking did occur, it was present in both study groups, albeit the relationship was significantly stronger in the treatment group. In addition, stereotype threat susceptibility did have a negative relationship with some noncognitive variables, but there was evidence that initial framing was not related. In addition, there were some findings that were unexpected.

\section{Academic Placement and Noncognitive Variables}

The first research question was: How does the high-stakes nature of academic placement impact student responses on noncognitive scales? This question was studied in two ways: to determine if there was a relationship between high-stakes framing and noncognitive variables, and to determine if there was a relationship between the placement test and noncognitive variables. The question will first be addressed by interactions with high stakes framing, followed by a discussion of each significant noncognitive variable.

There is strong evidence to suggest that the high stakes nature of academic placement had a relationship with five noncognitive scales: Academic Self Efficacy (ASE), College Identity, Teamwork, Hope-Combined, and Hope-Agency. With one exception, this relationship was negative. Two noncognitive scales, College Identity and 
Teamwork, were related to the placement test. Taking the placement test had a positive relationship with College Identity, but a negative relationship with Teamwork when the noncognitive scale was administered with high stakes framing. Being given high stakes framing appears to have decreased scores on Teamwork and Hope-Combined compared to participants given low stakes framing.

In addition, there were three scales where the high stakes framing appears to have had a negative relationship amongst participants with specific backgrounds: Academic Self Efficacy, Teamwork, and Hope-Agency. Given high stakes framing, lower income students performed worse on Academic Self Efficacy than higher income students. On Teamwork, participants with a 3.0 to 3.49 high school GPA performed significantly worse when given high stakes framing compared to their peers given low stakes framing. With Hope-Agency, participants classified as Non-Underrepresented Minorities (White and other Asian) performed significantly worse when given high stakes framing. Finally, there was evidence that high stakes framing was related to the institution the participant applied to: Teamwork, Hope-Combined, and Hope-Agency. Applicants to Diablo Valley College who were given high stakes framing scored significantly worse on all three noncognitive scales compared to their peers given low stakes framing. As Hope-Agency was related to ethnicity as well, it is possible that the difference in study group was due to the interaction of ethnicity and institution 
combined. What follows is a more thorough discussion for the noncognitive variables with the most remarkable findings.

Academic Self Efficacy. Academic Self Efficacy (ASE) is used to determine "[o]ne's confidence in successfully completing school-related tasks and in one's ability to regulate learning and study behaviors...." (Farr et al., 2014, p. 39). Findings from this study suggest that high-stakes framing is related to lower scores on ASE among students from lower income families. One possible explanation is that a student's background may be compound by high stakes scenarios. Conversely, it is possible that this scale is biased against lower-income families. Some of the questions on ASE ask about finding a distraction-free place to study, being able to study when there are other things to do, and finishing assignments on time - all of which can be challenging for lower-income students if they do not have reliable food or housing, or if they have to take care of family members. A recent survey of current students in the participating district found that $55 \%$ of students were food insecure, $49 \%$ were housing insecure, and 14\% were homeless (Stoup, 2017). National trends mirror these proportions (GoldrickRab, Richardson, \& Hernandez, 2017). The large proportion of students with food and housing insecurity may partially explain the relationship observed between Academic Self Efficacy and family income. These findings also suggest that ASE has a disproportionally negative relationship with lower income students. As such, this scale 
may not be a good indicator of students' readiness when administered as part of assessment and placement.

Teamwork. Teamwork measures college readiness by determining how one identifies "as a college student, [including] communication skills, and aspects of personal responsibility that affect interaction with others" (Farr et al., 2014, p. 39). There is strong evidence to suggest that the high-stakes nature of assessment had a negative relationship with Teamwork. Comparing study groups, the treatment group had significantly lower average scores than the control group. When comparing the groups by who had already taken a placement test, the average score of the control group was higher, widening the gap between the two. One of the things that Teamwork measures is the ability to handle stress, so it is possible that the lower scores among the treatment group and the test-takers makes sense. However, it could be argued that the stress being measured was an extension of the students' concern about the assessment test, or with regard to the test-takers, it could be the concern that their placement might change. It is possible that the lower scores observed for treatment group participants who took placement tests are, at least in part, a product of the high-stakes nature of placement. Regardless, it seems odd to be testing a students' ability to handle stress in a high stakes environment, when there is evidence that doing so may in itself be having a negative impact, which in turn may lower their scores. Teamwork appears to be particularly 
sensitive to high-stakes scenarios, especially if it is measured in a secondary survey, and as such, it may not be an appropriate tool for use in academic placement.

College Identity. College Identity measures the same items as Teamwork, with a focus on the role being a college student plays in one's self-image. Contrary to the findings of Teamwork, there is evidence of a negative relationship between College Identity scores and not having taken a placement test. Participants who had not yet taken a placement test tended to score lower on College Identity compared those who had taken a test prior to participation. There was no evidence that framing was related. This suggests that the act of taking the test may have made participants feel more like a college student, and as such, they scored higher. Alternatively, the difference could be attributed that students who identify more as a college student are more proactive and have the agency to get things done well before they are necessary. In addition, some students who apply to this district take the placements tests while they are still in high school, which could also account for some of the difference in scores. More research is necessary to fully understand the relationship between assessment and College Identity and if this relationship changes when students are placed using other methods, such as multiple measures. As it stands, these findings suggest that College Identity may not be an appropriate tool to use for placement as it may just be a reflection of already having been through the assessment and placement process. 
High stakes and assessment. There is strong evidence to suggest that high stakes situations increased concern that responses would be used for placement. When the data was disaggregated by having taken an assessment test, a striking difference between spring and fall applicants emerged. Not only did responses vary by term, evidence suggests that the differences seen between study groups may be attributable to whether or not one has already taken a placement test. Within spring applicants, participants who had taken a placement test and were given a high-stakes framing were dramatically more worried that their responses would be used for course placement compared to the rest of the applicants. This suggests that being given a second highstakes scenario may have a negative impact for spring applicants.

Within fall applicants, the data shows a different outcome. Across the entire fall data set, participants who were given high stakes framing and had not taken a placement test were significantly more worried that their responses would be used for course placement. Disaggregating the data by both study group and whether a placement test had been taken showed that the treatment group who had not taken a test was significantly more worried that their responses would be used for course placement than the control group participants who had taken a test. The treatment group was more likely to believe the high-stakes framing, perhaps because of the unknown aspects of placement. The data suggest that incoming students are worried about assessment and placement, even if given questions that are not content-specific. 
These findings give insight into the behavioral differences between spring and fall applicants and provide strong evidence that they have different needs when it comes to assessment and placement. In a high stakes setting, spring applicants may be more concerned about assessment and placement after they take an assessment test, whereas fall applicants may be more concerned before the test. Among the former, is unclear if participants were more likely to believe the deception because of having had taken the test or if they were worried their placement results would change. This would be a good topic for further research.

Summary. The evidence is clear that assessment that is not content related has a negative impact and as such institutions should be conscious of this. There is strong evidence to suggest that Academic Self Efficacy, College Identity, and Teamwork are sensitive to high takes scenarios and/or biased against people with specific backgrounds, suggesting that none of them are appropriate for academic placement. Further research is needed to determine if one specific test has an impact, or if it is placement tests in general. Further research is also necessary to determine how grade point average, income, financial aid status, and ethnicity interact with noncognitive scales. Further research is also needed to determine if spring applicants respond differently to noncognitive scales in a high-stakes setting. 


\section{Stereotype Threat}

The second research question was: How does the context, demand, characteristics, and framing of the noncognitive variables impact stereotype threat, if at all? There was no evidence of a relationship between framing, noncognitive variables, and susceptibility to stereotype threat for any of the three identities. However, there was evidence of a relationship between susceptibility to stereotype threat and five noncognitive scales across the data set as a whole: College Identity, MindfulnessObserving, Grit, Hope-Agency, and Mindset. In all cases, participants with some form of stereotype threat susceptibility scored higher on the noncognitive scale. However, there was evidence that both SST Ethnic and Gender Identities were related to faking. What follows is a summary of how each of the five noncognitive variables were related to susceptibility to stereotype threat.

SST Math Identity. Susceptibility to stereotype threat for Math Identity was related to College Identity, Hope-Agency, and Mindset. In all three cases, Unidentified participants scored lower on the noncognitive scale compared to those with some kind of SST Math. The relationships of SST Math Identity with Hope-Agency and Mindset both had a interactions with specific ethnicities and specific institutions. Among NonUnderrepresented Minorities (White and other Asian), those with Low SST Math scored nearly a point higher on Hope-Agency than those who were Unidentified. A similar relationship was observed on Mindset: among traditionally Underrepresented Minorities 
(Black, Latino/a, Pacific Islander, Filipino, and Native Americans), Low SST Math scored nearly half a point higher on Mindset compared to those who were Unidentified. The interaction between Mindset, SST Math, and Diablo Valley College was also similar: applicants with Low SST Math scored higher on Mindset than applicants who were Unidentified. There was no evidence of a relationship between faking and SST Math Identity.

These findings are consistent with research, as people with strong math identification tend to value math and have the skills to be successful in it (Picho \& Brown, 2009), which is a large part of identifying as a college student, having agency, and having a growth mindset.

SST Ethnic Identity. Susceptibility to stereotype threat for Ethnic Identity was related to College Identity, Mindfulness-Observing, and Hope-Agency. Participants with Disengaged or High SST Ethnic scored higher on all three noncognitive scales. On College Identity, they scored over a full point higher than Unidentified.

Disengaged/High SST Ethnic scored over half a point higher than Low SST Ethnic on all three noncognitive scales. These differences were even stronger among Underrepresented Minorities responding to Mindfulness-Observing and College Identity. The relationship between Mindfulness-Observing, ethnicity, and susceptibility to stereotype threat is consistent with the literature. Mindfulness-Observing measures how conscious a person is of their body, emotions, thoughts, and behaviors and the 
literature suggests that people susceptible to stereotype threat tend to be aware of what is happening around them (Steele et al., 2002).

However, responses may be unreliable due to the relationship between faking and SST Ethnic Identity. There is evidence to suggest that participants with some form of susceptibility were somewhat more likely to decrease their answers. At the same time, participants with Disengaged/High SST Ethnic scoring statistically higher than other groups makes it difficult to interpret the results. As discussed below, within the whole data set there was a strong relationship between decreasing and increasing answers, suggesting the apparent contradiction observed in the noncognitive scores may be a result of faking.

SST Gender Identity. Susceptibility to stereotype threat for Gender Identity was related to College Identity and Grit, but in somewhat opposite manners. On College Identity, Disengaged/High SST Gender scored nearly a full point higher than Unidentified and over half a point higher than Low SST Gender. The difference was larger among traditionally Underrepresented Minorities, with participants having some form of susceptibility to stereotype threat scoring roughly one point higher than Unidentified. On Grit, participants with Low SST Gender scored roughly half a point lower than both High SST Gender and Unidentified. There was evidence of a relationship with ethnicity and with institution, but these were likely spurious due to the low $\mathrm{N}$ values within the groups. 
However, there is strong evidence to suggest there differences may be a result of faking. Participants with some form of susceptibility to stereotype threat for Gender Identity were more likely to decrease their answers. Given the strong relationship between decreasing and increasing answers, these relations are all the more unreliable.

Summary. While this study found a difference in responses with participants susceptible to stereotype threat, the effect did not occur in the manner the literature suggests. This may be related to the controversy that has developed in recent years (e.g., Flore \& Wicherts, 2015; Inzlicht, 2016; Stoet \& Geary, 2012). The relationship between susceptibility to stereotype threat, faking, and College Identity, Mindfulness-Observing, Grit, and Hope-Agency makes the findings unreliable. It is especially important to note that this study found the most erratic responses within the control group-that is, in a low-stakes scenario, making these scales all the more problematic. As such, these scales are not recommended to be used for academic placement.

Further research is necessary to fully understand the interactions between ethnicity, institution, noncognitive scale, and susceptibility to stereotype threat. More research is also necessary to determine if the faking was a result of stereotype threat, or if faking was a moderator for responses.

\section{Faking}

Institutions and decision-makers are always concerned about self-reported information, as they often assume students will be untruthful, increasing and decreasing 
their answers, either in an attempt to give what they feel are socially desirable responses, or by trying to game the system to achieve a specific desired result. Kyllonen (2012) cautions that having students self-report may pose some problems, such as faking, but admits that self-reporting is appropriate for placement in higher education. In this context, the evidence about faking is especially surprising. Findings from this research study suggest that in general, students are honest, but that those who are not honest may adjust their answers erratically. This erratic behavior would make sense if a large number of questions were reverse-coded, but only eleven questions were-which is certainly not enough to explain why participants would have been both increasing and decreasing their answers. While there were limitations to the findings due to differences in questions between the treatment and control group ${ }^{15}$, responses between the groups were similar enough that the researcher felt comfortable analyzing them in terms of faking.

There is evidence that susceptibility to stereotype threat may increase the likelihood of faking. This relationship was more erratic within the control group. Participants susceptible to stereotype threat for Ethnic Identity were more likely to increase their answers regardless of framing. Participants susceptible to Ethnic and

15 The treatment group was asked if they "increased their answers for fear of being placed to low" and if they "decreased their answers for fear of being placed too high", whereas the control group was simply asked if they increased or decreased their answers. See Chapter 3 for more details. 
Gender Identities who were given low stakes framing answered erratically: participants with Low SST were more likely to decrease answers, and Disengaged and High SST were prone to both increasing and decreasing answers, with increasing being slightly more likely. These in turn suggests that the relationships observed between the stereotype threat identities and the noncognitive variables may be artifacts of faking.

\section{Implications for Policy}

Community colleges have been considering using noncognitive variables as part of the assessment and placement process. While noncognitive variables may seem like benign questions, the results from this study suggest that many of them may be sensitive to personal, and perhaps unrelated, factors. Moreover, there is evidence that biographical and background information could be used in place of noncognitive scales. Taking together, the findings from this study and the existing literature suggest that noncognitive variables may not be appropriate for use in assessment and placement. In particular, there are seven noncognitive scales that are problematic and should not be used: Academic Self Efficacy, College Identity, Teamwork, Mindfulness-Observing, Grit, Hope-Agency, and Mindset.

For any tool used for assessment or placement, it is common practice to check for disproportionate impacts, but this step is often limited to data such as ethnicity, gender, and age. Findings from this study suggest that disproportionate impacts and 
biases should also be checked with regard to household income, educational background, and having already taken the assessment process or taken a placement test. This study suggests that even seemingly-benign questions that are unrelated to coursework can have a negative impact on students. Institutions should be thoughtful and deliberate about when they survey students, and how they preface the questions. In the interest of transparency and equity, when giving students a survey, best practices suggest that students be informed of how their responses will be used, especially they will be used for high stakes decisions, including assessment and placement.

Finally, there is strong evidence to suggest that assessment and placement has a negative impact for some students, both before and after the process is completed. Moreover, spring and fall applicants feel differently about assessment and placement, so care should be taken to make the process as friendly as possible. Indeed, separate processes may be in order. Regardless, these findings suggest that institutions should be conscientious about how they approach students about assessment and placement and about what resources are offered before and after students go through the process. 


\section{References}

Academy for College Excellence [ACE]. (2014). Evidence of success. Author.

Adler, S., \& Aronczyk, A. (Producers). (2017). Radiolab. [Audio podcast, November 23]. Retrieved from http://www.radiolab.org/story/stereothreat/.

American Mathematics Association of Two-Year Colleges. (2013). Position on initial placement. Memphis, TN: Author.

American Mathematics Association of Two-Year Colleges Developmental Mathematics Committee. (2013). The appropriate use of intermediate algebra as a prerequisite course. Memphis, TN: Author.

Bahr, P. R., Hayward, C., Hetts, J. J., Lamoree, D., Newell, M., Pellegrin, N., ... Willett, T. (2014). Multiple measures for assessment and placement white paper. Sacramento, CA: Research and Planning Group for California Community Colleges.

Bailey, T. (2009). Challenge and opportunity: Rethinking the role and function of developmental education in community college. New Directions for Community Colleges, 2009(145), 11-30. https://doi.org/10.1002/cc.352

Bailey, T., Jaggars, S. S., \& Jenkins, D. (2015). Redesigning America's community colleges: A clearer path to student success. Cambridge, MA: Harvard University Press.

Bailey, T., Jeong, D. W., \& Cho, S.-W. (2010). Referral, enrollment, and completion in 
developmental education sequences in community colleges. Economics of Education Review, 29(2), 255-270.

https://doi.org/10.1016/j.econedurev.2009.09.002

Baron, R. M.. \& Kenny, D. A. (1986). The Moderator-Mediator Variable Distinction in Social The Moderator-Mediator Variable Distinction in Social Psychological Research: Conceptual, Strategic, and Statistical Considerations. Journal of Personality and Social Psychology, 5](6), 1173-1182. https://doi.org/10.1037/0022-3514.51.6.1173

Belfield, C. R. (2014). Improving assessment and placement at your college: A tool for institutional researchers. Community College Research Center, Teachers College, Columbia University.

Belfield, C. R., \& Crosta, P. M. (2012). Predicting success in college: The importance of placement tests and high school transcripts. (CCRC Working Paper No. 42).

Booth, K., Bracco, K. R., Chaplot, P., \& Lagunoff, R. (2014). Interim environmental scan report to the common assessment initiative steering committee. Oakland, CA: WestEd in partnership with Cal-PASS Plus in association with Butte-Glenn Community College District and San Joaquin Delta College.

Bowen, W. G., Chingos, M. M., \& McPherson, M. S. (2009). Crossing the finish line: Completing college at America's public universities. Princeton. NJ: Princeton University Press. 
Boylan, H. R. (2009). Targeted intervention for developmental education students (T.I.D.E.S.). Journal of Developmental Education, 32(3), 14-23.

Bracco, K. R., Dadgar, M., Austin, K., Klarin, B., Broek, M., Finkelstein, N., ... Bugler, D. (2014). Exploring the use of multiple measures for placement into college-level courses: Seeking alternatives or improvements to the use of a single standardized test. San Francisco, CA: WestEd. Retrieved from http://www.wested.org/ resources/core-to-college-evaluation-exploring-the-use-of-multiple-measures-forplacement-into-college-level-courses/

Burdman, P. (2012). Where to begin? The evolving role of placement exams for students starting college. Retrieved from http://www.jff.org/sites/default/files/publications/ ATD_WhereToBegin 050213.pdf

Burdman, P. (2015a). Degrees of freedom: Diversifying math requirements for college readiness and graduation (Report 1 of a 3-part series). Sacramento, CA: Policy Analysis for California Education. Retrieved from http://www.edpolicyinca.org/ publications/degrees-freedom-probing-math-placement-policies-californiacolleges-and-universities-report-3-3-part-series 
Burdman, P. (2015b). Degrees of freedom: Probing math placement policies at California colleges and universities (Report 3 of a 3-part series). Sacramento, CA: Policy Analysis for California Education. Retrieved from www.edpolicyinca.org/ publications/degrees-freedom-probing-math-placement-policies-californiacolleges-and-universities-report-3-3-part-series

Byrd, K. L., \& MacDonald, G. (2005). Defining college readiness from the inside out: First-generation college student perspectives. Community College Review, 33(1), 22-37. https://doi.org/10.1177/009155210503300102

California Code of Regulations, Title $5 \$ 53200$ (1994). California State Legislature. Retrieved from https://govt.westlaw.com/calregs/Document/ I6EED7180D48411DEBC02831C6D6C108E?viewType=FullText\&originationCo ntext $=$ documenttoc $\&$ transitionType $=$ CategoryPageItem $\&$ contextData $=(s c$. Default $)$ California Community College Chancellor's Office [CCCCO]. (2015). California community colleges key facts. Author.

California Community Colleges Chancellor's Office [CCCCO]. (2014a). California community colleges student success and support program (3SP) handbook. Author.

California Community Colleges Chancellor's Office [CCCCO]. (2014b). Firstgeneration students in the California community college system. 
Carter, N. T., Williamson, R. L., Guan, A. L., Shaikh, S., Benson, M., Davidson, A., ... Viran, R. (2014). The unfolding five factor model inventory (UFFM-I): A free-touse, unfolding hierarchical measure of personality. Athens, GA: University of Georgia.

Center for K-12 Advancement and Performance Management at ETS. (2010). A fresh start: Creating the next generation of assessment systems. Princeton, NJ: Educational Testing Service (ETS). Retrieved from www.ncbi.nlm.nih.gov/pubmed/23909171

Cobb, G. W. (2008). Introduction to design and analysis of experiments. Wiley. https://doi.org/10.1198/000313001300339978

Cohen, J. (1988). Statistical power analysis for the behavioral sciences. Hillsdale, New Jersey: L. Erlbaum Associates. https://doi.org/10.1234/12345678

Community College Research Center [CCRC]. (2013). Frequently asked questions about C'CRC's assessment validity studies.

Conley, D. T. (2007). Redefining college readiness. Eugene, OR: Educational Policy Improvement Center. https://doi.org/10.1002/he.321

Conley, D. T. (2011). Redefining college readiness. Eugene, OR: Educational Policy Improvement Center. https://doi.org/10.1002/he.321

Creswell, J. W., \& Plano Clark, V. L. (2010). Designing and conducting mixed methods research (2nd ed.). Thousand Oaks, CA: SAGE Publications. 
Day, L., Hanson, K., Maltby, J., Proctor, C., \& Wood, A. (2010). Hope uniquely predicts objective academic achievement above intelligence, personality, and previous academic achievement. Journal of Research in Personality, 44, 550-553. https://doi.org/10.1016/j.jrp.2010.05.009

Duckworth, A. L. (2016). Research. Retrieved May 14, 2016, from http://angeladuckworth.com/research/

Duckworth, A. L., Peterson, C., Matthews, M. D., \& Kelly, D. R. (2007). Grit: perseverance and passion for long-term goals. Journal of Personality and Social Psychology, 92(6), 1087-1101. https://doi.org/10.1037/0022-3514.92.6.1087

Duckworth, A. L., \& Yeager, D. S. (2015). Measurement matters: Assessing personal qualities other than cognitive ability for educational purposes. Educational Researcher, 44(4), 237-251. https://doi.org/10.3102/0013189X15584327

Dweck, C. S. (1986). Motivational Processes Affecting Learning. American Psychologist, 4I(10), 1040-1048.

Farr, B., Rotermund, S., Radwin, D., Robles, J., \& Choy, S. (2014). Evaluation of the Academy for College Excellence: Report on implementation and student outcomes. Berkeley, CA: Research Triangle Institute International. 
Farrington, C. A., Roderick, M., Allensworth, E., Nagaoka, J., Keyes, T. S., Johnson, D. W., \& Beechum, N. O. (2012). Teaching adolescents to become learners. The role of noncognitive factors in shaping school performance: A critical literature review. Chicago, IL: University of Chicago Consortium on Chicago School Research.

Fay, M. P., Bickerstaff, S., \& Hordara, M. (2013). Why student do not prepare for math placement exams: Student perspectives. (CCRC Research Brief No. 57). New York, NY: Columbia University, Teachers College, Community College Research Center. https://doi.org/10.1016/S2213-8587(14)70039-7

Fields, R., \& Parsad, B. (2012). Tests and cut scores used for student placement in postsecondary education: Fall 2011. Washington, DC: National Assessment Governing Board. Retrieved from https://www.nagb.org/content/nagb/assets/ documents/commission/researchandresources/test-and-cut-scores-used-for-studentplacement-in-postsecondary-education-fall-2011.pdf

Flore, P. C., \& Wicherts, J. M. (2015). Does stereotype threat influence performance of girls in stereotyped domains? A meta-analysis. Journal of School Psychology, 53, 25-44. https://doi.org/10.1016/j.jsp.2014.10.002

Fong, K. E., \& Melguizo, T. (2015). Using additional measures to buffer against students' lack of math confidence and improve placement accuracy in developmental math. Manuscript submitted for publication. Rossier School of Education, University of Southern California, Los Angeles, California. 
Fong, K. E., Melguizo, T., \& Prather, G. (2015). Increasing success rates in developmental math: The complementary role of individual and institutional characteristics. Research in Higher Education, 56, 719-749. https://doi.org/10.1007/s11162-015-9368-9

Fraenkel, J. R., Wallen, N. E., \& Huyn, H. H. (2012). How to Design and Evaluate Research in Education (8th ed.). New York, NY: McGraw Hill. https://doi.org/10.1037/032719

Ganley, C. M., Mingle, L. A., Ryan, A. M., Ryan, K., Vasilyeva, M., \& Perry, M. (2013). An examination of stereotype threat effects on girls' mathematics performance. Developmental Psychology, 49(10), 1886-1897. https://doi.org/10.1037/a0031412

Geiser, S. (2015). The growing correlations between race and SAT scores: New findings from California. Research \& Occasional Paper Series, October(CSHE.10.15).

Geiser, S., \& Atkinson, R. C. (2013). Beyond the master plan: The case for restructuring baccalaureate education in California. California Journal of Politics and Policy, 4(1), 67-123. https://doi.org/10.1515/cjpp-2012-0042

Goldrick-Rab, S., Richardson, J., \& Hernandez, A. (2017). Hungry and homeless in college: Results from a national study of basic needs insecurity in higher education. Association of Community College Trustees. 
Grimes-Hillman, M., Holcroft, C., Fulks, J., Lee, D., \& Smith, P. (2014). Multiple measures in assessment: The requirements and challenges of multiple measures in the California community colleges. Sacramento, CA: Academic Senate for California Community Colleges.

Grubb, W. N., \& Gabriner, R. (2013). Basic skills education in community colleges: Inside and outside the classrooms. New York, NY: Routledge.

Guillory, L. (2014). Identifying stereotype threat susceptibility to enhance academic performance for African American undergraduates. Walden University. https://doi.org/10.1111/j.1467-8616.2008.00521.x Malik,

Harris, B. W. (2015). Student success scorecard: 2014 state of the system report. Sacramento, CA: California Community Colleges Chancellor's Office. Retrieved from http://californiacommunitycolleges.cccco.edu/ Portals/0/FlipBooks/2014_StateOfSystem/2014_State_of the_System_FINAL.pdf

Hays, B., Hayward, C., Purnell, R. D., \& Willett, T. (2014). Toward a common assessment for California community colleges. [Presentation slides]. Presentation to the California Assessment Initiative Steering Committee. Sacramento, CA.

Hayward, C. (2011). The transfer velocity project: A Comprehensive look at the transfer function. Journal of Applied Research in the Community College, 18(2), $21-32$ 
Hayward, C., \& Fagioli, L. (2016). Non-cognitive measure at SOCCCD. Unpublished manuscript.

Hayward, C., Nguyen, A., \& Willett, T. (2015, April). Assessment: A renaissance of multiple measures in California. Perspectives, 7-9. Retrieved from http://rpgroup.org/resources/perspectives

Hayward, C., \& Willett, T. (2014). Curricular redesign and gatekeeper completion: A multi-college evaluation of the California acceleration project. Sacramento, CA: Research and Planning Group for California Community Colleges. Retrieved from http://bit.ly/1Ih4cT7

Hayward, C., \& Willett, T. (2016). Opportunities for improving assessment for placement. [Slideshow]. Author: [Presentation slides]. Presentation at the Association for Institutional Research annual forum. New Orleans, LA.

Hayward, C., Willett, T., Hern, K., \& Snell, M. (2014). Scaling up increased student completion: Results and design principles from the California acceleration project. In Strengthening Student Success Conference of the Research and Planning Group of California Community Colleges. Irvine, CA.

Heckman, J. J., \& Kautz, T. (2013). Fostering and measuring skills: Interventions that improve character and cognition. (NBER Working Paper 19656).

https://doi.org/10.1017/CBO9781107415324.004 
Hern, K., \& Snell, M. (2010). Exponential attrition and the promise of acceleration in developmental English and math. In Perspectives. Berkeley, CA: Research and Planning Group for California Community Colleges.

https://doi.org/10.1016/jeconedurev.2009.09.002

Hetts, J. J. (2015a). Research review and resources to help to make your case. Retrieved from http://rpgroup.org/projects/multiple-measures-assessmentproject/presentations

Hetts, J. J. (2015b, April). Multiple measures at multiple colleges: Reimagining student capacity. Perspectives, 2-3. Retrieved from http://rpgroup.org/resources/perspectives

Hetts, J. J., \& Willett, T. (2013). Assessing transcript-based placement. Long Beach, CA: Association of Institutional Research Annual Forum. Retrieved from http://forum.airweb.org/2013/Documents/Presentations/1708_94318854-0d27410b-9e32-41 fc835de98a.pdf

Hiss, W. C., \& Franks, V. W. (2014). Defining Promise: Optional Standardized Testing Policies in American College and University Admissions.

Hodara, M., Smith, S., Melinda, J., \& Karp, M. (2012). Improving developmental education assessment and placement: Lessons from community colleges across the country. (CCRC Working Paper No. 51). 
Hoy, W. K., \& Adams, C. M. (2015). Quantitative research in education: A primer (2nd ed.). Thousand Oaks, CA: SAGE Publications.

Hsu, E., \& Bressoud, D. (2015). Placement and student performance in Calculus I. In D. Bressoud, V. Mesa, \& C. Rasmussen (Eds.), Insights and Recommendations from the MAA National Study of College Calculus (pp. 59-67). San Francisco, CA: MAA Press. Retrieved from https://www.maa.org/programs/faculty-anddepartments/curriculum-development-resources/national-studies-college-calculus

Hughes, K. L., \& Scott-Clayton, J. (2011). Assessing developmental assessment in community colleges. Community College Review, 39(4), 327-351. https://doi.org/10.1177/0091552111426898

Inzlicht, M. (2016). Reckoning with the past. [Blog, February 29]. Retrieved from http://michaelinzlicht.com/getting-better/2016/2/29/reckoning-with-the-past.

Jaggars, S. S., Hodara, M., \& Stacey, G. W. (2013). Designing meaningful developmental reform. Research Overview. New York, NY: Columbia University, Teachers College, Community College Research Center.

Jaggars, S. S., \& Stacey, G. W. (2014). What we know about developmental education outcomes. Columbia University, 'Teachers College, Community College Research Center. 
Jenkins, D., \& Belfield, C. (2014). Can community colleges do more with less? Change: The Magazine of Higher Learning, 46(3), 6-13. https://doi.org/10.1080/00091383.2014.905417

Jusim, L. (2015). Is stereotype threat overcooked, overstated, and oversold? Psychology Today. Retrieved from: https://www.psychologytoday.com/blog/rabblerouser/201512/is-stereotype-threat-overcooked-overstated-and-oversold.

Karp, M. M., \& Bork, R. H. (2014). "They never told me what to expect, so I didn't know what to do": Defining and clarifying the role of a community college student. Teachers College Record, 116(5), 1-40. Retrieved from http://www.tcrecord.org/PrintContent.asp?ContentID=17414

Kaufman, J. C., Agars, M. D., \& Lopez-Wagner, M. C. (2008). The role of personality and motivation in predicting early college academic success in non-traditional students at a Hispanic-serving institution. Learning and Individual Differences, 18, 492-496. https://doi.org/10.1016/j.lindif.2007.11.004

King, P. M., \& Bowman, N. A. (2006). Beyond the big test: Noncognitive assessment in higher education (review). The Journal of Higher Education, 77(6), 1104-1110. https://doi.org/10.1353/jhe.2006.0052 
Komarraju, M., Ramsey, A., \& Rinella, V. (2012). Cognitive and non-cognitive predictors of college readiness and performance: Role of academic discipline. Learning and Individual Differences, 24, 103-109. https://doi.org/doi:10.1016/j.lindif.2012.12.007

Kurlaender, M., \& Larsen, M. F. (2013). K-12 and postsecondary alignment: Racial/ethnic differences in freshmen course-taking and performance at California's community colleges. Education Policy Analysis Archives, 21(16), 124. Retrieved from http://epaa.asu.edu/ojs/article/view/1195

Kyllonen, P. C. (2012). The importance of higher education and the role of noncognitive attributes in college success. Pensamiento Educativo: Revista de Investigación Educacional Latinoamericana, 79(2), 84-100. https://doi.org/10.7764/PEL.49.2.2012.7

Laerd Statistics. (2015). Statistical tutorials and software guides. Retrieved from: https://statistics.laerd.com/.

Lemay, C. A. (1994). The identification and validation of multiple criteria for placement into selected entry-level community college English and mathematics classes. (Doctoral dissertation). Retrieved from ProQuest Dissertation \& Theses. (Order No. 9427217). Retrieved from http://0-search.proquest.com.opac.sfsu.edu/ docview/304188151?accountid=13802 
Lowry, R. (2017). Significance of the difference between two correlation coefficients. Retrieved from: http://vassarstats.net/rdiff.html.

Maloney, E. A., Schaeffer, M. W., \& Beilock, S. L. (2013). Mathematics anxiety and stereotype threat: Shared mechanisms, negative consequences and promising interventions. Research in Mathematics Education, I5(2), 115-128. https://doi.org/10.1080/14794802.2013.797744

McKinsey \& Company. (2009a). Detailed findings on the economic impact of the achievement gap in America's schools. Retrieved from mckinseyonsociety.com/ downloads/reports/Education/detailed_achievement_gap_findings.pdf

McKinsey \& Company. (2009b). The economic impact of the achievement gap in America's schools. Retrieved from http://mckinseyonsociety.com/downloads/ reports/Education/achievement_gap_report.pdf

McKinsey Company. (2009). The Economic Impact of the Achievement Gap in America's Schools. Education Next, 1-23.

Melguizo, T., Bos, J. M., \& Prather, G. (2013). Are community colleges making good placement decisions in thier math trajectories? Los Angeles, CA: The University of Southern California. 
Melguizo, T., Bos, J. M., Prather, G., Kosiewicz, H., Fong, K. E., \& Ngo, F. (2015).

Assessment and placement policies and practices in developmental math: Evidence from experimentation in a large urban community college district in California. Los Angeles, CA: Pullias Center for Higher Education, Rossier School of Education, University of Southern California.

Melguizo, T., Kosiewicz, H., Prather, G., \& Bos, J. (2014). How are community college students assessed and placed in developmental math? Grounding our understanding in reality. The Journal of Higher Education, 85(5), 691-722.

Mery, P. M. (2011). A mixed methods study of a statistics pathway for community college students placed into developmental mathematics. San Francisco, CA. Monaghan, D. B., \& Attewell, P. (2014). The Community College Route to the Bachelor's Degree. Educational Evaluation and Policy Analysis, 37(1), 70-91. https://doi.org/10.3102/0162373714521865

Myers, S. A. (2012). Community college counseling, student education plans, and educational outcomes: A quantitative analysis. San Francisco State University.

Nasim, A., Roberts, A., Harrell, J. P., \& Young, H. (2005). Non-cognitive predictors of academic achievement for African Americans across cultural contexts. Journal of Negro Education, 74(4), 344-358. Retrieved from http://www.jstor.org/stable/40026734 
National Center for Education Statistics. (2016). The Condition of Education 2016. Author. https://doi.org/10.1037/e492172006-019

National Center for Public Policy and Higher Education and The Southern Regional Education Board [NCPPHE \& SREB]. (2010). Beyond the rhetoric: Improving college readiness through coherent state policy. Higher Education. Retrieved from http:/highereducation.org/reports/college_readiness/index.shtml

Ngo, F., Kwon, W., Melguizo, T., Prather, G., \& Bos, J. M. (n.d.). Course placement in developmental mathematics: Do multiple measures work?

Ngo, F., \& Kwon, W. W. (2014). Using multiple measures to make math placement decisions: Implications for access and success in community colleges. Research in Higher Education, 56(5), 442-470. https://doi.org/10.1007/s11162-014-9352-9

Ngo, F., \& Melguizo, T. (2015). How can placement policy improve math remediation outcomes? Evidence from experimentation in community colleges. Educational Evaluation and Policy Analysis, 38(1), 171-196. https://doi.org/10.3102/0162373715603504

Oakes, J. (1985). The search for equity. In Keeping track: How schools structure inequality (1st ed.). New Haven, CT: Yale University Press.

Parsad, B., Lewis, L., \& Greene, B. (2003). Remedial education at postsecondary institutions in fall 2000. Washington, DC. Retrieved from http://nces.ed.gov/pubs2004/2004010.pdf 
Perry, M., Bahr, P. R., Rosin, M., \& Woodward, K. M. (2010). Course-taking patterns, policies, and practices in developmental education in the California community colleges. Mountain View, CA: EdSource.

Picho, K. (2011): Stereotype Threat in Context: The psychosocial experience of Stereotype Threat susceptible urban high school girls in honors mathematics classes. ProQuest Dissertations and Theses. University of Connecticut. Retrieved from proquest: http://search.proquest.com/docview/915016934?accountid=13802

Picho, K., \& Brown, S. W. (2009). Social Identity Attitudes Scale (SIAS).

Picho, K., \& Brown, S. W. (2011). Can stereotype threat be measured? A validation of the social identities and attitudes scale (SIAS). Journal of Advanced Academics, $22(3), 374-411$.

Porchea, S. F., Allen, J., Robbins, S., \& Phelps, R. P. (2010). Predictors of long-term enrollment and degree outcomes for community college students: Integrating academic, psychosocial, socio-demographic, and situational factors. The Journal of Higher Education, 8I(6), 750-778. Retrieved from muse.jhu.edu.jpllnet.sfsu.edu/ journals/journal_of_higher_education/v081/81.6.porchea.html 
Regional Educational Lab (REL) West at WestEd. (2011). 1.2.110 Types of multiple measures used in California community college mathematics, English, and English as a second language course placement: Summary report of survey results. San Francisco, CA: WestEd. Retrieved from http://extranet.cccco.edu/Portals/1/SSSP/ Matriculation/Assessment/CCCCOMultipleMeasureSurveyReport2011.pdf Research and Planning Group for California Community Colleges [R.P. Group]. (n.d.). Multiple measures assessment project: Non-cognitive variables criteria scales. Research and Planning Group for California Community Colleges [R.P. Group]. (2015a). Multiple measures assessment project: Menu of socialpsychological/noncognitive scales for MMAP pilot testing in 2015. https://doi.org/10.1017/CBO9781107415324.004

Research and Planning Group for California Community Colleges [R.P. Group]. (2015b). Multiple measures assessment project and non cognitive variables updates (Presentation to the Common Assesssment Initiative steering committee). [Slideshow]. Author.

Research and Planning Group for California Community Colleges [RP Group]. (2015). Multiple measures assessment project: Non cognitive variable - implementation guide. Sacramento, CA: Research and Planning Group for California Community Colleges. https://doi.org/10.1017/CBO9781107415324.004 
Sackett, P. R., Hardison, C. M., \& Cullen, M. J. (2004). "On interpreting stereotype threat as accounting for African American-White differences on cognitive tests": Clarification. American Psychologist, 59(3), 189-189. https://doi.org/10.1037/h0087868

Safran, S., \& Visher, M. G. (2010). Case studies of three community colleges the policy and practice of assessing and placing students in developmental education courses. Education. (An NCPR Working Paper). Retrieved from http://www.mdrc.org/sites/default/files/full_54.pdf

Schmitt, N., Billington, A., Keeney, J., Reeder, M., Pleskac, T. J., Sinha, R., \& Zorzie, M. (2011). Development and validation of measures of noncognitive college student potential. (Research Report 2011-1): The College Board. Retrieved from https://research.collegeboard.org/sites/default/files/publications/2012/7/researchrep ort-2011-1-validation-measures-noncognitive-college-student-potential.pdf Scott-Clayton, J. (2012). Do high-stakes placement exams predict college success? (CCRC Working Paper No. 41).

Scott-Clayton, J., Crosta, P. M., \& Belfield, C. R. (2014). Improving the targeting of treatment: Evidence from college remediation. Educational Evaluation and Policy Analysis, 36(3), 371-393. https://doi.org/10.3102/0162373713517935 
Scott-Clayton, J., \& Stacey, G. W. (2015). Improving the accuracy of remedial placement. New York, NY: Columbia University, Teachers College, Community College Research Center.

Sedlacek, W. E. (2011). Using noncognitive variables in assessing readiness for higher education. Readings on Equal Education, 25, 187-205.

Sinha, R., Oswald, F., Imus, A., \& Schmitt, N. (2011). Criterion-focused approach to reducing adverse impact in college admissions. Applied Measurement in Education, 24(2), 137-161. https://doi.org/10.1080/08957347.2011.554605

Skinner, E. (2012). Basic skills accountability: Supplement to the ARCC report. Sacramento, CA: California Community College Chancellor's Office.

Smith, L. V., \& Cokley, K. (2016). Stereotype threat vulnerability: A psychometric investigation of the Social Identities and Attitudes Scale. Measurement Evaluation in Counseling Development, 49(2), 145-162.

https://doi.org/10.1177/0748175615625752

Snyder, C. R. (n.d.). Adult hope scale. Retrieved from https://ppc.sas.upenn.edu/resources/questionnaires-researchers/adult-hope-scale Snyder, C. R., Harris, C., Anderson, J. R., Holleran, S. A., Irving, L. M., Sigmon, S. T., ... Harney, P. (1991). The will and the ways: Development and validation of an individual-differences measure of hope. Journal of Sersonality and Social Psychology, 60(4), 570-585. https://doi.org/10.1037/0022-3514.60.4.570 
Steele, C. M. (1997). A threat in the air: How stereotypes shape intellectual identity and performance. American Psychologist, 52(6), 613-629.

Steele, C. M., \& Aronson, J. (1995). Stereotype threat and the intellectual test performance of African Americans. Journal of Personality and Social Psychology, 69(5), 797-811. https://doi.org/10.1037/0022-3514.69.5.797

Steele, C. M., Spencer, S. J., \& Aronson, J. (2002). Contending with group image: The psychology of stereotype and identity threat. In M. P. Zanna (Ed.), Advances in Experimental Social Psychology (Vol. 34, pp. 379-440). San Diego, CA:

Academic Press. https://doi.org/10.1016/S0065-2601(02)80009-0

Stoet, G., \& Geary, D. C. (2012). Can stereotype threat explain the gender gap in mathematics performance and achievement? Review of General Psychology, 16(1), 93-102. https://doi.org/10.1037/a0026617

Stoup, G. (2017). 4CD Research Briefs. Martinez, CA.

Student Services and Special Programs Division of the California Community College Chancellor's Office [CCCCO]. (2011). California community colleges matriculation program handbook. Retrieved from http://extranet.cccco.edu/Portals/ 1/SSSP/Matriculation/MatriculationHandbookRevSeptember2011.pdf

Thomas, L. L., Kuncel, N. R., \& Credé, M. (2007). Noncognitive variables in college admissions: The case of the non-cognitive questionnaire. Educational and Psychological Measurement, 67(4), 635-657. 
Times Wire Services. (1991, June 4). Latinos settle dispute with 2-year colleges. Retrieved from http://articles.latimes.com/1991-06-04/news/mn-210_1_californiacommunity-colleges

Ting, S. R., \& Sedlacek, W. E. (n.d.). Validity of the Noncognitive QuestionnaireRevised 2 in Predicting the Academic Success of University Freshmen. Research Report \# 1-00. Retrieved from http://williamsedlacek.info/publications.html

Tough, P. (2012). How children succeed: Grit, curiosity, and the hidden power of character. New York, NY: Houghton Mifflin Harcourt.

Tracey, T. J., \& Sedlacek, W. E. (1987). Prediction of college graduation using noncognitive variables by race. Measurement Evaluation in Counseling Development, 19(4), 177-184. Retrieved from http://files.eric.ed.gov/fulltext/ED271513.pdf

Venezia, A., Bracco, K. R., \& Nodine, T. (2010). One-shot deal? Students' perceptions of assessment and course placement in California's community colleges. San Francisco, CA: WestEd.

Walton, G. M., \& Spencer, S. J. (2009). Latent ability: Grades and test scores systematically underestimate the intellectual ability of negatively stereotyped students. Psychological Science, 20(9), 1132-1139. https://doi.org/10.1111/j.14679280.2009.02417.x 
Willett, T. (2013). Student transcript-enhanced placement study (STEPS): Technical report. Sacramento, CA: Research and Planning Group for California Community Colleges.

Willett, T., Hayward, C., \& Dahlstrom, E. (2008). An early alert system for remediation needs of entering community college students: Leveraging the California standards test. California Partnership for Achieving Student Success. Retrieved from www.pathwaylibrary.org/ViewBiblio.aspx?aid=18554

Willett, T., Hayward, C., Nguyen, A., Newell, M., Bahr, P., Hetts, J. J., ... Duran, D. (2015). Multiple measures assessment project (MMAP) spring 2015 technical report. Sacramento, CA: Research and Planning Group for California Community Colleges.

Wiseley, W. C. (2009). Effectiveness of contextual approaches to developmental math in California community colleges. (Unpublished doctoral dissertation). University of the Pacific, Stockton CA.

Wong, R. K. (2014). Factors promoting the adoption of acceleration among community college mathematics faculty. San Francisco State University, San Francisco, CA.

Wyner, J. S. (2014). What excellent community colleges do: Preparing all students for success. Cambridge, MA: Harvard Education Press.

Yeager, D. S., \& Walton, G. M. (2011). Social-psychological interventions in education: They're not magic. Review of Educational Research, 81(2), 267-301. 


\section{Appendix A}

\section{Data Tables}

Table A1.

Pilot-Participant Background ${ }^{a}$

\begin{tabular}{|c|c|c|c|}
\hline Item & $\begin{array}{c}\text { Combined } \\
\mathrm{N}=141\end{array}$ & $\begin{array}{c}\text { Treatment } \\
\mathrm{n}=78\end{array}$ & $\begin{array}{c}\text { Control } \\
n=63\end{array}$ \\
\hline \multicolumn{4}{|l|}{ Biographical Background } \\
\hline Female & $70 \%$ & $72 \%$ & $67 \%$ \\
\hline $18-24$ years old & $48 \%$ & $51 \%$ & $45 \%$ \\
\hline $40+$ years old & $23 \%$ & $19 \%$ & $27 \%$ \\
\hline Underrepresented Minority $^{b}$ & $39 \%$ & $45 \%$ & $32 \%$ \\
\hline Non-Underrepresented Minority ${ }^{c}$ & $43 \%$ & $41 \%$ & $44 \%$ \\
\hline \multicolumn{4}{|l|}{ Household Background } \\
\hline Parent(s) have no higher ed. experience & $24 \%$ & $26 \%$ & $22 \%$ \\
\hline Parent(s) holds Bachelor's Degree or higher & $41 \%$ & $39 \%$ & $44 \%$ \\
\hline Lower or Lower Middle Class & $33 \%$ & $37 \%$ & $29 \%$ \\
\hline Middle Class & $45 \%$ & $47 \%$ & $41 \%$ \\
\hline \multicolumn{4}{|l|}{ Educational Background } \\
\hline Attended High School & $98 \%$ & $96 \%$ & $100 \%$ \\
\hline Attended a California High School ${ }^{d}$ & $79 \%$ & $74 \%$ & $86 \%$ \\
\hline High School GPA 3.0 to $4.0^{d}$ & $68 \%$ & $65 \%$ & $72 \%$ \\
\hline Previous College Experience & $70 \%$ & $68 \%$ & $73 \%$ \\
\hline College GPA 3.0 to $4.0^{\mathrm{d}}$ & $74 \%$ & $67 \%$ & $82 \%$ \\
\hline Last math Class within last 2 years & $43 \%$ & $47 \%$ & $37 \%$ \\
\hline Last math class $5+$ years ago & $40 \%$ & $35 \%$ & $48 \%$ \\
\hline \multicolumn{4}{|l|}{ District-Level Data } \\
\hline Applied to Diablo Valley College & $71 \%$ & $64 \%$ & $79 \%$ \\
\hline Taken Assessment Test(s) & $57 \%$ & $58 \%$ & $57 \%$ \\
\hline
\end{tabular}

Notes. ${ }^{\text {a. }}$ Percentages have been rounded and are based on the total number of participants except where noted; ${ }^{b}$ Black, Latina/o, Pacific Islander, Filipina/o, or Native American; ${ }^{c}$. White or Other Asian; ${ }^{d}$ Percentage is based on the number of people responding to the question. 
Table A2.

Pilot-T-Test of Participant Background by Study Group

\begin{tabular}{lccccc}
\hline \multirow{2}{*}{ Variable } & \multicolumn{3}{c}{ Test Assumptions } & t & \multirow{2}{*}{ df } \\
\cline { 2 - 4 } & Outliers $^{\mathrm{a}}$ & Normal $^{\mathrm{b}}$ & Homog. & Statistic & \\
\hline High School GPA & Yes & No & Yes & $-2.667^{* *}$ & 125 \\
College GPA & Yes & No & Yes & $-3.382^{* *}$ & 90 \\
Age & No & No & Yes & -1.220 & 139 \\
Parent's Education & No & No & Yes & -0663 & 128 \\
Family Income & Yes & No & Yes & $-1.993^{*}$ & 130 \\
\hline
\end{tabular}

Notes. ${ }^{\text {a }}$ Determined by visual inspection of boxplots. ${ }^{\text {b. Normal distribution }}$ determined by Shapiro-Wilk, $p>0.05 .{ }^{c}$ Homogeneity of variances determined by Levene's, $\mathrm{p}>0.05$.

${ }^{*} p<0.05,{ }^{* *} p<0.01,{ }^{* * *} p<0.001$ (2-tailed).

Table A3.

T-Test of Participant Background by Study Group

\begin{tabular}{|c|c|c|c|c|c|}
\hline \multirow{2}{*}{ Variable } & \multicolumn{3}{|c|}{ Test Assumptions } & \multirow{2}{*}{ Statistic $^{d}$} & \multirow{2}{*}{$d f$} \\
\hline & Outliers $^{a}$ & Normal ${ }^{b}$ & Homog. ${ }^{c}$ & & \\
\hline High School GPA & Yes & No & No & $-3.875^{* * *}$ & 115.698 \\
\hline College GPA & Yes & No & Yes & -1.903 & 50 \\
\hline Years Since Math & No & No & Yes & -0.067 & 149 \\
\hline Age & No & No & Yes & -0.495 & 149 \\
\hline Parent's Education & No & No & Yes & -1.026 & 141 \\
\hline Family Income & No & No & Yes & -0.050 & 142 \\
\hline
\end{tabular}

Notes. ${ }^{\text {a }}$ Determined by visual inspection of boxplots. ${ }^{b}$ Normal distribution determined with Shapiro-Wilk, $p>0.05$. ${ }^{c}$ Homogeneity of variances determined by Levene's, $p>0.05 .{ }^{d}$ If assumption of homogeneity met, $t$ statistic is given, else Welch's $\mathrm{t}$ is given. ${ }^{* * *} \mathrm{p}<0.001$ (2-tailed). 
Table A4.

T-Test of Noncognitive Variables across Study Group

\begin{tabular}{|c|c|c|c|c|c|}
\hline \multirow{2}{*}{ Variable } & \multicolumn{3}{|c|}{ Test Assumptions } & \multirow{2}{*}{$\begin{array}{c}\mathrm{t} \\
\text { Statistic }\end{array}$} & \multirow{2}{*}{$\mathrm{df}$} \\
\hline & Outliers $^{\text {a }}$ & Normal $^{b}$ & Homog. ${ }^{c}$ & & \\
\hline ASE & No & Yes & Yes & $-2.003^{*}$ & 153 \\
\hline College Identity & Yes & No & Yes & -0.261 & 153 \\
\hline Teamwork & No & No & Yes & $-2.304^{*}$ & 153 \\
\hline Interact-Comb & No & Yes & Yes & -1.132 & 153 \\
\hline Interact-Comm & Yes & No & Yes & -0.769 & 151 \\
\hline Interact-Choice & Yes & No & Yes & -0.690 & 151 \\
\hline Mindf D & No & Yes & Yes & 0.55 & 153 \\
\hline Mindf Obs & Yes & Yes & Yes & -1.435 & 152 \\
\hline Grit & No & Yes & Yes & -0.518 & 153 \\
\hline Hope-Comb & Yes & No & Yes & $-2.271^{*}$ & 146 \\
\hline Hope-Path & No & Yes & Yes & -1.059 & 153 \\
\hline Hope-Agency & Yes & No & Yes & $-2.037^{*}$ & 148 \\
\hline Consc & No & Yes & Yes & -1.257 & 153 \\
\hline Mindset & No & No & Yes & -0.475 & 153 \\
\hline
\end{tabular}

Notes. ${ }^{a}$. Determined by visual inspection of boxplots. ${ }^{b}$ Normal distribution determined with Shapiro-Wilk, $p>0.05$. ${ }^{c}$ Homogeneity of variances determined by Levene's, $p>0.05$. " $p<0.05$ (2-tailed).

Table A5.

Correlations Between Noncognitive Variables and Study Group

\begin{tabular}{lccccc}
\hline \multirow{2}{*}{ Variable } & \multicolumn{2}{c}{ Controlling for High School GPA } & \multicolumn{2}{c}{ Controlling for Study Group } \\
\cline { 2 - 5 } & \multicolumn{2}{c}{ Study Group } & \multicolumn{2}{c}{ High School GPA } \\
& $\mathrm{r}$ & $\mathrm{p}$ & $\mathrm{r}$ & $\mathrm{p}$ \\
\hline $\mathrm{ASE}$ & -.114 & .170 & $.279^{* *}$ & .001 \\
Teamwork & -.148 & .414 & .013 & .881 \\
Hope-Comb & -.143 & .572 & .125 & .134 \\
Hope-Agency & -.159 & .562 & $.220^{* *}$ & .008 \\
\hline Notes. ${ }^{* *}$ p $<0.01$ (2-tailed). & & &
\end{tabular}


Table A6.

ANCOVA of Noncognitive Variables by Study Group With Covariate High School GPA

\begin{tabular}{|c|c|c|c|c|c|c|c|c|}
\hline \multirow{2}{*}{ Variable } & \multicolumn{5}{|c|}{ Assumptions ${ }^{\text {a }}$} & \multirow{2}{*}{$\begin{array}{c}\text { F Statistic } \\
\text { (HS GPA) }\end{array}$} & \multirow{2}{*}{$\begin{array}{l}\text { F Statistic } \\
\text { (study group) }\end{array}$} & \multirow{2}{*}{$\mathrm{df}$} \\
\hline & Reg. ${ }^{\prime}$ & Norm. ${ }^{c}$ & Homo. $^{d}$ & Var. $^{\mathrm{e}}$ & Out. ${ }^{r}$ & & & \\
\hline $\mathrm{ASE}$ & Yes & Yes & Yes & Yes & Yes & $12.614^{* *}$ & 2.775 & 1,142 \\
\hline Teamwork & Yes & No & Yes & Yes & Yes & .048 & 2.312 & 1,142 \\
\hline Hope-Comb & Yes & No & Yes & Yes & Yes & 1.740 & 2.209 & 1,142 \\
\hline Hope-Agency & Yes & No & Yes & Yes & Yes & $8.984^{* *}$ & 1.968 & 1,141 \\
\hline
\end{tabular}

Notes. ${ }^{\text {a }}$ All items met assumption of linearity, determined by visual inspection of scatterplots. ${ }^{b}$. Homogeneity of regression determined by slopes of study group*HSGPA, $p>0.05{ }^{c}$. Normality determined by within-group residuals, Shapiro-Wilk $p>0.05$. ${ }^{\mathrm{d}}$ Homoscedasticity determined by visual inspection of scatterplots. ${ }^{c}$. Homogeneity of variance determined by Levene's Test for equality of error variances, $p>0.05 .{ }^{\text {f }}$ Outliers determined by standardized residuals. ${ }^{\mathrm{g} .}$ Moderator statistic. ${ }^{\text {h. }}$ After adjustment for moderator. ${ }^{* *} p<0.01$ (2-tailed).

Table A7.

Two-Way ANOVA of Study Group and High School GPA Across Noncognitive Variables

\begin{tabular}{|c|c|c|c|c|c|c|}
\hline \multirow{2}{*}{ Variable } & \multicolumn{3}{|c|}{ Test Assumptions } & \multirow{2}{*}{$\begin{array}{c}\mathrm{F} \\
\text { Statistic }\end{array}$} & \multirow{2}{*}{$d f$} & \multirow{2}{*}{$\begin{array}{l}\text { Signiticant } \\
\text { Simple } \\
\text { Main Effect }\end{array}$} \\
\hline & Outliers $^{\text {a }}$ & Normal $^{b}$ & Homog. ${ }^{c}$ & & & \\
\hline ASE & Yes (12) & Yes & Yes & 1.265 & 4,136 & Yes \\
\hline Teamwork & Yes (4) & No & No & $3.222^{*}$ & 4,136 & Yes \\
\hline Hope-Comb & Yes (5) & No & Yes & .369 & 4,136 & No \\
\hline Hope-Agency & Yes (5) & No & Yes & .326 & 4,136 & No \\
\hline
\end{tabular}

Notes. ${ }^{\text {a }}$ Determined by visual inspection of boxplots of residuals; outliers were not removed. ${ }^{b}$. Normal distribution determined by Shapiro-Wilk, $p>0.05 .{ }^{c}$ Homogeneity of variances determined by Levene's, $p>0.05$. " $p<0.05$ (2-tailed). 
Table A8.

Two-Way ANOVA of Study Group and Institution Across Noncognitive Variables

\begin{tabular}{|c|c|c|c|c|c|c|}
\hline \multirow{2}{*}{ Variable } & \multicolumn{3}{|c|}{ Test Assumptions } & \multirow{2}{*}{$\begin{array}{c}F \\
\text { Statistic }\end{array}$} & \multirow{2}{*}{$\mathrm{df}$} & \multirow{2}{*}{$\begin{array}{c}\text { Significant } \\
\text { Simple Main } \\
\text { Effect } \\
\end{array}$} \\
\hline & Outliers ${ }^{a}$ & Normal ${ }^{b}$ & Homog. & & & \\
\hline $\mathrm{ASE}$ & Yes & No & Yes & .919 & 2,134 & No \\
\hline Teamwork & Yes & No & Yes & .577 & 2,137 & Yes \\
\hline Hope-Comb & Yes & No & Yes & .379 & 2,138 & Yes \\
\hline Hope-Agency & Yes & No & Yes & .615 & 2,139 & Yes \\
\hline
\end{tabular}

Notes. ${ }^{a}$ Determined by visual inspection of boxplots of residuals; outliers were removed for

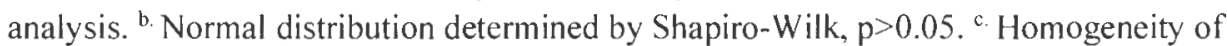
variances determined by Levene's, $\mathrm{p}>0.05$.

Table A9.

Two-Way ANOVA of Study Group and Ethnicity Across Noncognitive Variables

\begin{tabular}{|c|c|c|c|c|c|c|}
\hline \multirow[b]{2}{*}{ Variable } & \multicolumn{3}{|c|}{ Test Assumptions } & \multirow{2}{*}{$\begin{array}{c}\mathrm{F} \\
\text { Statistic }\end{array}$} & \multirow[b]{2}{*}{$d f$} & \multirow{2}{*}{$\begin{array}{c}\text { Significant } \\
\text { Simple Main } \\
\text { Effect }\end{array}$} \\
\hline & Outliers ${ }^{a}$ & Normal $^{b}$ & Homog. ${ }^{c}$ & & & \\
\hline ASE & Yes & Yes & Yes & .470 & 2,134 & No \\
\hline Teamwork & Yes & Yes & Yes & .331 & 2,141 & No \\
\hline Hope-Comb & Yes & No & No & .582 & 2,135 & No \\
\hline Hope-Agency & Yes & No & No & 1.104 & 2,134 & Yes \\
\hline
\end{tabular}

Notes. ${ }^{2}$. Determined by visual inspection of boxplots of residuals; outliers were removed for

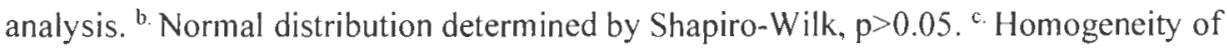
variances determined by Levene's, $\mathrm{p}>0.05$. 
Table A 10

T-Test of Noncognitive Variables by Taken Assessment Test

\begin{tabular}{|c|c|c|c|c|c|}
\hline \multirow{2}{*}{ Variable } & \multicolumn{3}{|c|}{ Test Assumptions } & \multirow{2}{*}{ t Statistic } & \multirow{2}{*}{$d f$} \\
\hline & Outliers ${ }^{a}$ & Normal ${ }^{b}$ & Homog. & & \\
\hline $\mathrm{ASE}$ & No & Yes & Yes & -0.556 & 153 \\
\hline College Identity & Yes & No & Yes & $1.981^{*}$ & 148 \\
\hline Team & Yes & No & Yes & 0.686 & 152 \\
\hline Interact-Comb & Yes & No & Yes & 0.347 & 149 \\
\hline Interact-Comm & Yes & No & Yes & -0.508 & I 49 \\
\hline Interact-Choice & Yes & No & Yes & 0.155 & 149 \\
\hline Mindf D & Yes & No & Yes & -1.134 & 144 \\
\hline Mindf Obs & No & No & Yes & .0468 & 153 \\
\hline Grit & No & Yes & Yes & -0.593 & 153 \\
\hline Hope-Comb & Yes & No & Yes & -0.842 & 149 \\
\hline Hope-Path & Yes & No & Yes & .294 & 150 \\
\hline Hope-Agency & No & No & Yes & -0.754 & 153 \\
\hline Consc & Yes & Yes & Yes & 0.505 & I51 \\
\hline Mindset & No & Yes & Yes & 1.040 & I53 \\
\hline
\end{tabular}

Notes. ${ }^{\text {a. }}$ Determined by visual inspection of boxplots. ${ }^{b}$. Normal distribution determined by Shapiro-Wilk, $p>0.05$. ' Homogeneity of variances determined by Levene's, $p>0.05$. ${ }^{*} p<0.05$ (2-tailed).

Table Al1.

ANOVA of College Identity, Assessment Test, and Confounding Variables

\begin{tabular}{|c|c|c|c|c|c|c|}
\hline \multirow{2}{*}{$\begin{array}{l}\text { Confounding } \\
\text { Variable }\end{array}$} & \multicolumn{3}{|c|}{ Test Assumptions } & \multirow{2}{*}{$\begin{array}{c}F \\
\text { Statistic }\end{array}$} & \multirow{2}{*}{$\mathrm{df}$} & \multirow{2}{*}{$\begin{array}{c}\text { Significant } \\
\text { Simple Main } \\
\text { Effect }\end{array}$} \\
\hline & Outliers $^{a}$ & Normal $^{b}$ & Homog. & & & \\
\hline Ethnic Group & Yes & No & Yes & .217 & 2,139 & No \\
\hline Institution & Yes & Yes & Yes & 2.099 & 2,135 & No \\
\hline
\end{tabular}

Notes. ${ }^{2}$ Determined by visual inspection of boxplots of residuals; outliers were removed for analysis. $\quad$ b. Normal distribution determined by Shapiro-Wilk, $p>0.05$. ${ }^{c}$ Homogeneity of variances determined by Levene's, $\mathrm{p}>0.05$. 
Table A 12.

One-Way ANOVA of Noncognitive Variables by Study Group \& Assessment Test

\begin{tabular}{|c|c|c|c|c|c|}
\hline \multirow{2}{*}{ Variable } & \multicolumn{3}{|c|}{ Test Assumptions } & \multirow{2}{*}{$\begin{array}{c}\mathrm{F} \\
\text { Statistic }^{\mathrm{d}}\end{array}$} & \multirow{2}{*}{$d f$} \\
\hline & Outliers $^{\mathrm{a}}$ & Normal $^{b}$ & Homog. ${ }^{\mathrm{c}}$ & & \\
\hline ASE. & No & Yes & Yes & 1.627 & 3,151 \\
\hline College Identity & Yes & Yes & Yes & 1.208 & 3,147 \\
\hline Teamwork & Yes & Yes & Yes & $3.280^{*}$ & 3,149 \\
\hline Interact-Comb & Yes & Yes & Yes & 0.410 & 3,148 \\
\hline Interact-Comm & Yes & Yes & Yes & 0.693 & 3,151 \\
\hline Interact-Choice & No & No & Yes & 0.289 & 3,149 \\
\hline Mindf-Distracted & Yes & Yes & No & 0.281 & $3,79.497$ \\
\hline Mindf-Observing & No & Yes & Yes & 0.690 & 3,151 \\
\hline Grit & Yes & Yes & Yes & 0.027 & 3,149 \\
\hline Hope-Comb & Yes & No & Yes & 2.081 & 3,147 \\
\hline Hope-Path & Yes & Yes & No & 1.928 & $3,78.851$ \\
\hline Hope-Agency & Yes & No & Yes & 1.443 & 3,146 \\
\hline Conscientious & Yes & No & Yes & 0.916 & 3,149 \\
\hline Mindset & No & No & Yes & 1.329 & 3,151 \\
\hline
\end{tabular}

Table A13,

ANOVA of Teamwork, Assessment Test, \& Confounding Variables

\begin{tabular}{|c|c|c|c|c|c|c|}
\hline \multirow{2}{*}{ Variable } & \multicolumn{3}{|c|}{ Test Assumptions } & \multirow{2}{*}{$\begin{array}{c}\mathrm{F} \\
\text { Statistic }\end{array}$} & \multirow{2}{*}{$\mathrm{df}$} & \multirow{2}{*}{$\begin{array}{l}\text { Significant } \\
\text { Simple } \\
\text { Main Effect }\end{array}$} \\
\hline & Outliers $^{a}$ & Normal $^{b}$ & Homog. ${ }^{\mathrm{c}}$ & & & \\
\hline Ethnicity & Yes & No & Yes & .840 & 6,135 & No \\
\hline Institution & Yes & No & Yes & .726 & 6,135 & Yes \\
\hline
\end{tabular}

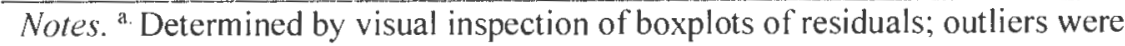
removed for analysis. ${ }^{b}$ Normal distribution determined by Shapiro-Wilk, $p>0.05{ }^{c}$. Homogeneity of variances determined by Levene's, $p>0.05$. 
Table A 14.

One-Way ANOVA of SST Math Identity Across Noncognitive Variables

\begin{tabular}{|c|c|c|c|c|c|}
\hline \multirow{2}{*}{ Variable } & \multicolumn{3}{|c|}{ Test Assumptions } & \multirow{2}{*}{$\begin{array}{c}F \\
\text { Statistic }^{d}\end{array}$} & \multirow{2}{*}{$d f$} \\
\hline & Outliers ${ }^{\mathrm{a}}$ & Normal $^{b}$ & Homog. ${ }^{c}$ & & \\
\hline ASE & Yes & Yes & Yes & 1.336 & 2,151 \\
\hline College Identity & Yes & No & Yes & $5.669^{* *}$ & 2,150 \\
\hline Team & Yes & No & Yes & 1.192 & 2,150 \\
\hline Interact-Comb & Yes & No & Yes & .361 & 2,149 \\
\hline Interact-Comm & Yes & No & No & 2.936 & $2,65.658$ \\
\hline Interact-Choice & Yes & No & Yes & 1.793 & 2,148 \\
\hline Mindf Distracted & Yes & Yes & No & 2.406 & $2,52.631$ \\
\hline Mindf Observing & No & Yes & Yes & .507 & 2,152 \\
\hline Grit & No & Yes & Yes & 2.449 & 2,152 \\
\hline Hope-Comb & Yes & No & No & 2.780 & $2,55.300$ \\
\hline Hope-Path & Yes & No & Yes & 2.607 & 2,151 \\
\hline Hope-Agency & Yes & No & No & $9.995^{* * *}$ & $2,62.209$ \\
\hline Conscientiousness & No & Yes & Yes & 2.205 & 2,152 \\
\hline Mindset & No & No & Yes & $4.771^{*}$ & 2,152 \\
\hline
\end{tabular}

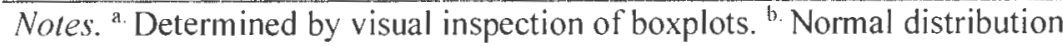
determined by Shapiro-Wilk, $p>0.05{ }^{c}{ }^{c}$ Homogeneity of variances determined by Levene's, $p>0.05$. ${ }^{d}$ If assumption of homogeneity met, $F$ statistic is given, else Welch's $F$ is given. ${ }^{*} p<0.05,{ }^{* *} p<0.01,{ }^{* * *} p<0.001$. 
Table A15.

Two-Way ANOVA of Noncognitive Variables, Math Identity, and Confounding Variables

\begin{tabular}{ccccccc}
\hline Variable & \multicolumn{3}{c}{ Test Assumptions } & F & df & $\begin{array}{c}\text { Significant } \\
\text { Simple } \\
\text { Main Effect }\end{array}$ \\
\cline { 2 - 3 } $\begin{array}{c}\text { Ethnicity } \\
\text { College Identity }\end{array}$ & Yes & No & Yes & .917 & 4,138 & No \\
Hope-Agency & Yes & No & No & 2.395 & 4,134 & Yes \\
$\begin{array}{c}\text { Mindset } \\
\text { Institution }\end{array}$ & Yes & No & Yes & .691 & 4,136 & Yes \\
$\begin{array}{c}\text { College Identity } \\
\text { Hope-Agency }\end{array}$ & No & No & Yes & .591 & 4,139 & No \\
Mindset & Yes & No & No & 1.547 & 4,132 & No \\
\hline
\end{tabular}

Notes. ${ }^{a}$ Determined by visual inspection of boxplots of residuals; outliers were removed for analysis. ${ }^{b}$ Normal distribution determined by Shapiro-Wilk, $p>0.05 .{ }^{c}$. Homogeneity of variances determined by Levene's, $p>0.05$.

Table A16.

One-Way ANOVA of SST Ethnic Identity Across Noncognitive Variables

\begin{tabular}{|c|c|c|c|c|c|}
\hline \multirow{2}{*}{ Variable } & \multicolumn{3}{|c|}{ Test Assumptions } & \multirow{2}{*}{$\begin{array}{c}F \\
\text { Statistic }^{\mathrm{d}}\end{array}$} & \multirow{2}{*}{$d f$} \\
\hline & Outliers $^{\mathrm{a}}$ & Normal $^{b}$ & Homog. & & \\
\hline$\overline{A S E}$ & Yes & Yes & Yes & 0.142 & 2,149 \\
\hline College Identity & Yes & No & No & $16.791^{* * *}$ & $2,48.072$ \\
\hline Teamwork & Yes & No & Yes & 0.281 & 2,151 \\
\hline Interact-Comb & Yes & No & Yes & 0.252 & 2,150 \\
\hline Interact-Comm & Yes & No & Yes & 1.734 & 2,149 \\
\hline Interact-Choice & Yes & No & Yes & 0.359 & 2,150 \\
\hline Mindf Distracted & Yes & Yes & No & 2.067 & $2,40.233$ \\
\hline Mindf Observing & Yes & Yes & Yes & $3.353^{*}$ & 2,150 \\
\hline Grit & No & Yes & No & 2.331 & $2,41.498$ \\
\hline Hope-Comb & Yes & No & Yes & 1.311 & 2,150 \\
\hline Hope-Path & Yes & No & Yes & 2.015 & 2,149 \\
\hline Hope-Agency & Yes & No & No & $7.264^{* *}$ & $2,45.829$ \\
\hline Conscientiousness & Yes & No & No & 0.472 & $2,41.049$ \\
\hline Mindset & No & No & Yes & 2.010 & 2,152 \\
\hline
\end{tabular}

Notes. ${ }^{a}$. Determined by visual inspection of boxplots. ${ }^{6}$ Normal distribution determined by Shapiro-Wilk, $p>0.05$. ${ }^{c}$ Homogeneity of variances determined by Levene's, $p>0.05$.

d. If assumption of homogeneity met, $F$ statistic is given, else Welch's $F$ is given.

" $\mathrm{p}<0.05,{ }^{* *} \mathrm{p}<0.01,{ }^{* * *} \mathrm{p}<0.001$. 
Table A 17.

Two-Way ANOVA of Noncognitive Variables, Ethnic Identity, and Confounding Variables

\begin{tabular}{|c|c|c|c|c|c|c|}
\hline \multirow{2}{*}{ Variable } & \multicolumn{3}{|c|}{ Test Assumptions } & \multirow{2}{*}{$\begin{array}{c}\mathrm{F} \\
\text { Statistic }\end{array}$} & \multirow{2}{*}{$\mathrm{df}$} & \multirow{2}{*}{$\begin{array}{l}\text { Significant } \\
\text { Simple } \\
\text { Main Effect }\end{array}$} \\
\hline & Outliers $^{\mathrm{a}}$ & Normal ${ }^{b}$ & Homog. ${ }^{c}$ & & & \\
\hline \multicolumn{7}{|l|}{ Ethnicity } \\
\hline College Identity & Yes & No & No & 2.117 & 4,138 & Yes \\
\hline Mindf-Observing & No & Yes & Yes & 1.260 & 4,139 & Yes \\
\hline Hope-Agency & Yes & No & Yes & 1.520 & 4,135 & No \\
\hline \multicolumn{7}{|l|}{ Institution } \\
\hline College Identity & Yes & No & Yes & 1.523 & 4,133 & Yes \\
\hline Mindf-Observing & No & No & No & 2.293 & 4,139 & Yes \\
\hline Hope-Agency & Yes & No & Yes & 1.161 & 4,136 & No \\
\hline
\end{tabular}

Notes. ${ }^{a}$. Determined by visual inspection of boxplots of residuals; outliers were removed for

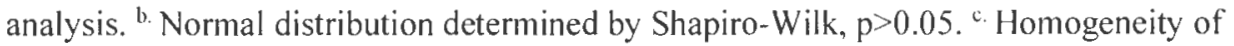
variances determined by Levene's, $p>0.05$.

Table A 18.

ANOVA of SST Gender Identity Across Noncognitive Variables

\begin{tabular}{|c|c|c|c|c|c|}
\hline \multirow{2}{*}{ Variable } & \multicolumn{3}{|c|}{ Test Assumptions } & \multirow{2}{*}{$\begin{array}{c}\mathrm{F} \\
\text { Statistic }^{\mathrm{d}} \\
\end{array}$} & \multirow{2}{*}{$\mathrm{df}$} \\
\hline & Outliers ${ }^{a}$ & Normal $^{b}$ & Homog. ${ }^{c}$ & & \\
\hline $\mathrm{ASE}$ & Yes & Yes & Yes & 1.013 & 2,147 \\
\hline College Identity & Yes & No & No & $17.498^{* * *}$ & $2,55.134$ \\
\hline Teamwork & Yes & No & Yes & .894 & 2,150 \\
\hline Interact-Comb & Yes & No & Yes & .521 & 2,149 \\
\hline Interact-Comm & Yes & No & Yes & 1.662 & 2,150 \\
\hline Interact-Choice & Yes & No & Yes & 1.235 & 2,150 \\
\hline Mindf Distracted & Yes & Yes & Yes & 1.772 & 2,149 \\
\hline Mindf Observing & No & Yes & Yes & .258 & 2,152 \\
\hline Grit & Yes & Yes & Yes & $6.644^{* *}$ & 2,150 \\
\hline Hope-Comb & Yes & No & Yes & .844 & 2,149 \\
\hline Hope-Path & Yes & No & Yes & .544 & 2,150 \\
\hline Hope-Agency & Yes & No & Yes & 1.355 & 2,149 \\
\hline Conscientiousness & No & Yes & Yes & 2.487 & 2,152 \\
\hline Mindset & No & No & Yes & .066 & 2,152 \\
\hline
\end{tabular}


Table A 19.

Two-Way ANOVA of Noncognitive Variables, SST Gender, and Confounding Variables

\begin{tabular}{|c|c|c|c|c|c|c|}
\hline \multirow{2}{*}{ Variable } & \multicolumn{3}{|c|}{ Test Assumptions } & \multirow{2}{*}{$\begin{array}{c}\text { F } \\
\text { Statistic }\end{array}$} & \multirow{2}{*}{$\mathrm{df}$} & \multirow{2}{*}{$\begin{array}{l}\text { Significant } \\
\text { Simple } \\
\text { Main Effect }\end{array}$} \\
\hline & Outliers ${ }^{a}$ & Normal ${ }^{b}$ & Homog. ${ }^{c}$ & & & \\
\hline \multicolumn{7}{|l|}{ Ethnicity } \\
\hline College Identity & Yes & No & No & .232 & 3,134 & Yes \\
\hline Grit & No & Yes & Yes & 1.911 & 3,140 & Yes \\
\hline \multicolumn{7}{|l|}{ Institution } \\
\hline College Identity & Yes & No & Yes & .110 & 4,137 & Yes \\
\hline Grit & Yes & Yes & Yes & 1.558 & 4,134 & Yes \\
\hline
\end{tabular}

Notes. ${ }^{\text {a. }}$ Determined by visual inspection of boxplots of residuals; outliers were removed for analysis. ${ }^{b}$ Normal distribution determined by Shapiro-Wilk, $p>0.05 .{ }^{c}$. Homogeneity of variances determined by Levene's, $\mathrm{p}>0.05$.

Table A20.

Independent Samples t-Test of SST by Study Group

\begin{tabular}{lccccc}
\hline \multirow{2}{*}{ Variable } & \multicolumn{3}{c}{ Assumptions $^{\mathrm{t}}$} & df \\
\cline { 2 - 5 } & Outliers $^{\mathrm{a}}$ & Normal $^{\mathrm{b}}$ & Homog. $^{\mathrm{c}}$ & Statistic $^{\mathrm{d}}$ & No \\
\hline SST Math Identity & No & No & Yes & -1.765 & 153 \\
SST Ethnic Identity & No & No & Yes & -1.247 & 153 \\
SST Gender Identity & Yes & No & No & $-5.910^{* * *}$ & 76.000 \\
\hline
\end{tabular}

Notes. ${ }^{\text {a. }}$ Determined by visual inspection of boxplots. ${ }^{b}$ etermined by Shapiro-Wilk, $\mathrm{p}>0.05{ }^{c}{ }^{c}$ Homogeneity of variances determined by Levene's, $p>0.05 .{ }^{d}$. If assumption of homogeneity met, $t$ statistic is given, else Welch's $t$ is given. ${ }^{* * *} p<0.001$. 
Table A21.

ANCOVA of Noncognitive Variables by Study Group with Covariate SST Math Identity

\begin{tabular}{|c|c|c|c|c|c|c|c|c|}
\hline \multirow[b]{2}{*}{ Variable } & \multicolumn{5}{|c|}{ Assumptions ${ }^{a}$} & \multirow{2}{*}{$\begin{array}{c}\text { F } \\
\text { Statistic }^{\mathrm{g}} \\
\text { (SST Math) }^{\text {SST }}\end{array}$} & \multirow{2}{*}{$\begin{array}{c}\text { F } \\
\text { Statistic }^{\text {h }} \\
\text { (Study group) } \\
\end{array}$} & \multirow[b]{2}{*}{$\mathrm{df}$} \\
\hline & Reg." & Norm. ${ }^{c}$ & Hom. ${ }^{d}$ & Var. ${ }^{e}$ & Out. ${ }^{\mathrm{r}}$ & & & \\
\hline $\mathrm{ASE}$ & No & - & - & - & - & - & - & - \\
\hline College Identity & Yes & No & Yes & Yes & No & $9.013^{* *}$ & .025 & 1,152 \\
\hline Teamwork & Yes & Yes & Yes & Yes & Yes & - & - & - \\
\hline Interact-Comb & Yes & No & Yes & Yes & Yes & 1.344 & .450 & 1,151 \\
\hline Interact-Comm & Yes & No & Yes & Yes & Yes & .918 & .718 & 1,151 \\
\hline Interact-Choice & Yes & No & Yes & Yes & Yes & .579 & .329 & 1,150 \\
\hline Mindf Distracted & Yes & No & Yes & Yes & No & .007 & .004 & 1,152 \\
\hline Mindf Observing & Yes & Yes & Yes & Yes & No & .666 & 1.253 & 1,152 \\
\hline Grit & Yes & Yes & Yes & Yes & No & 1.252 & .124 & 1,152 \\
\hline Hope-Comb & Yes & No & Yes & Yes & Yes & 2.773 & 2.267 & 1,151 \\
\hline Hope-Path & Yes & No & Yes & Yes & Yes & 3.504 & .232 & 1,151 \\
\hline Hope-Agency & Yes & No & Yes & Yes & Yes & 2.640 & 2.573 & 1,150 \\
\hline Conscientiousness & No & - & - & - & - & - & - & - \\
\hline Mindset & Yes & Yes & Yes & Yes & No & 3.590 & .043 & 1,152 \\
\hline
\end{tabular}

Notes. ${ }^{\text {a }}$ All items met assumption of linearity, as determined by visual inspection of scatterplots.

b. Homogeneity of regression determined by slopes of study group*SST Math $p>0.05$. ${ }^{\text {c }}$

Normality determined by within-group residuals, Shapiro-Wilk $\mathrm{p}>0.05 .{ }^{\text {d. }}$ Homoscedasticity determined by visual inspection of scatterplots. ${ }^{c}$ Homogeneity of variance determined by Levene's, $p>0.05 .{ }^{f}$ Outliers determined by standardized residuals, and were removed for

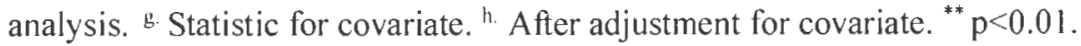


Table A22.

ANCOVA of Noncognitive Variables by Study Group with Covariate SST Ethnic Identity

\begin{tabular}{|c|c|c|c|c|c|c|c|c|}
\hline \multirow{2}{*}{ Variable } & \multicolumn{5}{|c|}{ Assumptions ${ }^{a}$} & \multirow{2}{*}{$\begin{array}{c}\mathbf{F} \\
\text { Statistic's } \\
\text { (SST Ethnic) }\end{array}$} & \multirow{2}{*}{$\begin{array}{c}\mathrm{F} \\
\text { Statistic }^{\mathrm{h}} \\
\text { (study group) }\end{array}$} & \multirow{2}{*}{$\mathrm{df}$} \\
\hline & Reg. ${ }^{b}$ & Norm. ${ }^{\mathrm{c}}$ & Homo. $^{d}$ & Var. $^{e}$ & Out. $^{f}$ & & & \\
\hline ASE & Yes & Yes & Yes & Yes & No & .001 & $3.960^{\circ}$ & 1,152 \\
\hline College Identity & Yes & Yes & Yes & Yes & No & $20.475^{* * *}$ & .032 & 1,152 \\
\hline Teamwork & Yes & No & Yes & Yes & Yes & - & - & - \\
\hline Interact-Comb & Yes & No & Yes & Yes & Yes & .657 & .567 & 1,151 \\
\hline Interact-Comm & Yes & No & Yes & Yes & Yes & 2.183 & .715 & 1,151 \\
\hline Interact-Choice & Yes & No & Yes & Yes & Yes & .045 & .443 & 1,150 \\
\hline Mindf Distracted & Yes & Yes & Yes & Yes & No & .168 & .009 & 1,152 \\
\hline Mindf Observing & Yes & Yes & Yes & Yes & No & .038 & 1.485 & 1,152 \\
\hline Grit & Yes & Yes & Yes & Yes & No & .990 & .173 & 1,152 \\
\hline Hope-Comb & Yes & No & Yes & Yes & Yes & .474 & 2.758 & 1,151 \\
\hline Hope-Path & Yes & No & Yes & Yes & Yes & .898 & .413 & 1,151 \\
\hline Hope-Agency & No & - & - & - & - & - & - & - \\
\hline Conscientiousness & Yes & Yes & Yes & Yes & No & 1.729 & 1.257 & 1,152 \\
\hline Mindset & Yes & No & Yes & Yes & No & .926 & .141 & 1,152 \\
\hline
\end{tabular}

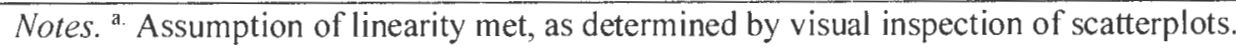

${ }^{b}$ Homogeneity of regression determined by slopes of study group*SST Ethnic $p>0.05 .{ }^{c}$. Normality determined by within-group residuals, Shapiro-Wilk $p>0.05$. ${ }^{\mathrm{d}}$. Homoscedasticity determined by visual inspection of scatterplots. ${ }^{e}$. Homogeneity of variance determined by Levene's, $p>0.05$. ${ }^{f}$ Outliers determined by standardized residuals. ${ }^{\mathrm{g}}$. Statistic for covariate. ${ }^{\mathrm{h}}$ After adjustment for covariate. " $\mathrm{p}<0.05,{ }^{* * *} \mathrm{p}<0.001$. 
Table A23.

ANCOVA of Noncognitive Variables by Study Group with Covariate SST Gender Identity

\begin{tabular}{|c|c|c|c|c|c|c|c|c|}
\hline \multirow{2}{*}{ Variable } & \multicolumn{5}{|c|}{ Assumptions ${ }^{a}$} & \multirow{2}{*}{$\begin{array}{c}\mathrm{F} \\
\text { Statistic" } \\
\text { (SST Gender) }\end{array}$} & \multirow{2}{*}{$\begin{array}{c}\mathrm{F} \\
\text { Statistich } \\
\text { (study group) }\end{array}$} & \multirow{2}{*}{$\mathrm{df}$} \\
\hline & Reg.' & Norm. ${ }^{c}$ & Homo. ${ }^{d}$ & Var. ${ }^{e}$ & Out. ${ }^{f}$ & & & \\
\hline $\mathrm{ASE}$ & Yes & Yes & Yes & Yes & No & .356 & $4.290^{*}$ & 1,152 \\
\hline College Identity & Yes & No & Yes & Yes & No & $16.826^{* * *}$ & .181 & 1,152 \\
\hline Teamwork & Yes & No & Yes & Yes & Yes & .592 & 3.594 & 1,151 \\
\hline Interact-Comb & Yes & No & Yes & Yes & Yes & .496 & .496 & 1,151 \\
\hline Interact-Comm & Yes & No & Yes & Yes & Yes & 1.387 & .606 & 1,151 \\
\hline Interact-Choice & Yes & No & Yes & Yes & Yes & .017 & .489 & 1,150 \\
\hline Mindf Distracted & Yes & Yes & Yes & Yes & No & .332 & .023 & 1,152 \\
\hline Mindf Observing & Yes & Yes & Yes & Yes & No & .261 & 1.302 & 1,152 \\
\hline Grit & Yes & Yes & Yes & Yes & No & .088 & .313 & 1,152 \\
\hline Hope-Comb & Yes & No & Yes & Yes & Yes & .274 & 3.030 & 1,151 \\
\hline Hope-Path & Yes & No & Yes & Yes & Yes & .007 & .544 & 1,151 \\
\hline Hope-Agency & Yes & No & Yes & Yes & Yes & - & - & - \\
\hline Conscientiousness & Yes & Yes & Yes & Yes & No & .180 & 1.353 & 1,152 \\
\hline Mindset & Yes & No & Yes & Yes & No & .080 & .175 & 1,152 \\
\hline
\end{tabular}

Notes. ${ }^{\text {a }}$ Assumption of linearity met, as determined by visual inspection of scatterplots.

${ }^{b}$. Homogeneity of regression determined by slopes of study group*SST Gender $p>0.05$. ${ }^{\text {c. Normality }}$ determined by within-group residuals, Shapiro-Wilk $p>0.05$. ${ }^{d}$ Homoscedasticity determined by visual inspection of scatterplots. ${ }^{e}$ Homogeneity of variance determined by Levene's, $p>0.05$. ${ }^{f}$ Outliers determined by standardized residuals. ${ }^{\text {B. }}$ Statistic for covariate. ${ }^{\text {h. }}$ After adjustment for covariate. ${ }^{*} p<0.05,{ }^{* * *} p<0.001$.

Table A24.

ANCOVA of Faking by Ethnic Group with Covariate Study Group

\begin{tabular}{|c|c|c|c|c|c|c|c|c|}
\hline \multirow{2}{*}{ Variable } & \multicolumn{5}{|c|}{ Assumptions ${ }^{a}$} & \multirow{2}{*}{$\begin{array}{c}\mathrm{F} \\
\text { Statistic }^{\mathrm{g}} \\
\text { (Study Group) }\end{array}$} & \multirow{2}{*}{$\begin{array}{c}\mathrm{F} \\
\text { Statistich }^{\text {hetich) }} \\
\text { (Ethnic Group) }\end{array}$} & \multirow{2}{*}{$\mathrm{df}$} \\
\hline & Reg. ${ }^{b}$ & Norm. ${ }^{c}$ & Homs. ${ }^{d}$ & $\operatorname{Var}^{\mathrm{e}}$ & Out. ${ }^{f}$ & & & \\
\hline Decreased Answers & Yes & No & Yes & Yes & Yes & 2.221 & 1.118 & 2,129 \\
\hline Increased Answers & Yes & No & Yes & Yes & Yes & 2.515 & 1.710 & 2,126 \\
\hline
\end{tabular}

Notes. ${ }^{\text {a }}$ Both items met assumption of linearity, as determined by visual inspection of scatterplots. ${ }^{b}$ Homogeneity of regression determined by slopes of study group*ethnic rouping, $p>0.05$. ${ }^{\text {c. Normality }}$ determined by within-group residuals, Shapiro-Wilk $p>0.05$. Homoscedasticity determined by visual inspection of scatterplots. ${ }^{e}$ Homogeneity of variance determined by Levene's, $p>0.05$. ${ }^{\text {f }}$ Outliers determined by standardized residuals. ${ }^{*}$. Statistic for covariate. " ${ }^{\text {". }}$ After adjustment for covariate. 
Table A25.

One-Way ANOVA of Faking by Institution

\begin{tabular}{|c|c|c|c|c|c|}
\hline \multirow{2}{*}{ Variable } & \multicolumn{3}{|c|}{ Test Assumptions } & \multirow{2}{*}{$\begin{array}{c}\mathrm{F} \\
\text { Statistic }^{d}\end{array}$} & \multirow{2}{*}{$\mathrm{df}$} \\
\hline & Outliers $^{\mathrm{a}}$ & Normal $^{\mathrm{b}}$ & Homog. & & \\
\hline Decreased Answers & Yes & No & No & 1.793 & $2,44.716$ \\
\hline Increased Answers & Yes & No & No & 1.777 & $2,35.505$ \\
\hline
\end{tabular}

Table A26.

ANCOVA of Faking by Institution with Covariate Study Group

\begin{tabular}{|c|c|c|c|c|c|c|c|c|}
\hline \multirow{2}{*}{ Variable } & \multicolumn{5}{|c|}{ Assumptions ${ }^{\text {a }}$} & \multirow{2}{*}{$\begin{array}{l}\text { F statistic }{ }^{2} \\
\text { (Study Group) }\end{array}$} & \multirow{2}{*}{$\begin{array}{l}\text { F statistic h } \\
\text { (Institution) }\end{array}$} & \multirow{2}{*}{$\mathrm{df}$} \\
\hline & Reg." & Norm. ${ }^{\mathrm{c}}$ & Homs. $^{d}$ & Var. $^{\mathrm{e}}$ & Out. ${ }^{r}$ & & & \\
\hline Decreased Answers & Yes & No & Yes & $\mathrm{No}^{i}$ & Yes & .556 & 1.523 & 2,141 \\
\hline Increased Answers & No & - & - & - & - & - & - & - \\
\hline
\end{tabular}

Notes. ${ }^{a}$ All items met assumption of linearity, as determined by visual inspection of scatterplots. ${ }^{b}$. Homogeneity of regression determined by slopes of study group*institution $p>0.05$. Normality $^{c}$. No determined by within-group residuals, Shapiro-Wilk $p>0.05$.

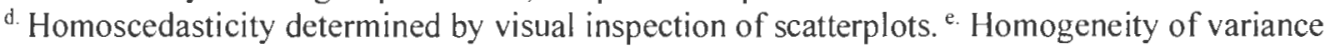
determined by Levene's, $p>0.05$. 'Outliers determined by standardized residuals. ". Statistic for covariate. '. After adjustment for covariate. i. After removal of outliers; test was run anyway, without outliers.

Table A27.

ANCOVA of Faking by Ethnic Group with Covariate Study Group

\begin{tabular}{|c|c|c|c|c|c|c|c|c|}
\hline \multirow[b]{2}{*}{ Variable } & \multicolumn{5}{|c|}{ Assumptions } & \multirow{2}{*}{$\begin{array}{c}\text { F } \\
\text { Statistic }{ }^{\prime} \\
\text { (Study Group) }\end{array}$} & \multirow{2}{*}{$\begin{array}{c}\text { F } \\
\text { Statistic h }^{h} \\
\text { (Ethnic Group) }\end{array}$} & \multirow[b]{2}{*}{$\mathrm{df}$} \\
\hline & Reg. ${ }^{b}$ & Norm. ${ }^{c}$ & Homs. $^{d}$ & Var. $^{e}$ & Out. ${ }^{f}$ & & & \\
\hline Decreased Answers & Yes & No & Yes & No & Yes & .003 & $3.846^{*}$ & 2,143 \\
\hline Increased Answers & Yes & No & Yes & Yes & Yes & .021 & $5.523^{* *}$ & 2,140 \\
\hline
\end{tabular}

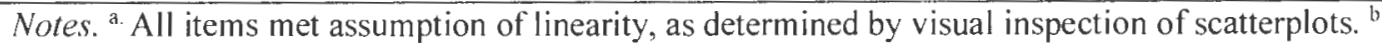
Homogeneity of regression determined by slopes of ethnic group* study group $p>0.05$. ' Normality determined by within-group residuals, Shapiro-Wilk $p>0.05 .{ }^{d}$. Homoscedasticity. determined by visual inspection of scatterplots. ${ }^{e}$ Homogeneity of variance determined by Levene's, $p>0.05$. '. Outliers

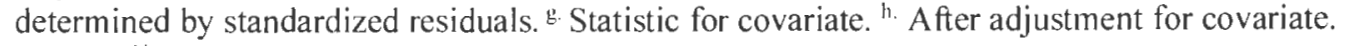
$\mathrm{p}<0.05,{ }^{* *} \mathrm{p}<0.01$. 
Table A28.

Independent Samples t-Test of Faking Across Study Groups

\begin{tabular}{|c|c|c|c|c|c|}
\hline \multirow{2}{*}{ Variable } & \multicolumn{3}{|c|}{ Test Assumptions } & \multirow{2}{*}{ t Statistic ${ }^{d}$} & \multirow{2}{*}{$\mathrm{df}$} \\
\hline & Outliers & Normal $^{b}$ & Homog. ${ }^{c}$ & & \\
\hline Decreased Answers & Yes & No & No & 1.461 & 137.286 \\
\hline Increased Answers & Yes & No & No & 0.778 & 127.654 \\
\hline
\end{tabular}

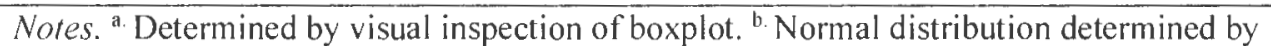
Shapiro-Wilk, $p>0.05$. 'Homogeneity of variances determined by Levene's, $p>0.05$.

${ }^{d}$ Welch's $\mathbf{t}$ statistic is given.

Table A29.

(Control) One-Way ANOVA of Debrief Questions by Ethnicity

\begin{tabular}{|c|c|c|c|c|c|}
\hline \multirow{2}{*}{ Variable } & \multicolumn{3}{|c|}{ Test Assumptions } & \multirow[t]{2}{*}{ F Statistic } & \multirow{2}{*}{$\mathrm{df}$} \\
\hline & Outliers ${ }^{\mathrm{a}}$ & Normal $^{\mathrm{b}}$ & Homog. & & \\
\hline Decreased Answers & Yes & No & Yes & .659 & 2,75 \\
\hline Increased Answers & Yes & No & Yes & .557 & 2,72 \\
\hline
\end{tabular}

Notes. ${ }^{\text {a }}$ Determined by visual inspection of boxplots. ${ }^{b}$ Normal distribution determined by Shapiro-Wilk, $p>0.05$. ${ }^{c}$ Homogeneity of variances determined by Levene's, $p>0.05$.

Table A30.

(Control) One-Way ANOVA of Faking by Institution

\begin{tabular}{|c|c|c|c|c|c|}
\hline \multirow{2}{*}{ Variable } & \multicolumn{3}{|c|}{ Test Assumptions } & \multirow{2}{*}{$\begin{array}{c}F \\
\text { Statistic }^{d}\end{array}$} & \multirow{2}{*}{$\mathrm{df}$} \\
\hline & Outliers $^{\mathrm{a}}$ & Normal $^{b}$ & Homog. ${ }^{\circ}$ & & \\
\hline Decreased Answers & Yes & No & No & $f$ & - \\
\hline Increased Answers & Yes & No & No & 1.655 & $2,16.529$ \\
\hline \multicolumn{6}{|c|}{ 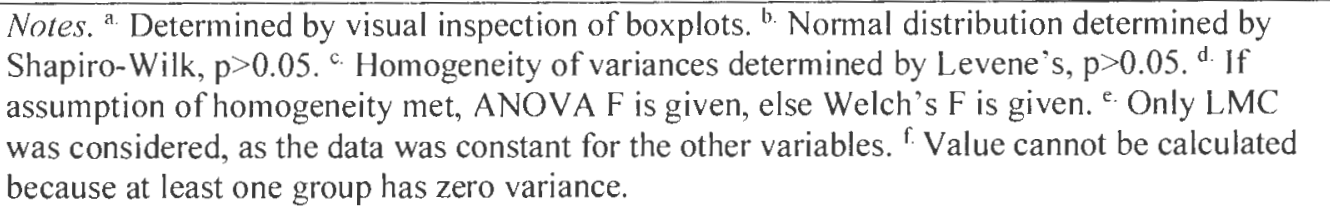 } \\
\hline
\end{tabular}


Table A31.

(Treatment) One-Way ANOVA of Debrief Questions by Institution

\begin{tabular}{lccccc}
\hline \multirow{2}{*}{ Variable } & \multicolumn{3}{c}{ Test Assumptions } & F Statistic & df \\
\cline { 2 - 5 } & Outliers $^{\mathrm{a}}$ & Normal $^{\mathrm{b}}$ & Homog. $^{\mathrm{c}}$ & & \\
\hline Decreased Answers & No & No & Yes & .022 & 2,62 \\
Increased Answers & Yes & No & Yes & .051 & 2,58 \\
\hline
\end{tabular}

Notes. ${ }^{a}$ Determined by visual inspection of boxplots. ${ }^{b}$ Normal distribution determined by Shapiro-Wilk, $p>0.05{ }^{c}$. Homogeneity of variances determined by Levene's, $p>0.05$.

Table A32.

Pilot - Independent Sample t-Test of SST by Study Group

\begin{tabular}{lccccc}
\hline \multirow{2}{*}{ Variable } & \multicolumn{3}{c}{ Test Assumptions } & t Statistic & df \\
\cline { 2 - 5 } & Outliers $^{{ }^{2}}$ & Normal $^{b}$ & Homog. & & \\
\hline SST Math Identity & Yes & No & Yes & 0.137 & 135 \\
SST Ethnic Identity & No & No & Yes & 0.667 & 139 \\
SST Gender Identity & No & No & Yes & -0.046 & 139 \\
\hline
\end{tabular}

Notes. ${ }^{\text {a }}$ Determined by visual inspection of boxplots. ${ }^{b}$ Normal distribution determined with Shapiro-Wilk, $p>0.05$. 'Homogeneity of variances determined by Levene's, $p>0.05$.

Table A33.

(Treatment) Correlations of SST and Faking (Outliers Removed)

\begin{tabular}{lcc}
\hline Variable & Increased Answers & Decreased Answers \\
\hline SST Math Identity & $.434^{* *}$ & $.359^{* *}$ \\
SST Ethnic Identity & $.332^{* *}$ & $.399^{* *}$ \\
SST Gender Identity & $.392^{* *}$ & $.388^{* *}$ \\
\hline Notes. N=70; ${ }^{* *}<0.01$ (2-tailed). &
\end{tabular}


Table A34.

One-way ANOVA of Faking by Stereotype Threat Identities

\begin{tabular}{|c|c|c|c|c|c|}
\hline \multirow{2}{*}{ Variable } & \multicolumn{3}{|c|}{ Test Assumptions } & \multirow{2}{*}{$\begin{array}{c}F \\
\text { Statistic }^{d}\end{array}$} & \multirow{2}{*}{$\mathrm{df}$} \\
\hline & Outliers $^{a}$ & Normal & Homog. ${ }^{\mathrm{c}}$ & & \\
\hline \multicolumn{6}{|l|}{ SST Math Identity } \\
\hline Decreased Answers & Yes & No & Yes & .369 & 2,141 \\
\hline Increased Answers & Yes & No & No & .689 & $2,53.374$ \\
\hline \multicolumn{6}{|l|}{ SST Ethnic Identity } \\
\hline Decreased Answers & Yes & No & No & 1.625 & $2,37.103$ \\
\hline Increased Answers & Yes & No & No & 3.155 & $2,38.269$ \\
\hline \multicolumn{6}{|l|}{ SST Gender Identity } \\
\hline Decreased Answers & Yes & No & Yes & 1.032 & 2,148 \\
\hline Increased Answers & Yes & No & Yes & 1.388 & 2,141 \\
\hline
\end{tabular}

Table A35.

Correlations Between SST and Faking

\begin{tabular}{lcccc}
\hline \multirow{2}{*}{ Variable } & \multicolumn{2}{c}{ Decreased Answers } & \multicolumn{2}{c}{ Increased Answers } \\
& $\begin{array}{c}\text { With } \\
\text { outliers }\end{array}$ & $\begin{array}{c}\text { Without } \\
\text { outliers }\end{array}$ & $\begin{array}{c}\text { With } \\
\text { outliers }^{\mathrm{a}}\end{array}$ & $\begin{array}{c}\text { Without } \\
\text { outliers }^{\mathrm{b}}\end{array}$ \\
\hline SST Math Identity & .130 & .065 & $.191^{*}$ & .071 \\
SST Ethnic Identity & $.239^{* *}$ & .145 & $.231^{* *}$ & $.278^{* *}$ \\
SST Gender Identity & $.175^{*}$ & .096 & .147 & .090 \\
\hline
\end{tabular}

Notes. ${ }^{\mathrm{a}} \mathrm{N}=154 ;{ }^{\mathrm{b}} \mathrm{N}=147 ;{ }^{*} \mathrm{p}<0.05 ;{ }^{* *} \mathrm{p}<0.01$ (2-tailed). 
Table A36.

(Control) ANOVA of Faking by Stereotype Threat Identities

\begin{tabular}{|c|c|c|c|c|c|}
\hline \multirow{2}{*}{ Variable } & \multicolumn{3}{|c|}{ Test Assumptions } & \multirow{2}{*}{$\begin{array}{c}F \\
\text { Statistic }^{d}\end{array}$} & \multirow{2}{*}{$d f$} \\
\hline & Outliers $^{\mathrm{a}}$ & Normal $^{b}$ & Homog. ${ }^{\mathrm{c}}$ & & \\
\hline \multicolumn{6}{|l|}{ SST Math Identity } \\
\hline Decreased Answers & Yes & No & Yes & .424 & 2,73 \\
\hline Increased Answers & Yes & No & Yes & .494 & 2,74 \\
\hline \multicolumn{6}{|l|}{ SST Ethnic Identity } \\
\hline Decreased Answers & Yes & No & No & e & - \\
\hline Increased Answers & Yes & No & No & $3.622^{*}$ & $2,21.395$ \\
\hline \multicolumn{6}{|l|}{ SST Gender Identity } \\
\hline Decreased Answers & Yes & No & No & e & - \\
\hline Increased Answers & Yes & No & No & $3.837^{*}$ & $2,24.518$ \\
\hline
\end{tabular}

Table A37.

(Treatment) ANOVA of Faking by Stereotype Threat Identities

\begin{tabular}{|c|c|c|c|c|c|}
\hline \multirow{2}{*}{ Variable } & \multicolumn{3}{|c|}{ Test Assumptions } & \multirow[t]{2}{*}{ F Statistic $^{d}$} & \multirow[t]{2}{*}{$\mathrm{df}$} \\
\hline & Outliers $^{\mathrm{a}}$ & Normal ${ }^{b}$ & Homog. ${ }^{c}$ & & \\
\hline \multicolumn{6}{|l|}{ SST Math Identity } \\
\hline Decreased Answers & No & No & Yes & .882 & 2,68 \\
\hline Increased Answers & No & No & No & 2.523 & $2,16.500$ \\
\hline \multicolumn{6}{|l|}{ SST Ethnic Identity } \\
\hline Decreased Answers & No & No & Yes & .635 & 2,68 \\
\hline Increased Answers & Yes & No & No & 1.417 & $2,15.691$ \\
\hline \multicolumn{6}{|l|}{ SST Gender Identity } \\
\hline Decreased Answers & No & No & Yes & .018 & 2,68 \\
\hline Increased Answers & Yes & No & Yes & .101 & 2,64 \\
\hline
\end{tabular}


Table A38.

Independent Sample t-Test of Belief of Deception Across Study Groups

\begin{tabular}{|c|c|c|c|c|c|}
\hline \multirow{2}{*}{ Study Version } & \multicolumn{3}{|c|}{ Test Assumptions } & \multirow[t]{2}{*}{ t Statistic $^{d}$} & \multirow[t]{2}{*}{$d f$} \\
\hline & Outliers ${ }^{a}$ & Normal & Homog. ${ }^{c}$ & & \\
\hline Pilot & Yes & No & No & $5.770^{* * *}$ & 73.000 \\
\hline Study, & Yes & No & No & $3.406^{* *}$ & 109.493 \\
\hline
\end{tabular}

Table A38.

Independent Sample t-Test of Belief of Deception Across Assessment Test

\begin{tabular}{|c|c|c|c|c|c|}
\hline \multirow{2}{*}{ Study Version } & \multicolumn{3}{|c|}{ Test Assumptions } & \multirow[t]{2}{*}{ t Statistic ${ }^{d}$} & \multirow[t]{2}{*}{$\mathrm{df}$} \\
\hline & Outliers $^{a}$ & Normal $^{b}$ & Homog. ${ }^{c}$ & & \\
\hline Pilot & Yes & No & No & $-6.277^{* * *}$ & 80.000 \\
\hline Study & Yes & No & No & $-2.587^{*}$ & 119.956 \\
\hline
\end{tabular}

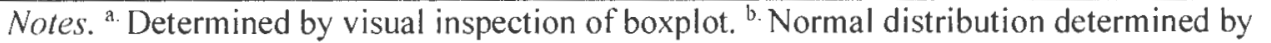
Shapiro-Wilk, $p>0.05 .{ }^{c}{ }^{c}$ Homogeneity of variances determined by Levene's, $p>0.05 .{ }^{d}$ Welch's $t$ statistic is given. ${ }^{* *} \mathrm{p}<0.001$ (2-tailed).

Table A40.

One-way ANOVA of Belief of Deception by Study Group and Assessment Test

\begin{tabular}{|c|c|c|c|c|c|}
\hline \multirow{2}{*}{ Study Version } & \multicolumn{3}{|c|}{ Test Assumptions } & \multirow[t]{2}{*}{ t Statistic ${ }^{d}$} & \multirow[t]{2}{*}{$\mathrm{df}$} \\
\hline & Outliers $^{a}$ & Normal $^{b}$ & Homog. ${ }^{c}$ & & \\
\hline Pilot & Yes & No & No & $23.522^{* * *}$ & 3,119 \\
\hline Study & Yes & No & No & $4.407^{* *}$ & 3,76 \\
\hline
\end{tabular}


Appendix B

Recruitment Text

\section{Subject line}

Graduate student's study - invitation to participate

\section{Body ${ }^{16}$}

Hello, my name is Katrina Keating. I am a mathematics instructor at Diablo Valley College, and am also a doctoral candidate in Educational Leadership at San Francisco State University. I am conducting a research study on community college placement during fall 2017 and spring 2017 semesters. I am writing to invite you to participate in my study because you completed an application to attend a California community college.

The findings from this study will become part of a doctoral dissertation and may be published. Participation in this research is completely voluntary, and your responses will be anonymous and confidential.

Participation includes answering questions about how you feel about college and education. It also includes some questions on your academic and personal background, including some information about your family. The survey should take about 15 minutes to complete, although some participants may finish sooner. You must be 18 years or older to participate.

\footnotetext{
${ }^{16}$ Adapted with permission from Myers (2012).
} 
Your participation in this study is purely voluntary; if you decide not to participate, there will not be any negative consequences whatsoever. You can choose to withdraw from the study at any time.

If you have any questions, please feel free to contact me at keating@mail.sfsu.edu.

This study will be open for participation for the next 14 days. If you are 18 years or older and would like to participate, please click the link below. If clicking the link does not work, please copy and paste the link into your browser.

$[[[\mathrm{LINK}]]]$

Thank you in advance for considering it! 


\section{Appendix C \\ Implied Consent \& Kick-Out Question}

\section{Implied Consent to Participate in Research}

Thank you for your interest in my research!

You have been invited to participate because you completed an application to attend California Community College.

Data collected from this confidential survey will be used for completion of a doctorate in Educational Leadership at San Francisco State University. The information gathered will be used for research exploring ways to improve the California community colleges.

The survey will ask you how you feel about college and education. It also includes some questions on your academic and personal background, and some questions about your family. The survey should take about 15 minutes to complete, although some participants may finish sooner.

You must be 18 years of age or older to participate. There are no risks or benefits to you in participating in this survey. You may choose to participate or not. You may answer only the questions you feel comfortable answering, and you may stop at any time. If you do not wish to participate, you may simply exit the survey, with no penalty to yourself or your standing at the institution you applied to. If you decide to stop the survey, your responses will not be included and will be deleted.

Research designs often require that the full intent of the study not be explained prior to participation. When the study is completed, you will receive a full debriefing on the purpose and the procedures of the research. 
If you elect to participate, completion of the survey indicates your consent to the above conditions. Your decision whether or not to participate in this research will have no influence on your present or future status at San Francisco State University, or the community college you applied to.

Please print this page for your records. Any questions or concerns should be directed to the principal investigator, Katrina Keating, at keating@mail.sfsu.edu, or her research supervisor, Professor Kysh, at ikyshrivisu.cdu.

\section{Kick-Out Question}

Are you 18 years or older?

- Yes

- No

Participants answering "No" will receive the following text:

Thank you for being willing to participate. Unfortunately, you do not qualify for this study. 


\section{Appendix D \\ Instrumentation Part One - Introductory Wording}

\section{Wording for Treatment Group ${ }^{17}$}

Welcome to the Assessment Center's Placement Survey.

Please read the instructions carefully because some of the questions are complicated. This survey will ask you about your thoughts, feelings, and behaviors both in general and at school, and will help the Assessment Center determine what class(es) you should begin in and what coursework you are eligible for. Your individual responses are strictly confidential and will not have any impact on your grades, but the overall results will be reported to Admissions and Records. This placement survey should take about 15 minutes, although some people finish sooner.

\section{Wording for Control Group ${ }^{2}$}

Welcome to the Advancing Student Success Survey.

Please read the instructions carefully because some of the questions are complicated. This survey will ask you about your thoughts, feelings, and behaviors both in general and at school. Your completion of this survey will help to improve instruction. Your participation will not have any impact on your placement or your grades. Your individual responses are strictly confidential, and will not be reported to the college. This survey should take about 15 minutes, although some people finish sooner.

\footnotetext{
${ }^{17}$ Wording adapted with permission from Hayward and Fagioli (2016).
} 


\author{
Appendix E \\ Instrumentation Part Two - Noncognitive Scales
}

\title{
College Student Self-Assessment Survey (CSSAS)
}

\section{Academic Self-Efficacy (ASE)}

1. I know how to study in order to perform well on tests.

2. I know of many strategies I can use to succeed in my classes.

3. I can find a place to study without distractions.

4. I can think of many ways to earn good grades.

5. I can motivate myself to do schoolwork.

6. I am good at doing research.

7. I can study even when there are other things to do.

8. I know how to take notes.

9. I can finish my homework assignments by deadlines.

10. I know how to schedule my time to accomplish my tasks.

11. I can think of specific ways to do well in my classes.

\section{College Identity (Col-Ident)}

1. I think of myself as a "college student".

2. Being a college student is an important reflection of who I am.

3. Being a college student is an important part of my self-image.

\section{Teamwork (Team)}

1. I am able to allow other team members to contribute to the task when leading a team.

2. I am confident of my ability to influence a team I lead.

3. I can provide strong support for other members of any team that I am on.

4. I have confidence in my ability to function as part of a team.

5. I know how to encourage good team performance. 


\section{Interaction - Communication and Choices (Interact)}

1. I am able to change my communication style in order to maintain good communication. (Communication)

2. Other people trust me. (Communication)

3. I know how to think before speaking. (Communication)

4. I am understanding of others and compassionate. (Communication)

5. I am mainly responsible for my future. (Choices)

6. It is my choice whether or not I do well in school. (Choices)

7. I can choose how I feel about things that happen to me. (Choices)

8. I think of the consequences of my actions before doing something. (Choices)

9. I choose how I behave. (Choices)

\section{Mindfulness - Distracted (Mind-D) \& Observing (Mind-O)}

1. I find it difficult to stay focused on what's happening in the present. (Mind-D) $)^{18}$

2. When I do things, my mind wanders off and I'm easily distracted. (Mind-D) ${ }^{18}$

3. I rush through activities without being really attentive to them. (Mind-D) ${ }^{18}$

4. I don't pay attention to what I'm doing because I'm daydreaming, worrying, or otherwise distracted. (Mind-D) ${ }^{18}$

5. I pay attention to whether my muscles are tense or relaxed. (Mind-O)

6. I notice how foods and drinks affect my thoughts, bodily sensations, \& emotions. (Mind-O)

7. I pay attention to how my emotions affect my thoughts and behavior. (Mind-O)

\section{GRIT Scale - Shortened (Grit-S)}

1. New ideas and projects sometimes distract me from previous ones. ${ }^{18}$

2. Setbacks don't discourage me.

3. I have been obsessed with a certain idea or project for a short time but later lost interest. ${ }^{18}$

4. I am a hard worker.

5. I often set a goal but later choose to pursue a different one. ${ }^{18}$

6. I have difficulty maintaining my focus on projects that take more than a few months to complete. ${ }^{18}$

7. I finish whatever I begin.

8. I am diligent.

\footnotetext{
${ }^{18}$ Item is reverse coded.
} 


\section{HOPE Scale (Hope)}

1. I can think of many ways to get out of a jam. (Pathways)

2. I energetically pursue my goals. (Agency)

3. There are lots of ways around any problem. (Pathways)

4. I can think of many ways to get the things in life that are most important to me. (Pathways)

5. Even when others get discouraged, I know I can find a way to solve the problem. (Pathways)

6. My past experiences have prepared me well for my future. (Agency)

7. I've been pretty successful in life. (Agency)

8. I meet the goals that I set for myself. (Agency)

\section{Unfolding Five Factor Model Conscientiousness Scale - Concise (UFFM)}

1. I do not keep my room clean. ${ }^{19}$

2. I tend to do just enough work to get by. ${ }^{19}$

3. I would never jump into doing something without thinking about it.

4. I always go above and beyond what is expected.

5. I am very well organized.

\section{Mindset Scale (Mindset)}

1. You can always substantially change how intelligent you are.

2. Intelligence is something people are born with that can't be changed. ${ }^{19}$

3. The harder you work at something, the better you will be at it.

${ }^{19}$ Item is reverse coded. 


\author{
Appendix F \\ Instrumentation Part Three - Social Identities Attitudes Scale
}

Gender Identity

1. My gender influences how I feel about myself.

2. My gender contributes to my self confidence.

3. My gender is central in defining who I am.

4. My identity is strongly tied to my gender.

\title{
Gender Stigma Consciousness
}

5. My gender affects how people treat me.

6. My gender affects how people act towards me.

7. My gender influences how teachers interpret my behavior.

8. Most people judge me on the basis of my gender.

9. Members of the opposite sex interpret my behavior based on my gender.

\section{Ethnic Identity}

10. I feel a strong attachment to my ethnicity.

11. I value my ethnic background.

12. My ethnicity is an important reflection of who I am.

13. I am connected to my ethnic heritage.

\section{Ethnic Stigma Consciousness}

14. My ethnicity affects how my peers interact with me.

15. My ethnicity influences how teachers interact with me.

16. My ethnicity affects how I interact with people of other ethnicities.

17. Most people judge me on the basis of my ethnicity.

18. People from other ethnic groups interpret my behavior based on my ethnicity. 


\section{Math Identity}

19. Math is important to me.

20. I value math.

21. My math abilities are important to my academic success.

22. Doing well in math matters to me.

23. Being good at math will be useful to me in my future career.

24. Doing well in math is critical to my future success.

\section{Math Stigma Consciousness}

When doing difficult math problems on a test $I$...

25. Experience doubt about my math abilities.

26. Feel like l'm letting myself down.

27. Start to lose confidence in my abilities.

28. Feel like a failure.

29. Feel hopeless.

30. Feel like giving up. 


\section{Appendix G \\ Instrumentation Part Four - Demographic Questionnaire ${ }^{20}$}

The following questions ask about your academic background.

1. Please choose the name of the community college where you applied: [list institutions]

2. Have you taken the placement/assessment test at that college?
a. Yes
b. No
c. Not sure

3. Are you applying to the college with an F1 Visa?
a. Yes
b. No
c. Not sure

4. Are you currently, or have you ever taken any credit-bearing classes at another college or university?
a. Yes
b. No [skip to question 6]
c. Not sure

5. Please approximate your overall grade point average (GPA) at the other college or university.
a. $3.5-4.0(\mathrm{~A} / \mathrm{B}$ average $)$
b. $3.0-3.49$ (B average)
c. $2.5-2.9(\mathrm{~B} / \mathrm{C}$ average $)$
d. $2.0-2.49$ (C average)
e. Less than $2.0(\mathrm{D} / \mathrm{F}$ average $)$
f. I did not finish the course(s)
g. Not sure

${ }^{20}$ Adapted with permission from Myers (2012). 
6. How many years has it been since you have taken a mathematics course?

7. Did you attend High School?
a. Yes
b. No [skip to question 13]

Please answer the following questions about your high school.

8. Please approximate your overall high school grade point average (GPA).
a. $3.5-4.0(\mathrm{~A} / \mathrm{B}$ average $)$
b. $3.0-3.49$ (B average)
c. $2.5-2.9(\mathrm{~B} / \mathrm{C}$ average $)$
d. $2.0-2.49$ (C average)
e. Less than $2.0(\mathrm{D} / \mathrm{F}$ average $)$
f. Don't remember

9. Did you attend high school in the United States?
a. Yes
b. No [skip to Question 13]

10. What is the name of the high school you attended? If you attended more than one high school, please give the name of the school where you spent the most time.

11. What state is that high school in? [list of states]

12. What city/town is that high school in?

The following questions are about you and your family.

13. What is the highest level of education completed by your parents or primary caregiver(s)?
a. Some high school
b. Completed high school or equivalent
c. Some college or some technical/trade school
d. Associates degree or certificate
e. Bachelor's degree
f. Graduate school
g. Not sure 
14. In general, how would you describe your current household income or economic class level?
a. Lower class
b. Lower-middle class
c. Middle class
d. Upper-middle class
e. Upper class
f. Not sure
g. Decline to answer

15. What is your current age?

16. Please select the gender you most identify with:
a. Female
b. Male
c. Neither of the above

17. What race/ethnicity do you most identify with?
a. Latino/a, Hispanic, or Chicano/a
b. Native American
c. Black or African American
d. Southeast Asian
e. South Asian
f. Pacific Islander or Chamorro
g. Filipino American
h. Other Asian American not listed here
i. White, not Hispanic
j. Multi-ethnic or bi-racial
k. Other
1. Decline to answer 


\author{
Appendix $\mathrm{H}$ \\ -Instrumentation Part Five - Debriefing \& Verification
}

\title{
Debrief Wording for Treatment Group
}

Study Debrief for Noncognitive Variables for Placement: A Randomized Control Trial

Thank you for your participation. This study was designed to understand how community college students react to placement tests. In order to do that, I had to initially lead some participants to believe the results would be used to determine what coursework they are eligible for.

Now that the study is complete, I can tell you that you were part of the group who were told this survey would be used in course placement. This was not an official Assessment Center survey. Your responses will not be reported to the college, and your responses will not be used to determine what courses you are eligible for. Your responses will remain strictly confidential.

You can decide whether or not to have your responses included in this research. Neither your decision nor your responses will influence your present or future status at any community college or at San Francisco State University.

The purpose of this study is to help determine if this survey will be used for future community college students.

Now that you know that this survey will not impact you, but may be used to help make placement better for future students, please answer the following questions as they relate to you.

1. When I answered, I thought that my responses would be used for course placement.

2. I was especially concerned about mathematics placement. 
3. I gave lower answers than were true because I was worried about being placed too high.

4. I gave higher answers than were true because I was worried about being placed too low.

Please verify that you understand the purpose of this study by answering the following question.

5. This purpose of this study is to help determine if this survey will be used for future community college students.

a. True

b. False

6. Now that you know that this was a study, do you want your data to be used in the study? If your answer "no" your data will be destroyed.

a. Yes, include my responses in the study

b. No, do not include my responses in the study

The study is now complete! Thank you again for your participation.

\section{Debrief Wording for Control Group}

Study Debrief for Noncognitive Variables for Placement: A Randomized Control Trial

Thank you for your participation. This study was designed to understand how community college students react to placement tests. In order to do that, I had to initially lead some participants to believe the results would be used to determine what coursework they would be eligible for.

Your responses will remain strictly confidential. Your responses will not be reported to the college, and your responses will not be used for course placement. You can decide whether or not to have your responses included in this research. Your decision whether or not to participate in this research will not influence your present or future status at any community colleges or San Francisco State University. 
The purpose of this study is to help determine if this survey will be used for future community college students.

Now that you know the nature of the research, please answer the following questions.

1. When I answered, I was worried that my responses would be used for course placement.

2. I was especially worried that my responses would be used for mathematics placement.

3. I gave lower answers than were true.

4. I gave higher answers than were true.

Please verify that you understand the purpose of this study.

5. This purpose of this study is to help determine if this survey will be used for future community college students.
a. True
b. False

6. Do you still want your data to be used in the study? If your answer "no" your data will be destroyed.

a. Yes, include my responses in the study

b. No, do not include my responses in the study

The study is now complete! Thank you again for your participation. 
Appendix I

Operational Definitions

Completion. Refers to earning a community college degree or transferring to a 4-year institution.

Ethnicity. For the research study, ethnicities were grouped into one of four categories:

- Traditionally Underrepresented Minorities (URM): Black, Latino/a, Pacific Islander, Filipino, and Native Americans $(\mathrm{N}=60)$;

- Non-Underrepresented Minorities (non-URM): White and Other Asians $(\mathrm{N}=62)$;

- Unsure: South Asian, Southeast Asian, Multi- or Bi-Racial, and Other $(\mathrm{N}=26)$;

- Unknown: Participants who declined to answer were not included in the analysis $(\mathrm{N}=7)$.

Faking. A way in which people respond to questions by answering in way that the respondent wants to be seen as true, but is not accurate for them.

Gatekeeper course. Used interchangeably with transfer-level course (see below).

Multiple measures. A method of determining student proficiency that uses more than one factors, including previous courses taken, high school GPA, length of time since their last mathematics course, or performance on an assessment test. In the California community colleges, it generally means an assessment test score in conjunction with something else.

Noncognitive scale. A tool used to measure noncognitive skills. They often take the form of a Likert scale survey. Referred to as NCV scale interchangeably. The scales being proposed for this research are in Table 1. 
Noncognitive skills. The "sets of behaviors, skills, attitudes, and strategies that are crucial to [students'] academic performance in their classes, but that may not be reflected in their scores on cognitive tests" (Farrington et al., 2012, p. 2).

Noncognitive measures. A holistic term referring to noncognitive scales, noncognitive skills, and noncognitive variables.

Noncognitive variables (NCVs). Used to analyze responses to noncognitive scales.

Remedial course. Courses below the transfer-level. For math, refers to courses at or below intermediate algebra.

Remediation. The process of completing remedial coursework. Also referred to as the remedial pathway.

Susceptibility to Stereotype Threat (SST). People are susceptible to stereotype threat when they are concerned that their actions will result in confirming a negative stereotype. For this study, there were four profiles:

- Disengaged, which suggests the person has suffered from stereotype threat for so long that they have disengaged from it;

- High SST. High Susceptibility;

- Low SST. Low susceptibility;

- Unidentified. No susceptibility.

Throughput rate. The proportion of students able to successfully complete a transferlevel mathematics course. Most often used when referring to students who start coursework at the remedial level. Coined by Hayward and Willett (2014).

Transfer-level courses. Transfer-level mathematics courses have intermediate algebra as a prerequisite. Used interchangeably with gatekeeper. 
Page intentionally left blank. 
Page intentionally left blank. 